Aus der Klinik für Nephrologie und Rheumatologie

(Prof. Dr. med. G. A. Müller)

der Medizinischen Fakultät der Universität Göttingen

\title{
Analyse organoprotektiver Effekte der renalen Denervation zur Behandlung therapierefraktärer arterieller Hypertonie
}

\author{
INAUGURAL - DISSERTATION \\ zur Erlangung des Doktorgrades \\ der Medizinischen Fakultät der \\ Georg-August-Universität zu Göttingen
}

vorgelegt von

Martina Rita Monika Bonss

aus

Nürnberg

Göttingen 2018 
Dekan:

Referent:

Ko-Referent:

Drittreferent:
Prof. Dr. rer. nat. H. K. Kroemer

PD Dr. med. M. Wallbach

Prof. Dr. med. M. R. Schroeter

Prof. Dr. med. M. Oppermann

Datum der mündlichen Prüfung: 30.04.2019 
Hiermit erkläre ich, die Dissertation mit dem Titel "Analyse organoprotektiver Effekte der renalen Denervation zur Behandlung therapierefraktärer arterieller Hypertonie" eigenständig angefertigt und keine anderen als die von mir angegebenen Quellen und Hilfsmittel verwendet zu haben.

Göttingen, den 


\section{Inhaltsverzeichnis}

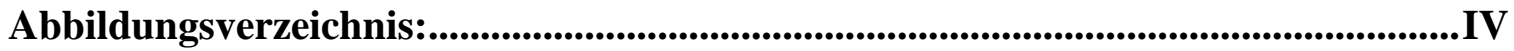

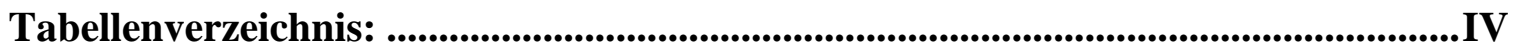

Abkürzungsverzeichnis: .............................................................................................. V

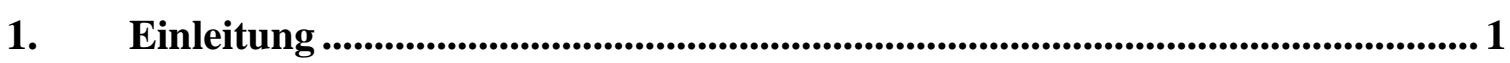

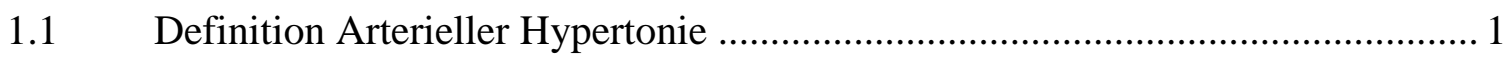

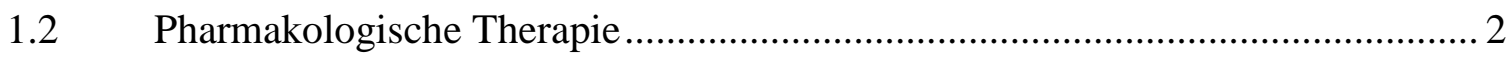

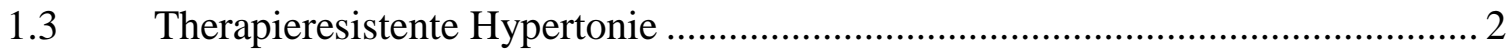

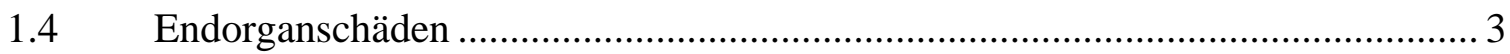

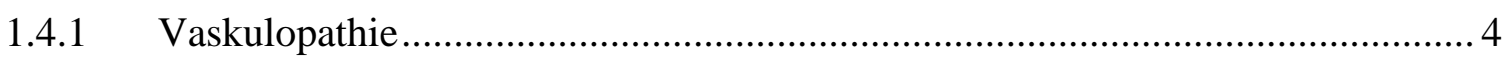

1.4.1.1 Endotheliale Progenitorzellen (EPCs) ...................................................... 4

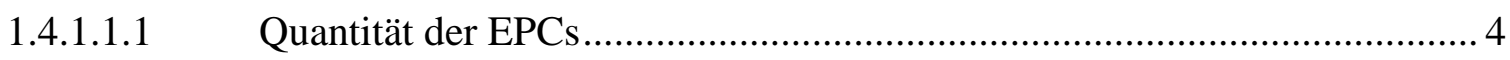

1.4.1.1.2 Proliferationsfähigkeit der EPCs........................................................ 5

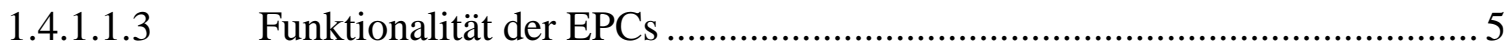

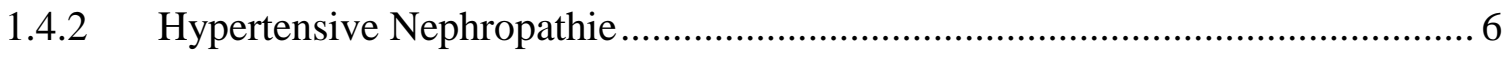

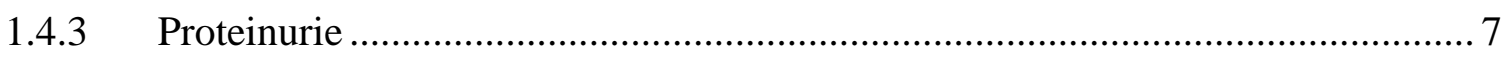

1.5 Rolle des sympathischen Nervensystems in der Pathogenese der arteriellen

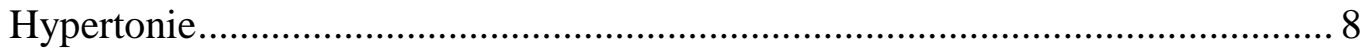

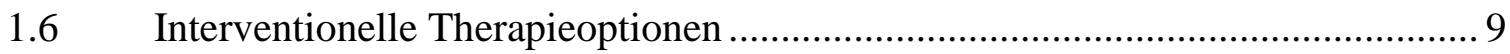

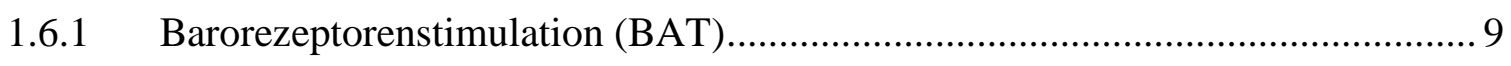

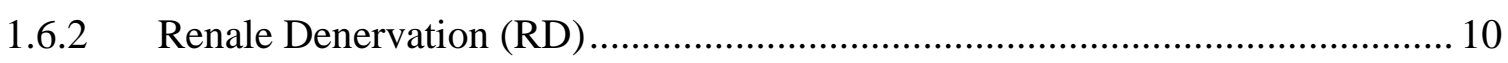

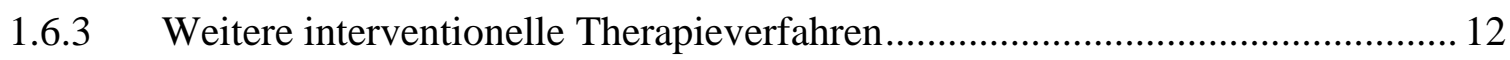

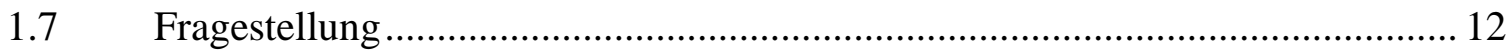

2. Material und Methoden ............................................................................................... 14

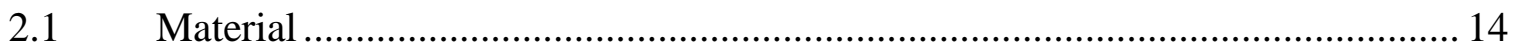

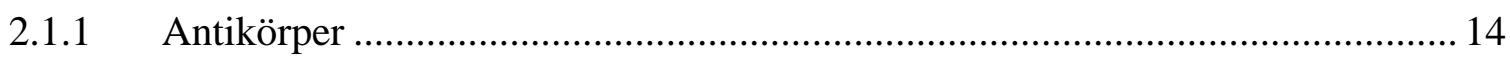

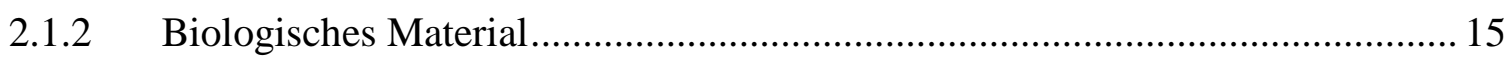

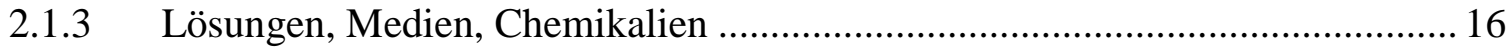

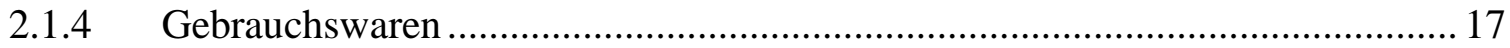

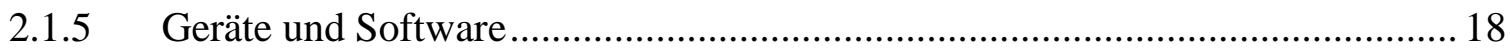

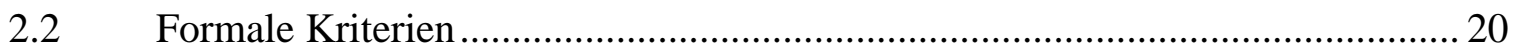

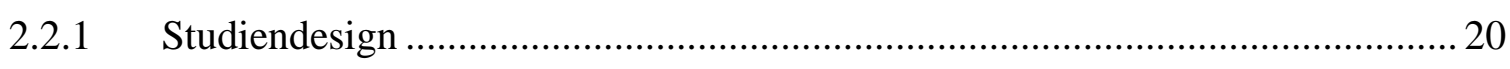

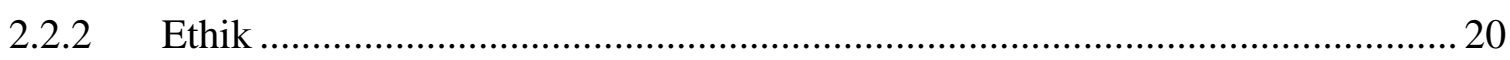




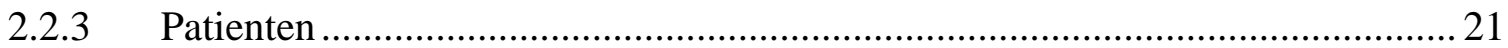

2.2.4 Ein- und Ausschlusskriterien der Studie ....................................................... 22

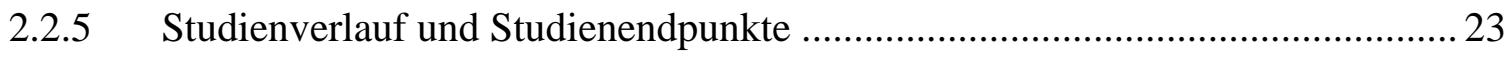

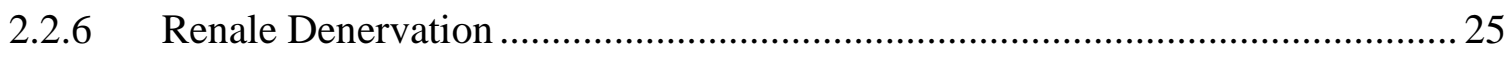

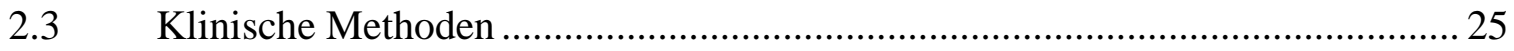

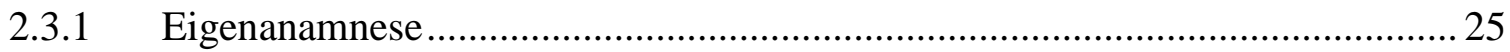

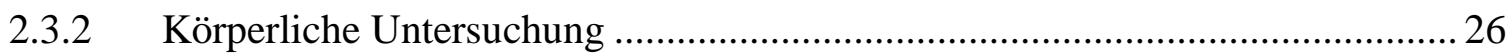

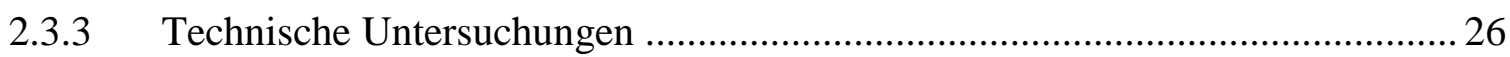

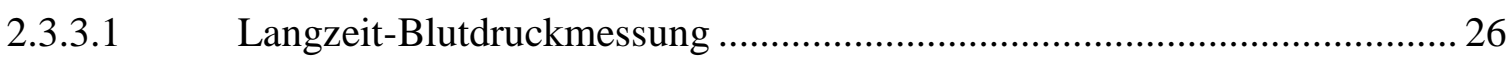

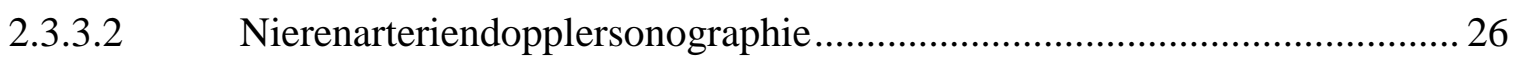

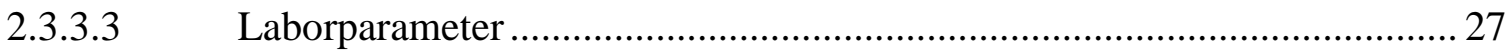

2.3.3.3.1 Berechnete glomeruläre Filtrationsrate - Estimated Glomerular Filtration Rate

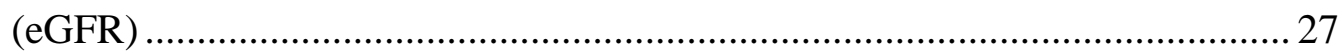

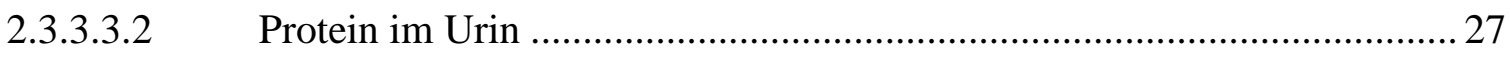

2.3.3.3.3 Laborchemische Beurteilung der Nierenfunktion.................................. 28

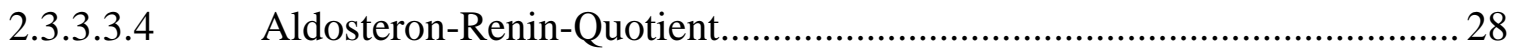

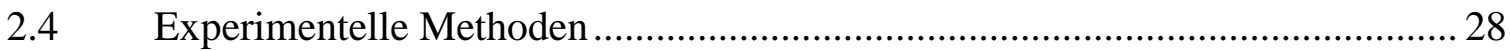

2.4.1 Isolation von PBMCs (Peripheral Blood Mononuclear Cells) ........................... 28

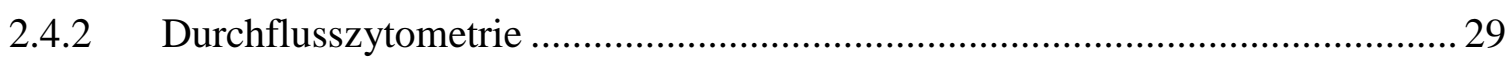

2.4.2.1 Durchflusszytometrische Quantifizierung endothelialer Progenitorzellen

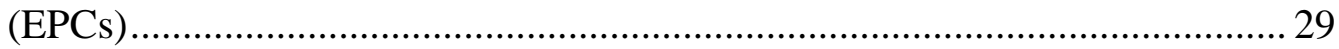

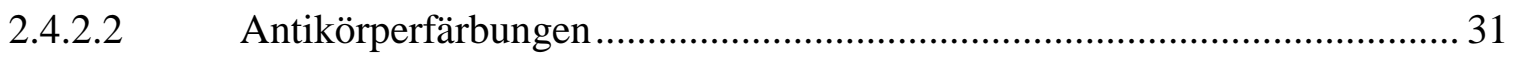

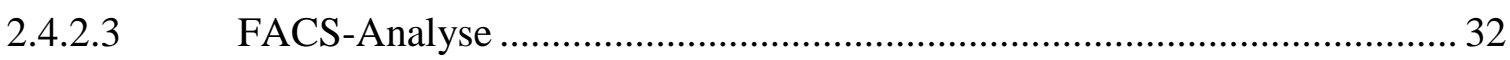

2.4.3 Zellkultur von Colony Forming Units (CFU) endothelialer Progenitorzellen

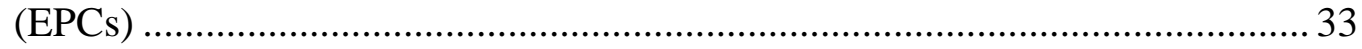

2.4.4 Immunfluoreszenzmikroskopische Analyse ................................................. 33

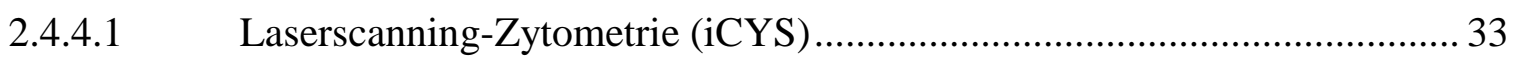

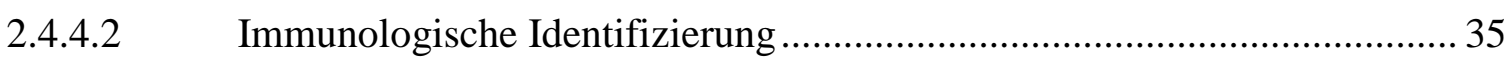

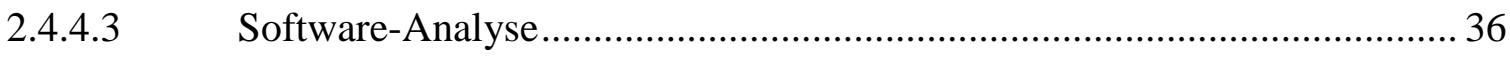

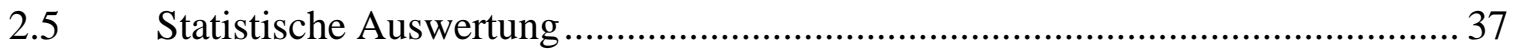

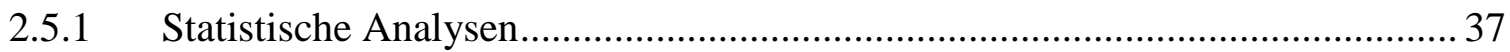

2.5.2 Graphische Darstellung der Ergebnisse ...................................................... 37

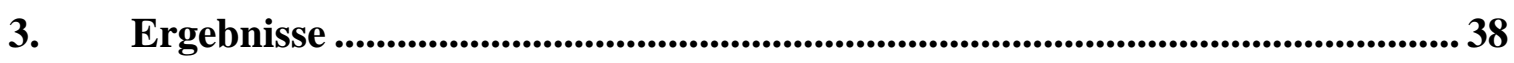

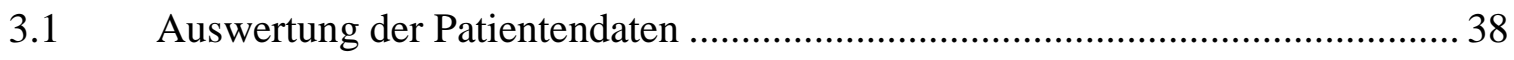

3.2 Auswertung der Blutdruckmessungen vor und nach renaler Denervation ......... 40 


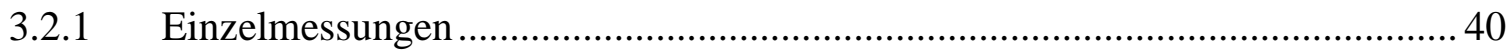

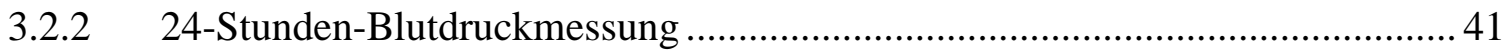

3.3 Auswertung von Laborparametern vor und nach renaler Denervation............... 43

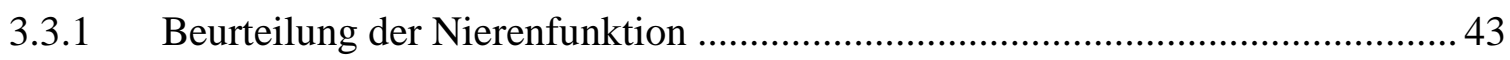

3.3.2 Laborchemische Marker einer Proteinurie ….................................................. 45

3.4 Auswertung der Quantifizierung endothelialer Progenitorzellen mittels Durchflusszytometrie (FACS-Analyse)

3.5 Auswertung der Proliferationsfähigkeit endothelialer Progenitorzellen (EPCs) über Quantifizierung von Colony Forming Units (CFUs) in Zellkultur.

3.6 Auswertung der mittels Laserscanning-Zytometrie (iCys) bestimmten eNOS-

Expression endothelialer Progenitorzellen (EPCs) .......................................... 51

4. Diskussion............................................................................................................ 53

4.1 Renale Denervation nach der SYMPLICITY HTN-3-Studie ............................. 53

4.1.1 Wissenschaftliche Diskussionen und Betrachtungen ..................................... 53

4.1.1.1 Überblick über die SYMPLICITY HTN-Studien ...................................... 53

4.1.1.2 Weiterer Studienhintergrund zur renalen Denervation ............................... 56

4.1.1.3 Kritik am Design früherer Studien ...................................................... 57

4.1.1.4 Kritik an der SYMPLICITY HTN-3-Studie ......................................... 58

4.1.1.4.1 Konsistenz im medikamentösen Therapieregime, Monitoring und

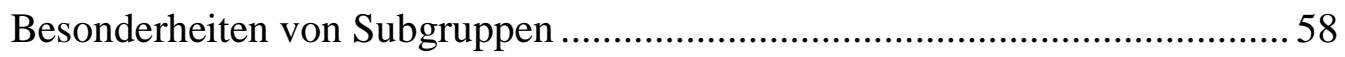

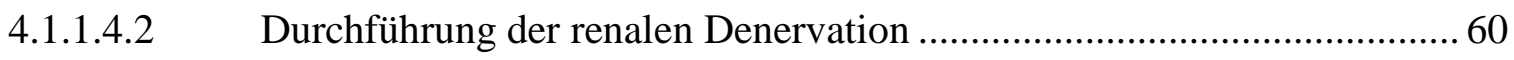

4.1.2 Auswirkungen der Publikation der SYMPLICITY HTN-3-Studie auf die

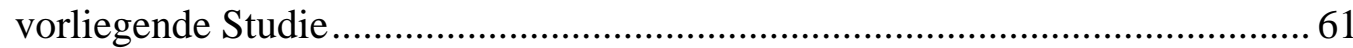

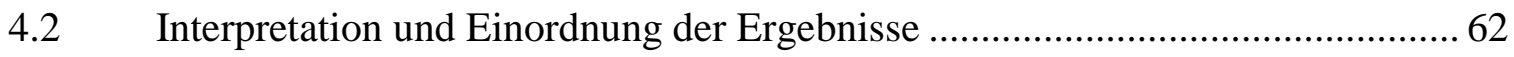

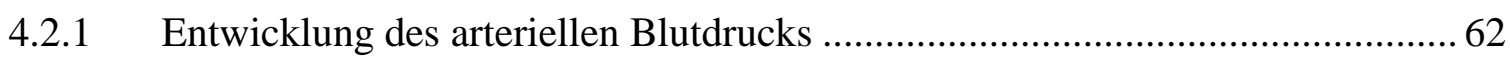

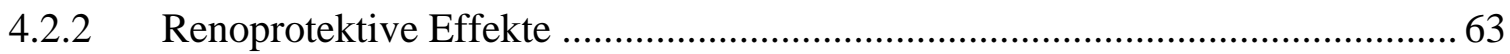

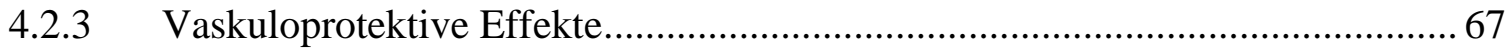

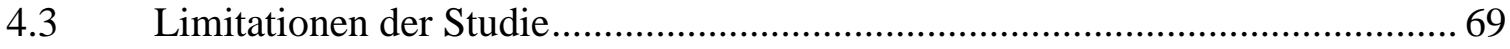

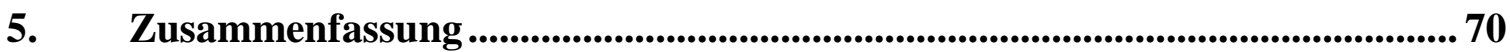

6. Abgrenzung der vorliegenden Dissertation mit Präsentation der nephrologischen Endpunkte von der Dissertation Schulze-Brock mit kardiologischen Endpunkten............................................................................. 72

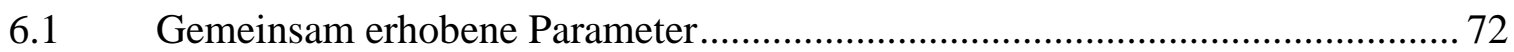

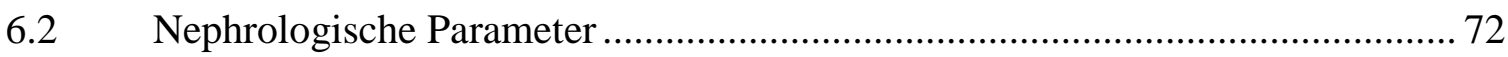

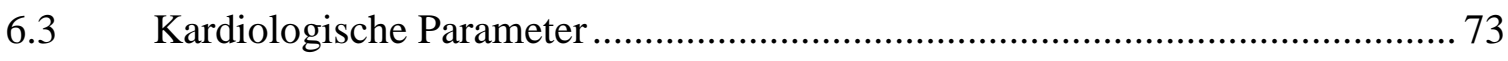

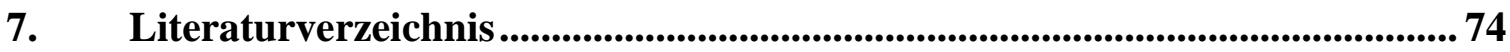




\section{Abbildungsverzeichnis:}

Abbildung 1: Endorganschäden

Abbildung 2: Charakteristische Auftrennung ungefärbter Zellen in der Durchflusszytometrie.30

Abbildung 3: Modell eines iCYS Laserscanning Zytometers

Abbildung 4: Box-Whiskers-Plot der Anzahl antihypertensiver Medikamente vor und sechs Monate nach renaler Denervation

Abbildung 5: Box-Whiskers-Plot der Veränderung der berechneten glomerulären

Filtrationsrate vor und sechs Monate nach renaler Denervation

Abbildung 6: Box-Whiskers-Plot der Quantität endothelialer Progenitorzellen (CD133/Flk-1 doppelt positiv) vor und sechs Monate nach renaler Denervation

Abbildung 7: Box-Whiskers-Plot der Quantität endothelialer Progenitorzellen (CD133/cKit doppelt positiv) vor und sechs Monate nach renaler Denervation

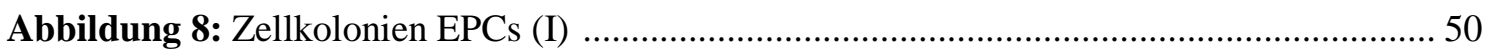

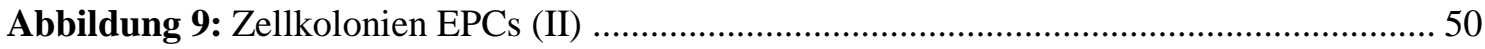

Abbildung 10: Balkendiagramm nach Gruppen entsprechend der Anzahl von Kolonien EPCs in der Zellkultur vor und sechs Monate nach renaler Denervation

\section{Tabellenverzeichnis:}

Tabelle 1: Studienverlauf und erhobene Studienparameter

Tabelle 2: Oberflächenmarker endothelialer Progenitorzellen und deren Chrakteristika in der Durchflusszytometrie

Tabelle 3: Oberflächenmarker endothelialer Progenitorzellen und deren Charakteristika in der Laserscanning-Zytometrie

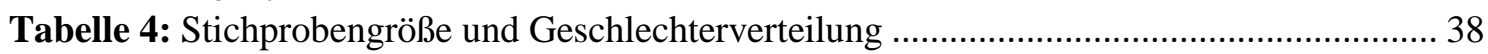

Tabelle 5: Demographische Daten des untersuchten Patientenkollektivs .................................. 38

Tabelle 6: Anzahl und Typ antihypertensiver Medikation vor und sechs Monate nach renaler Denervation....

Tabelle 7: Mittelwerte des arteriellen Blutdrucks in der klinischen Einzelmessung vor und sechs Monate nach renaler Denervation

Tabelle 8: Auswertung der Langzeitblutdruckaufzeichungen über 24 Stunden vor und sechs Monate nach renaler Denervation

Tabelle 9: Laborchemische Beurteilung der Nierenfunktion vor und sechs Monate nach renaler

Denervation.

Tabelle 10: Laborchemische Beurteilung einer Proteinurie vor und sechs Monate nach renaler Denervation.

Tabelle 11: Auswertung der Quantität der in der Durchflusszytometrie detektierten endothelialen Progenitorzellen

Tabelle 12: Auswertung der Expression der endothelialen Stickstoffmonoxid-Synthase endothelialer Progenitorzellen vor und sechs Monate nach renaler Denervation

Tabelle 13: Überblick über die SYMPLICITY HTN-Studien 


\section{Abkürzungsverzeichnis:}

ACE-Hemmer

ANP

AP

BAT

BMI

BNP

BSA

CD 133

CFUs

CK

c-Kit

CRP

DAPI

eGFR

eNOS

EPCs

ESH

FACS

Flk-1

FSC

$\curlyvee-G T$

GOT

GPT

HTN

iCYS

Ig G

IL-6

LZ-EKG

LZ-RR

MAD
Angiotensin-Converting-Enzyme-Hemmer

atriales natriuretisches Peptid

alkalische Phosphatase

Barorezeptorenstimulation

body mass index

brain natriuretic peptide

bovines Serumalbumin

cluster of differentiation 133

colony forming units

Kreatinkinase

Tyrosinkinase Kit

C-reaktives Protein

4`,6-Diamin-2-phenylindol

berechnete glomeruläre Filtrationsrate

endotheliale Stickstoffmonoxid-Synthase

endotheliale Progenitorzellen

European Society of Hypertension

fluorescence-activated cell sorting, Durchflusszytometrie

fetal liver kinase - 1

forward scatter, Vorwärtsstreulicht

Gamma-Glutamyltransferase

Glutamat-Oxalacetat-Transaminase

Glutamat-Pyruvat-Transaminase

Hypertonie

Laserscanning-Zytometrie

Immunglobulin $\mathrm{G}$

Interleukin 6

Langzeit-EKG (24h)

Langzeit-Blutdruckuntersuchung (24h)

mittlerer arterieller Druck 
MDRD-Formel

NO

PBMCs

PBS

PE-Antikörper

pTT

RD

RR

SSC

TNF- $\alpha$

WHO modification of diet in renal disease -Formel

Stickstoffmonoxid

peripheral blood mononuclear cells

Phosphatgepufferte Salzlösung

Phycoerythrin-Antikörper

partielle Thromboplastinzeit

renale Denervation

Blutdruck nach Riva-Rocci

sideward scatter, Seitwärtsstreulicht

Tumornekrosefaktor-Alpha

World Health Organization 


\section{1. $\quad$ Einleitung}

Die arterielle Hypertonie gehört zu den Hauptrisikofaktoren von HerzKreislauferkrankungen sowie der kardiovaskulären Mortalität. Weltweit sind laut den Zahlen der WHO von 2013 eine Milliarde Menschen betroffen (WHO 2013). In Deutschland meldet das Robert Koch-Institut eine Prävalenz von über $30 \%$ bei über 45 Jährigen, während in der Altersgruppe über 65 Jahren bereits über die Hälfte der Männer und Frauen betroffen sind mit deutlichem Anstieg mit fortschreitendem Lebensalter (RKI 2012). Steigende Blutdruckwerte stehen in nahezu linearem Zusammenhang mit einem Anstieg des kardiovaskulären Risikos. Jeder Anstieg um $20 \mathrm{mmHg}$ systolisch bzw. $10 \mathrm{mmHg}$ diastolisch über die Zielblutdruckwerte hinaus verdoppelt das Risiko, an einem Herzinfarkt oder Schlaganfall zu versterben (Chobanian et al. 2003).

\subsection{Definition Arterieller Hypertonie}

Die WHO wie auch die deutsche und europäische Leitlinie definieren die arterielle Hypertonie als Blutdruck von systolisch gleich oder höher $140 \mathrm{mmHg}$, bei gleichzeitig oder isoliert erhöhtem diastolischen Wert von größer oder gleich $90 \mathrm{mmHg}$.

Unterschieden werden Hypertonie-Grade 1-3:

Hypertonie Grad 1: $\quad$ systolischer Blutdruck 140-159 mmHg oder diastolischer Blutdruck 90-99 mmHg

Hypertonie Grad 2: $\quad$ systolischer Blutdruck 160-179 mmHg oder diastolischer Blutdruck 100-109 mmHg

Hypertonie Grad 3: $\quad$ systolischer Blutdruck $\geq 180 \mathrm{mmHg}$ oder diastolischer Blutdruck $\geq 110 \mathrm{mmHg}$

Entsprechend dem vorliegenden Hypertoniegrad und dem kardiovaskulären Gesamtrisiko eines Patienten wird eine Behandlung in Form von Lebensstiländerungen 
sowie eine medikamentöse Therapie mit dem Ziel einer Senkung des arteriellen Blutdrucks auf Werte kleiner 140/90 mmHg empfohlen. Bei Diabetikern sollte ein diastolischer Blutdruck zwischen $80 \mathrm{mmHg}$ und $85 \mathrm{mmHg}$ angestrebt werden (Mancia et al. 2013).

\subsection{Pharmakologische Therapie}

Zur pharmakologischen Therapie der arteriellen Hypertonie sind die fünf Substanzklassen der ACE-Hemmer, Angiotensinrezeptorblocker, Diuretika, Betablocker und Calciumantagonisten in gleicher Weise für eine Initial- und Dauerbehandlung geeignet (Mancia et al. 2013). Eine Behandlung ist unter Berücksichtigung der absoluten oder relativen Kontraindikationen jeweils in Mono- oder Kombinationstherapie möglich. Die Auswahl sollte entsprechend patienteneigenen spezifischen Indikationen erfolgen (Mancia et al. 2013).

\subsection{Therapieresistente Hypertonie}

Die therapieresistente Hypertonie ist definiert als nicht leitliniengerecht eingestellter arterieller Blutdruck trotz einer adäquaten Behandlung mit drei oder mehr Antihypertensiva oder entsprechend bei Behandlung mit vier oder mehr blutdrucksenkenden Medikamenten unabhängig davon, ob die Blutdruckwerte im Zielbereich liegen oder nicht. Unter den Antihypertensiva sollte mindestens ein Diuretikum sein (Fagard 2012).

Betrachtet man die hohe Prävalenz der arteriellen Hypertonie, so ist von Therapieresistenz ein durchaus beträchtlicher Anteil von Menschen betroffen. Große Studien beschrieben eine Prävalenz unter Patienten mit bekanntem Bluthochdruck von etwa 10-30 \% (vgl. Persell 2011, de la Sierra et al. 2011). Diese Zahl mag jedoch je nach Patientenkollektiv variieren. Prävalenzstudienergebnisse reichen von Angaben unter $5 \%$ (vgl. Weitzman et al. 2014) bis hin zu möglicherweise deutlich vermehrtem Vorkommen in spezialisierten Zentren, was darin mitbegründet liegen mag, dass bei 
Patienten mit ausgeprägterer arterieller Hypertonie häufiger eine Therapieresistenz beobachtet wird (Alper Jr. und Calhoun 1999).

\section{$1.4 \quad$ Endorganschäden}

Das Patientenkollektiv der therapierefraktären Hypertoniker ist durch den chronisch erhöhten Blutdruck in besonderer Weise durch Endorganschäden gefährdet. Patienten mit therapierefraktärer Hypertonie weisen häufiger und schwerere Endorganschäden im Vergleich zu Patienten mit kontrollierter Hypertonie auf (Cuspidi et al. 2001). Unabhängig von der Ausprägung der Hypertonie kommen relevante Cofaktoren zum Tragen, welche die Schwere der Endorganschäden mit bedingen. Als solche gelten zum Beispiel Störungen im Renin-Aldosteron-System, Übergewicht sowie erhöhter Salzkonsum (Schmieder 2010).

Als Endorganschäden der arteriellen Hypertonie werden im Allgemeinen folgende angesehen:

\section{Endorganschäden}

\section{Vaskulopathie}

- Endotheliale Dysfunktion

- Remodeling

- Arteriosklerose

- Aortenaneurysma

- Thrombose

\section{Nephropathie}

- Albuminurie

- Proteinurie

- Chronische Niereninsuffizienz

- Nierenversagen

\section{Zerebrovaskuläre Schäden}

- Akute hypertensive Enzephalopathie

- Schlaganfall

- Intrazereblare Blutung

- Lacunar-Infarkt

- Vaskuläre Demenz

- Hypertensive Retinopathie

\section{Herzerkrankungen}

- Linksventrikuläre Hypertophie

- Herzrhythmusstörungen

- Koronare Herzerkrankung

- Myokardinfarkt

- Systolische und diastolische Herzinsuffizienz

Abbildung 1: Endorganschäden; Abbildung in Anlehnung an Schmieder (2010) 


\subsubsection{Vaskulopathie}

Chronisch erhöhter arterieller Blutdruck führt zu Schäden im Gefäßsystem. Diese manifestieren sich in Form endothelialer Dysfunktion sowie Umbauprozessen der kleinen und großen Arterien, wodurch die Vasodilatationsfähigkeit der glatten Gefäßmuskulatur beeinträchtigt wird. Die Entstehung von Plaques, Stenosen und Aneurysmen wird begünstigt (Schmieder 2010). Klinisch manifest werden diese Veränderungen in Form von Angina pectoris, koronarer Herzkrankheit sowie weiter steigenden Blutdruckwerten aufgrund der sinkenden Volumen- und Anpassungskapazitäten im Gefäßsystem. Auch sämtliche oben gelistete Endorganschäden werden in ihrem Prozess begünstigt. Entscheidend ist deshalb, die Entstehung von Endorganschäden in einem möglichst frühen Stadium zu erkennen, um entsprechend frühzeitig im Sinne einer Sekundärprophylaxe intervenieren zu können. Es ist jedoch unklar, ob eine Absenkung des arteriellen Blutdrucks endogene Reparaturprozesse der Gefäßendothelien verbessert.

\subsubsection{Endotheliale Progenitorzellen (EPCs)}

\subsection{Quantität der EPCs}

Endotheliale Progenitorzellen (endothelial progenitor cells - EPCs) bilden eine im Blut zirkulierende Zellpopulation, welche mit der vaskulären Homöostase sowie der endogenen Fähigkeit zur Reparatur vaskulärer Endothelschäden in Verbindung gebracht werden (Asahara et al. 1999). Eine Reihe von Zusammenhängen zwischen der Anzahl zirkulierender EPCs sowie klinischen Parametern konnte gezeigt werden. Patienten mit kardiovaskulären Risikofaktoren wie arterielle Hypertonie, Diabetes mellitus, Nikotinabusus, Hypercholesterinämie, Alter und positiver Familienanamnese für die koronare Herzkrankheit zeigen verminderte Zahlen von EPCs (Werner et al. 2005). Darüber hinaus fand die Arbeitsgruppe um De Groot et al. bei Patienten mit Hyperurikämie im Rahmen fortgeschrittener Niereninsuffizienz eine verringerte Anzahl EPCs (De Groot et al. 2004), ebenso wie die Gruppe um Patschan et al. bei Patienten mit therapierefraktärer Hyperlipidämie (Patschan et al. 2009). Prognostisch werden niedrige Zahlen EPCs relationiert mit einer erhöhten Wahrscheinlichkeit des Fortschreitens atherosklerotischer Prozesse (Schmidt-Lucke 2005) sowie einem erhöhten Risiko kardiovaskulärer Ereignisse (Perticone et al. 2001). Eine erhöhte 
Anzahl zirkulierender EPCs konnte bei akutem Myokardinfarkt (Shintani et al. 2001), akuter Ischämie (Takahashi et al. 1999), sowie Therapie mit Statinen (Llevadot et al. 2001) nachgewiesen werden.

\subsection{Proliferationsfähigkeit der EPCs}

Die Proliferationsfähigkeit der EPCs konnte in verschiedenen Studien in signifikantem Zusammenhang mit dem kardiovaskulären Risiko, entsprechend dem klinisch bestimmten Framingham Risiko, gebracht werden (Perticone et al. 2001, Hill et al. 2003). Ebenso zeigte die Arbeitsgruppe um Hill et al. eine negative Korrelation zwischen dem Gefäßstatus und der Fähigkeit der EPCs, Kolonien, sogenannte colony forming units (CFUs), zu bilden (Hill et al. 2003). In verschiedenen Arbeiten konnten bereits Zusammenhänge zwischen der Bildung von CFUs, und vaskulären Erkrankungen, wie der koronaren Herzkrankheit (Vasa et al. 2001), Diabetes Mellitus Typ II (Tepper et al. 2002) sowie Hypercholesterinämie und Hypertonie (Hill et al. 2003), dargestellt werden.

\subsection{Funktionalität der EPCs}

Neben der Quantität sowie der Proliferationsfähigkeit ist die Funktionsfähigkeit der EPCs entscheidend. Die Bestimmung der Expression der endothelialen Stickstoffmonoxid-Synthase (eNOS) auf der Oberfläche der EPCs ermöglicht es Rückschlüsse auf ihre Funktionalität und ihren Beitrag zur Gefäßhomöostase zu ziehen. Das Enzym, das hauptsächlich von Endothelzellen exprimiert wird, katalysiert die Bildung von Stickstoffmonoxid (NO) aus der Aminosäure L-Arginin mit Hilfe verschiedener Kofaktoren und Sauerstoff. NO trägt auf verschiedene Weise dem Erhalt der vaskulären Homöostase, und einer normalen Endothelfunktion bei. Durch seine vasodilatatorische Wirkung an den glatten Muskelzellen ist es maßgeblich an der Regulation des Gefäßtonus beteiligt (Tousoulis et al. 2012). Aber auch der endotheliale Zellverband selbst wird durch NO vor freien Sauerstoffradikalen geschützt (Cai und Harrison 2000). Bei Patienten mit essentieller Hypertonie wurde eine endotheliale Dysfunktion im Sinne einer verminderten Freisetzung von NO sowohl in der basalen Rate als auch nach Stimulation mit Acetylcholin beschrieben (Panza et al. 1993, Taddei et al. 1998). Eine verringerte Bioverfügbarkeit von NO wiederum führt zu einer verminderten Mobilisation EPCs, wodurch die Fähigkeit zur Reparatur von 
Gefäßschäden herabgesetzt ist (Aicher et al. 2003). Die Funktion der EPCs selbst steht ebenfalls im Zusammenhang mit der Expression von eNOS. So wurde gezeigt, dass bei einer hohen eNOS-Expression apoptotische Zellvorgänge gehemmt, Proliferation und Differenzierung hingegen gefördert werden (Gao et al. 2014, Lemarié et al. 2011).

\subsubsection{Hypertensive Nephropathie}

Eine hypertensive Nephropathie ist eine häufige Folge der mit der arteriellen Hypertonie einhergehenden Vaskulopathie. Mit längerer Krankheitsdauer, etwa nach zehn bis fünfzehn Jahren, steigt das Risiko der Nierenschädigung - selbst bei nur moderat erhöhten Blutdruckwerten - deutlich an (Marín et al. 2005). Je höher das kardiovaskuläre Risikoprofil der Patienten ist, desto ausgeprägter erscheint eine chronische Nierenschädigung. Bis zu $35 \%$ der Hypertoniker mit zusätzlich hohen kardiovaskulären Risikofaktoren weisen eine berechnete glomeruläre Filtrationsrate (eGFR) kleiner $60 \mathrm{ml} / \mathrm{min} / 1,73 \mathrm{~m}^{2}$ auf (Ruilope und Bakris 2011). Es handelt sich um einen Prozess, der von Betroffenen meist unbemerkt vonstattengeht. Eine große Studie konnte zeigen, dass eine langjährige arterielle Hypertonie nach dem Diabetes mellitus die zweithäufigste Ursache für eine Dialysepflichtigkeit oder Nierentransplantation darstellt (Klag et al. 1996). Besteht ein dauerhaft erhöhter Blutdruck und somit ein erhöhter glomerulärer Kapillardruck, reagieren die Zellen des Mesangiums auf die gesteigerte mechanische Belastung mit einer vermehrten Synthese von extrazellulärer Matrix (Riser et al. 1992, Peng et al. 2007). Es kommt zur Nephrosklerose, welche charakterisiert ist durch histopathologische Veränderungen wie die Verbreiterung der Intima von Arterien, der Hyalinose von Arteriolen sowie dem ischämischen Untergang von Glomeruli, welche zur Glomerulosklerose, interstitieller Fibrosierung und Atrophie der Nierentubuli führt (Sumida et al. 2016). In der Folge ist die hypertensive Nephrosklerose ein häufiger Grund terminaler Niereninsuffizienz in den sogenannten entwickelten Ländern (Liang et al. 2016). 


\subsubsection{Proteinurie}

Ein wichtiger klinischer Faktor auf den bei Patienten mit arterieller Hypertonie ein Augenmerk $\mathrm{zu}$ richten ist, ist das Auftreten einer Proteinurie. Sie findet sich bei Hypertonikern etwa dreimal häufiger als bei Gesunden (Kannel et al. 1984). Proteinurie zeigt eine endotheliale Dysfunktion an, welche mit einer gesteigerten vaskulären Permeabilität für Eiweiße einhergeht (Schmieder et al. 2006). In verschiedenen Studien wurde zudem gezeigt, dass das Auftreten sowie das Ausmaß einer Proteinurie in signifikantem Zusammenhang mit der kardiovaskulären Gesamtmorbidität und -mortalität steht (Kannel et al. 1984, Ruilope 2002, Schmieder et al. 2006). Der klinisch als erstes erfassbare Schaden der Niere ist der Nachweis einer Mikroalbuminurie.

Jedoch ist das Vorliegen einer Proteinurie nicht nur ein Parameter zur Einschätzung eines bestehenden Nierenschadens, sondern bedingt selbst eine direkte pathogene Wirkung im Fortschreiten einer chronischen Nierenerkrankung. Dabei ist der nephrotoxische Effekt umso größer je unselektiver und ausgeprägter die Proteinurie ist (Cravedi und Remuzzi 2013). Pathophysiologisch führt eine arterielle Hypertonie wie oben beschrieben zur Nephrosklerose und dauerhafter Schädigung des Nierenparenchyms sowie Verlust von Glomeruli. Hierbei entwickelt sich ein Circulus vitiosus mit weiter steigendem glomerulärem Filtrationsdruck über den verbleibenden Glomeruli. Es kommt zur Dysfunktion bzw. Untergang der Podozyten und somit einer gesteigerten Permeabilität für Makromoleküle. Die Folge ist eine vermehrte Filtration von Plasmaproteinen und das Auftreten einer Proteinurie. Gleichzeitig kommt es zu einer exzessiven Reabsorption dieser Plasmaproteine, welche die Ausschüttung von vasoaktiven und inflammatorischen Proteinen bedingt. Es resultiert die Apoptose tubulärer Zellen, die Infiltration mit mononukleären Zellen sowie die Akkumulation von Extrazellulärmatrix im Interstitium. Es kommt somit zur Progression der Nephrosklerose und zu einer Reduktion der GFR (vgl. Cravedi und Remuzzi 2013). 


\subsection{Rolle des sympathischen Nervensystems in der Pathogenese der arteriellen Hypertonie}

Ein Zusammenhang zwischen dem sympathischen Nervensystem und arterieller Hypertonie ist seit langem bekannt. In der ersten Hälfte des 20. Jahrhunderts, als medikamentöse Therapiemöglichkeiten noch sehr eingeschränkt bestanden, führten Adson und Brown im Jahre 1934 erstmals eine operative subdiaphragmale Sympathektomie durch (Page und Heuer 1935). Diese Therapie der Ultima Ratio erzielte eine eindrückliche und dauerhafte Senkung des arteriellen Blutdrucks sowie eine Reduktion der Mortalität. Jedoch mussten beträchtliche Nebenwirkungen in Kauf genommen werden, wie eine ausgeprägte orthostatische Hypotonie, Gangunsicherheit, Tachykardien bzw. Palpitationen, gastrointestinale Beschwerden sowie Impotenz (Sudano et al. 2011). Mit der Entwicklung wirksamer antihypertensiver Medikamente rückten interventionelle Maßnahmen in den Hintergrund. Doch auch die moderne Medizin sieht sich mit dem Problem konfrontiert, dass ein gewisses Patientenkollektiv mit arterieller Hypertonie unter medikamentöser Therapie keine adäquate Senkung des Blutdrucks innerhalb des Zielbereiches erreicht. In diesem Zusammenhang rückte in den letzten Jahrzehnten erneut das sympathische Nervensystem in den Fokus der Forschung. Wissenschaftlich etablierte Untersuchungsmethoden zur Bestimmung der Aktivität sympathischer Nerven sind die Bestimmung der regionalen NorepinephrinFreisetzung, dem dominierenden Neurotransmitter dieses Nervensystems, sowie die Aufzeichnung mikroneurographischer Signale einzelner oder gebündelter sympathischer Nerven in Gefäßwänden Haut und Skelettmuskeln versorgender Gefäße (Parati und Esler 2012). Es konnte so ein eindeutiger gleichsinniger Zusammenhang zwischen dem Maß der Überaktivität des sympathischen Nervensystems und der Ausprägung einer essentiellen arteriellen Hypertonie detektiert werden (Grassi 2009). Es wird davon ausgegangen, dass es bei der Entwicklung einer arteriellen Hypertonie zu einer Störung des Natrium- und Wasserhaushaltes kommt, sodass ein erhöhter arterieller Druck nötig ist, um ein Gleichgewicht im Natrium- und Wasserhaushalt wiederherzustellen und aufrechtzuerhalten (Kopp 2011). Ein im besonderen Maße beteiligtes Organ sind die Nieren. Eine vermehrte Aktivität in efferenten sympathischen Nervenfasern führt zu einer Verringerung des renalen Blutflusses und der Natriumausscheidung über den Harn sowie zur Steigerung der Sekretion von Renin (Kopp 2015). Physiologischerweise 
besteht ein inhibitorischer renorenaler Reflex zwischen sympathischen Efferenzen und mechanosensorischen Afferenzen in dem Maße, dass die Aktivierung solcher Afferenzen zur Abschwächung der sympathischen Aktivität führt und es so zur gesteigerten Natriumexkretion über den Urin kommt (Kopp 2015). Unter pathophysiologischen Bedingungen mit erhöhter Natriumretention, wie bei der arteriellen Hypertonie oder Erkrankungen, welche mit der Ausbildung renaler Ödeme einhergehen, wie der dekompensierten Herzinsuffizienz und dem nephrotischen Syndrom, kommt es zur Überaktivität des efferenten sympathischen Nervensystems. Begründet findet sich dies in einer Schwächung der aortalen und arteriellen Baroreflexe. Zudem ergeben sich in neueren Studien Hinweise, dass eine Schädigung der Nieren zu einer Umkehr der inhibitorischen zu exzitatorischen renorenalen Reflexe führt, sodass eine Aktivierung mechanosensorischer Afferenzen die Überaktivität des sympathischen Nervensystems zusätzlich verstärkt, und es so zur vermehrten Natriumretention und Steigerung des arteriellen Blutdrucks kommt (Kopp 2015).

\subsection{Interventionelle Therapieoptionen}

Für Patienten, die die Kriterien einer therapierefraktären arteriellen Hypertonie erfüllen, empfehlen die Leitlinien der „European Society of Hypertension“ (ESH) (IIb-Empfehlung) den Einsatz interventioneller Verfahren wie der renalen Denervation bzw. der Barorzeptorenstimulation (Mancia et al. 2013).

\subsubsection{Barorezeptorenstimulation (BAT)}

Die Barorezeptorenstimulation ist eine Therapieoption, deren Ziel in der Senkung der Überaktivität im sympathischen Nervensystem liegt. Im Sinus caroticus und dem Aortenbogen nehmen arterielle Barorezeptoren Dehnungsreize wahr, welche durch Steigerung des arteriellen Blutdrucks während der Systole entstehen. Dies hat zur Folge, dass afferente Nervenimpulse in den Nucleus tractus solitarii im zentralen Nervensystem abgegeben werden, und so reflexhaft die Aktivität efferenter sympathischer Nerven gesenkt wird. Resultierend sind eine negative Inotropie am Herzen, eine periphere Vasodilatation sowie eine verminderte Reninsekretion. Weiterhin führt dies zur Stimulation parasympathischer Nerven, und somit zur 
Reduktion der Herzfrequenz. Die externe Barorezeptorenstimulation erfolgt durch die Implantation einer unipolaren Elektrode, welche operativ an den rechten Karotissinus angelegt wird. Diese ist mit einem Pulsgenerator verbunden, der subkutan im Bereich der Arteria subclavia zu liegen kommt (Ng et al. 2016). Eine dauerhafte Senkung des Blutdrucks von im Mittel $30 \mathrm{mmHg}$ über 22 bis 52 Monate konnte in der Langzeitauswertung des „Rheos Pivotal Trial“ gezeigt werden (Bakris et al. 2012). Derzeit wird eine Weiterentwicklung dieser Technologie, das „Barostim neo ${ }^{\mathrm{TM}}$-System“ verwendet. Die hypertensiologische Studiengruppe an der Universitätsmedizin Göttingen, konnte bei Patienten mit chronischer Nierenerkrankung zusätzlich einen nephroprotektiver Effekt durch Senkung des arteriellen Blutdrucks, Reduktion der Proteinurie sowie Stabilisierung der berechneten glomerulären Filtrationsrate nachweisen (Wallbach et al. 2014).

\subsubsection{Renale Denervation (RD)}

Das interventionelle Therapieverfahren, das zur Therapie der therapierefraktären arteriellen Hypertonie eingesetzt wird, mit der bisher dichtesten Studienlage ist die renale Denervation. Auch hier wird einer sympathischen Überaktivität entgegengewirkt (Ewen et al. 2013). Mittels Kathetersystemen wird über Punktion der Arteria femoralis die Nierenarterie erreicht, und dort Radiofrequenz- oder Ultraschall-Energie abgegeben. Hierdurch kommt es zur fokalen Erwärmung der arteriellen Gefäßwand, und zur Zerstörung der in der Adventitia gelegenen efferenten und afferenten renalen Nerven. Der Verlust efferenter sympathischer Nerven resultiert in einer verringerten Reninsekretion, renaler Gefäßdilatation sowie vermehrter Natriumexkretion $(\mathrm{Ng}$ et al. 2016). Durch die zusätzliche Destruktion afferenter mechanosensorischer Nerven werden exzitatorische renorenale Reflexe gemindert. Diese entstehen unter pathologischen Bedingungen, die mit einer Schädigung der Nieren einhergehen, wie die arterielle Hypertonie, Herzinsuffizienz, chronischem Nierenversagen, Diabetes und Übergewicht. Die hierbei häufig bestehende chronische Entzündung der Nieren führt zu einer Stimulation chemosensitiver Nerven und zur Verstärkung der sympathischen Nervenaktivität (Kopp 2015). Die erste SYMPLICITY HTN-1-Studie im Jahr 2009, konnte bei 45 eingeschlossenen Patienten eine mittlere Blutdruckreduktion um $-22 /-11 \mathrm{mmHg}$ nach sechs Monaten und um -27/-17 mmHg nach zwölf Monaten 
dokumentieren. Weiterhin zeigte sich eine verminderte Noradrenalinausschüttung um $47 \%$ (Krum et al. 2009). In die nachfolgende SYMPLICITY HTN-2-Studie ein Jahr darauf wurden 106 Patienten eingeschlossen. An 52 Patienten wurde interventionell die renale Denervation durchgeführt, während 54 Patienten der Kontrollgruppe ihre medikamentöse antihypertensie Therapie fortführten. Nach sechs Monaten konnten je $94 \%$ beider Gruppen nachuntersucht werden. Hier zeigte sich eine Reduktion arterieller Blutdruckwerte im Mittel um -32/-12 mmHg in der interventionell behandelten Gruppe. $84 \%$ dieser Patienten erreichten eine Blutdruckreduktion um $10 \mathrm{mmHg}$ oder mehr, während dies in der Kontrollgruppe bei lediglich $35 \%$ der Patienten der Fall war. Die Blutdruckmittelwerte zeigten sich in der nichtinterventionell behandelten Gruppe vom Ausgangspunkt unverändert (Simplicity HTN-2 Investigators et al. 2010). Bis zum Jahr 2014 waren alle Studien zur renalen Denervation als offene nicht-verblindete Studien durchgeführt worden, sodass die Kritik eines möglichen Placeboeffektes bestand, insbesondere begründet durch die Invasivität des Eingriffes. Die SYMPLICITY HTN-3-Studie welche im Frühjahr 2014 publiziert wurde, wandte erstmalig ein randomisiertes placebokontrolliertes Design an. Es wurden 535 Patienten im Verhältnis 2:1 randomisiert, und einfachverblindet zwei Gruppen zugeteilt. In einer Gruppe wurde die renale Denervation angewandt, während in der anderen lediglich eine Nierenarteriographie durchgeführt wurde. Nach sechs Monaten zeigten sich bei Patienten nach renaler Denervation die Blutdruckwerte um $-14,13( \pm 23,93) \mathrm{mmHg}$ systolisch und $-6,6( \pm 11,9) \mathrm{mmHg}$ diastolisch reduziert. In der Gruppe von Patienten in der das Placebo-Verfahren angewendet worden war, ergab sich ebenfall eine Blutdrucksenkung um $-11,74( \pm 25,95) \mathrm{mmHg}$ systolisch und $-4,6( \pm 13,6) \mathrm{mmHg}$ diastolisch. Mit der Differenz von $-2,39 \mathrm{mmHg}$ zwischen den gemittelten systolischen Blutdruckwerten bestand somit kein signifikanter Unterschied zwischen den beiden Gruppen. Auch im Vergleich der 24-Stunden-Blutdruckmessung ergab sich lediglich eine Differenz von $-1,96 \mathrm{mmHg}$ der renal denervierten Gruppe gegenüber der placebobehandelten Gruppe. Die Blutdrucksenkung belief sich hier auf $-6,75( \pm 15,11) \mathrm{mmHg}$ systolisch und $-4,1( \pm 9,2) \mathrm{mmHg}$ diastolisch nach renaler Denervation, und $-4,79( \pm 17,25) \mathrm{mmHg}$ systolisch und $-3,1( \pm 10,1) \mathrm{mmHg}$ diastolisch in der Vergleichsgruppe. Die primären Effektivitätsendpunkte konnten in dieser Studie somit nicht erreicht werden. Der primäre Sicherheitsendpunkt der Studie wurde erzielt. Dieser wurde definiert als das Auftreten in weniger als 9,8\% behandelter Patienten von Todesfällen jeglicher Ursache, terminales Nierenversagen, embolische Ereignisse mit 
Organversagen, Nierenarterien- oder andere vaskuläre Komplikationen, hypertensive Krisen innerhalb von 30 Tagen oder Nierenarterienstenosen von über $70 \%$ innerhalb von 6 Monaten. Lediglich bei fünf Patienten $(1,4 \%)$ kam es $\mathrm{zu}$ unerwünschten Ereignissen nach renaler Denervation. In der Kontrollgruppe kam es bei einem Patienten (0,6\%) zu einem solchen Ereignis (Bhatt et al. 2014). Dieses überraschende und früheren Studien entgegenstehende Ergebnis führte $\mathrm{zu}$ wissenschaftlichen Diskussionen und bedarf weiterer Forschung. Stellungnahmen der deutschen Hochdruckliga zusammen mit den deutschen Gesellschaften für Kardiologie, Angiologie, Nephrologie und Radiologie empfehlen die Anwendung invasiver Verfahren wie der renalen Denervation nur bei gesichtertem therapierestistentem Bluthochdruck bei Werten von systolisch $\geq 160 \mathrm{mmHg}$ oder diastolisch $\geq 110 \mathrm{mmHg}$ und nach Ausschluss einer Pseudoresistenz durch Langzeitblutdruckmessung. Zudem sollte die Diagnostik und Nachverfolgung auf spezialisierte Zentren beschränkt bleiben sowie die Durchführung invasiver Verfahren erfahrenen Interventionalisten vorbehalten bleiben. Die renale Denervation ist bei konservativ therapieresistenten Patienten im Einzelfall als zusätzliches Verfahren zu sehen (Vonend et al. 2015).

\subsubsection{Weitere interventionelle Therapieverfahren}

$\mathrm{Zu}$ weiteren interventionellen Therapieverfahren zur Behandlung therapieresistenter Hypertonie besteht derzeit zu geringe Evidenz bei noch limitierter Datenlage um eine breitere klinische Anwendung zu ermöglichen. Sie sollen an dieser Stelle lediglich genannt werden. Die Ablation des Glomus caroticum soll erhöhte efferente Signale dieser Paraganglien verhindern. Die Anlage einer proximalen Anastomose zwischen der Arteria iliaca externa und der Vena iliaca interna zielt darauf ab, das effektive systolische Blutvolumen und den systemischen Gefäßwiderstand zu reduzieren. Diskutiert werden weiterhin eine tiefe Hirnstimulation, eine Stimulation des Nervus medianus und des Nervus vagus ( $\mathrm{Ng}$ et al. 2016).

\subsection{Fragestellung}

Die renale Denervation könnte über Hemmung des sympathischen Nervensystems zu einer Reduktion des arteriellen Blutdrucks beitragen, was eine ausgesprochen große 
Bedeutung für die Vermeidung von Endorganschäden bei Patienten mit therpierefraktärer arterieller Hypertonie darstellen könnte.

Die im folgenden präsentierte Studie wurde im April 2013 initiiert, noch vor der Publikation der SYMPLICITY HTN-3-Studie. Die renale Denervation war zu diesem Zeitpunkt bereits, nach erfolgtem Wirksamkeitsnachweis in großen Studien, in der klinischen Routine der interdisziplinären Behandlung therapieresistenter Hypertonie in Deutschland integriert. Primäres Ziel der vorliegenden Studie ist es, das kardio-renovaskuläre Risiko von Patienten mit therapierefraktärer arterieller Hypertonie einzuschätzen und potentielle organoprotektive Effekte der renalen Denervation zu evaluieren. Als sekundäres Ziel sollte die Effektivität der renalen Denervation hinsichtlich der Blutdruckregulation untersucht werden. Es ist derzeit noch unklar, welche Patienten von der renalen Denervation profitieren, so dass Prädiktoren für ein mögliches Nicht-Ansprechen auf die Therapie (sogenannte Non-Responder) identifiziert werden sollen.

Die vorliegende Dissertationsarbeit befasst sich insbesondere mit nephrologischen Endpunkten. Mittels klinischer und experimenteller Methoden sollen Marker renovaskulärer Schädigung bei therapierefraktären Hypertonikern erfasst werden sowie deren Beeinflussung durch eine renale Denervation untersucht werden. Laborchemische Untersuchungen dienen der Einschätzung der Nierenfunktion. Eine glomeruläre Schrankenstörung soll durch Urinanalysen erfasst werden. Weiterhin soll durch die Untersuchung der Quantität und Funktionalität zirkulierender endothelialer Progenitorzellen die Fähigkeit der Gefäßendothelien zur Regeneration ermittelt werden, um mögliche Zusammenhänge zwischen Veränderungen des Blutdruckniveaus und der endogenen Regenerationsfähigkeit zu eruieren. 


\section{Material und Methoden}

\subsection{Material}

\subsubsection{Antikörper}

\begin{tabular}{|c|c|c|c|}
\hline Name & Hersteller & Chargennummer & Artikelnummer \\
\hline $\begin{array}{l}\text { CD133 Antibody } \\
\text { (Rabbit anti CD133 } \\
\text { antibody) }\end{array}$ & $\begin{array}{l}\text { EMELCA } \\
\text { Bioscience } \\
\text { Breda } \\
\text { Niederlande }\end{array}$ & $1009-25$ & MBS462020 \\
\hline $\begin{array}{l}\text { Flk-1, } \\
\text { Carboxyfluorescein- } \\
\text { conjugated Mouse Ig } \\
\text { G1 Monoclonal Anti- } \\
\text { human VEGF, KDR- } \\
\text { Fluorescein; } \\
\text { Clone \# } 89106\end{array}$ & $\begin{array}{l}\text { R\&D Systems } \\
\text { Minneapolis, } \\
\text { USA }\end{array}$ & LWS08 & FAB357F \\
\hline $\begin{array}{l}\text { c-Kit (Ab81) Mouse } \\
\text { monoclonal Anibody, } \\
\text { Alexa Fluor }{ }^{\circledR} 488 \\
\text { Conjugate }\end{array}$ & $\begin{array}{l}\text { Cell Signaling } \\
\text { Technology } \\
\text { Danvers } \\
\text { USA }\end{array}$ & 6 & $3310 \mathrm{~S}$ \\
\hline $\begin{array}{l}\text { Sekundärer PE- } \\
\text { Antikörper für CD } \\
\text { 133: }\end{array}$ & & & \\
\hline $\begin{array}{l}\text { R-Phycoerythrin- } \\
\text { conjugated } \\
\text { AffiniPure } \mathrm{F}\left(\mathrm{ab}^{`}\right)_{2} \\
\text { Fragment Goat Anti- } \\
\text { Rabbit IgG }(\mathrm{H}+\mathrm{L})\end{array}$ & $\begin{array}{l}\text { Dianova } \\
\text { (Jackson } \\
\text { Immuno } \\
\text { Research) } \\
\text { West Grove } \\
\text { USA }\end{array}$ & 109337 & $111-116-144$ \\
\hline
\end{tabular}




\begin{tabular}{|c|c|c|c|}
\hline Name & Hersteller & Chargennummer & Artikelnummer \\
\hline $\begin{array}{l}\text { Isotypkontrolle: } \\
\text { IgG1-FITC / IgG2a- } \\
\text { PE }\end{array}$ & $\begin{array}{l}\text { Immunotech } \\
\text { SAS Beckman } \\
\text { Coulter } \\
\text { Marseille } \\
\text { France }\end{array}$ & 16 & PN A10974 \\
\hline $\begin{array}{l}\text { FcR Blocking } \\
\text { Reagent (human) }\end{array}$ & $\begin{array}{l}\text { MACS } \\
\text { Miltenyi } \\
\text { Biotec } \\
\text { Auburn } \\
\text { USA }\end{array}$ & 120000442 & 130-059-901 \\
\hline $\begin{array}{l}\text { Anti-eNOS ; } \\
\text { Purified Mouse Anti- } \\
\text { eNOS/NOS Type III }\end{array}$ & $\begin{array}{l}\text { BD Bioscience } \\
\text { San Diego } \\
\text { USA }\end{array}$ & & 610296 \\
\hline $\begin{array}{l}\text { Northern Light } 637 \\
\text { Anti Mouse Ig G }\end{array}$ & $\begin{array}{l}\text { R\&D Systems } \\
\text { Minneapolis, } \\
\text { USA }\end{array}$ & LZ006 & NL 008 \\
\hline $\begin{array}{l}\text { DAPI: 4',6-diamdino- } \\
\text { 2-phenylindole, } \\
\text { dihydrochloride }\end{array}$ & $\begin{array}{l}\text { Molecular } \\
\text { Probes } \\
\text { Thermo Fisher } \\
\text { Scientific } \\
\text { Waltham } \\
\text { USA }\end{array}$ & & D1306 \\
\hline
\end{tabular}

\subsubsection{Biologisches Material}

\begin{tabular}{|l|l|l|l|}
\hline Name & Hersteller & Chargennummer & Artikelnummer \\
\hline Fibronektin (from & Sigma-Aldrich & $081 \mathrm{M} 7033$ & F0895-1MG \\
human plasma) $0,1 \%$ & Chemie & & \\
solution & GmbH & & \\
& Schnelldorf & & \\
& Deutschland & & \\
\hline
\end{tabular}




\begin{tabular}{|l|l|l|l|}
\hline Name & Hersteller & Chargennummer & Artikelnummer \\
\hline Bovine Serum & PAA & G16113-622 & K41-001-500 \\
Albumin (BSA) & Laboratories & & \\
& GmbH & & \\
& Pasching & & \\
& Österreich & & \\
& & & \\
&
\end{tabular}

\subsubsection{Lösungen, Medien, Chemikalien}

\begin{tabular}{|c|c|c|c|}
\hline Name & Hersteller & Chargennummer & Artikelnummer \\
\hline PBS Dulbeco & $\begin{array}{l}\text { Biochrom AG } \\
\text { Berlin } \\
\text { Deutschland }\end{array}$ & $0943 \mathrm{~B}$ & L1825 \\
\hline Nuclease Free Water & $\begin{array}{l}\text { Thermo Fisher } \\
\text { Scientific } \\
\text { Waltham } \\
\text { USA }\end{array}$ & 1211109 & AM9932 \\
\hline $\begin{array}{l}\text { Biocoll Separating } \\
\text { Solution }\end{array}$ & $\begin{array}{l}\text { Biochrom AG } \\
\text { Berlin } \\
\text { Deutschland }\end{array}$ & 0512 B & L6115 \\
\hline $\begin{array}{l}\text { CFU-Hill Medium } \\
\text { Supplements }\end{array}$ & $\begin{array}{l}\text { Stemcell } \\
\text { Technologies } \\
\text { Köln } \\
\text { Deutschland }\end{array}$ & $12 \mathrm{~A} 42659$ & 05902 \\
\hline $\begin{array}{l}\text { CFU-Hill Basal } \\
\text { Medium }\end{array}$ & $\begin{array}{l}\text { Stemcell } \\
\text { Technologies } \\
\text { Köln } \\
\text { Deutschland }\end{array}$ & 13G50734 & 05901 \\
\hline $\begin{array}{l}\text { Formaldehydlösung } \\
37 \%\end{array}$ & $\begin{array}{l}\text { Carl Roth } \\
\text { GmbH \& Co } \\
\text { Karlsruhe } \\
\text { Deutschland }\end{array}$ & 141167943 & 49792 \\
\hline
\end{tabular}




\begin{tabular}{|l|l|l|l|}
\hline Name & Hersteller & Chargennummer & Artikelnummer \\
\hline Triton-X 100 & Sigma-Aldrich & & $9002-93-1$ \\
& Chemie & & \\
& GmbH & & \\
& Steinheim & & \\
& Deutschland & & \\
& & & \\
\hline
\end{tabular}

\subsubsection{Gebrauchswaren}

\begin{tabular}{|c|c|c|}
\hline Name & Hersteller & Artikelnummer \\
\hline $\begin{array}{l}\text { Pipetten: } \\
\text { Eppendorf Research } \\
\text { ® } \\
(0,5-10 \mu 1 \text {, } \\
10-100 \mu 1 \text {, } \\
30-300 \mu 1 \text {, } \\
100-1000 \mu 1)\end{array}$ & $\begin{array}{l}\text { Eppendorf AG } \\
\text { Hamburg } \\
\text { Deutschland }\end{array}$ & $\begin{array}{r}0,5-10 \mu \mathrm{l}: 3120000020 \\
10-100 \mu \mathrm{l}: 3120000046 \\
30-300 \mu \mathrm{l}: 3120000100 \\
100-1000 \mu \mathrm{l}: 3120000909\end{array}$ \\
\hline $\begin{array}{l}\text { Pipettenspitzen: } \\
\text { Biosphere Filter } \\
\text { Tips }\end{array}$ & $\begin{array}{l}\text { Sarstedt AG\&Co } \\
\text { Nümbrecht } \\
\text { Deutschland }\end{array}$ & $\begin{array}{c}2,5 \mu \mathrm{l}: 70.760 .212 \\
100 \mu \mathrm{l}: 70.1130 .212 \\
1000 \mu \mathrm{l}: 70.762 .211\end{array}$ \\
\hline $\begin{array}{l}\text { Sterile Pipetten für } \\
\text { elekrische } \\
\text { Pipettierhilfen: } \\
\text { Sterile Serological } \\
\text { Pipette } \\
(2 \mathrm{ml}, 5 \mathrm{ml}, 10 \mathrm{ml} \text {, } \\
25 \mathrm{ml})\end{array}$ & $\begin{array}{l}\text { Greiner Bio-One GmbH } \\
\text { Frickenhausen } \\
\text { Deutschland }\end{array}$ & $\begin{array}{l}2 \mathrm{ml}: 05020301 \\
5 \mathrm{ml}: 13041171 \\
10 \mathrm{ml}: 14020551 \\
25 \mathrm{ml}: 14070741\end{array}$ \\
\hline $\begin{array}{l}\text { E-cups: } \\
\text { Eppendorf Tubes } \\
(1,5 \mathrm{ml}, 2,0 \mathrm{ml})\end{array}$ & $\begin{array}{l}\text { Eppendorf AG } \\
\text { Hamburg } \\
\text { Deutschland }\end{array}$ & $\begin{array}{l}\text { 1,5 ml: } 0030125.150 \\
\text { 2,0 ml: } 0030120.094\end{array}$ \\
\hline
\end{tabular}




\begin{tabular}{|c|c|c|}
\hline Name & Hersteller & Artikelnummer \\
\hline $\begin{array}{l}\text { Cellstar Tubes } \\
(15 \mathrm{ml}, 20 \mathrm{ml})\end{array}$ & $\begin{array}{l}\text { Greiner Bio-One GmbH } \\
\text { Frickenhausen } \\
\text { Deutschland }\end{array}$ & $\begin{array}{l}15 \mathrm{ml}: 188271 \\
20 \mathrm{ml}: 227261\end{array}$ \\
\hline $\begin{array}{l}\text { LeucosepTM } \\
\text { Röhrchen } \\
(50 \mathrm{ml})\end{array}$ & $\begin{array}{l}\text { Greiner Bio-One GmbH } \\
\text { Frickenhausen } \\
\text { Deutschland }\end{array}$ & 227290 \\
\hline $\begin{array}{l}\text { FACS-Röhrchen } \\
(5,0 \mathrm{ml})\end{array}$ & $\begin{array}{l}\text { Sarstedt AG\&Co } \\
\text { Nümbrecht } \\
\text { Deutschland }\end{array}$ & 55.476 \\
\hline $\begin{array}{l}\text { Steriler Filter: } \\
\text { Biosphere Filter } \\
\text { Tips }\end{array}$ & $\begin{array}{l}\text { Sarstedt AG\&Co } \\
\text { Nümbrecht } \\
\text { Deutschland }\end{array}$ & 83.1826 .001 \\
\hline 6-Well Cluture Plate & $\begin{array}{l}\text { Greiner Bio-One GmbH } \\
\text { Frickenhausen } \\
\text { Deutschland }\end{array}$ & 657160 \\
\hline $\begin{array}{l}\text { 24-Well Cluture } \\
\text { Plate }\end{array}$ & $\begin{array}{l}\text { Greiner Bio-One GmbH } \\
\text { Frickenhausen } \\
\text { Deutschland }\end{array}$ & 662160 \\
\hline
\end{tabular}

\subsubsection{Geräte und Software}

\begin{tabular}{|l|l|}
\hline Name & Bezeichnung/Hersteller \\
\hline Sterilbank: Hera Safe & Typ HS 12/2 \\
& Heraeus Instruments \\
& Hanau, Deutschland \\
\hline
\end{tabular}




\begin{tabular}{|c|c|}
\hline Name & Bezeichnung/Hersteller \\
\hline \multirow[t]{3}{*}{ Zentrifuge } & Sigma $3-18 \mathrm{~K}$ \\
\hline & Sigma Laborzentrifugen $\mathrm{GmbH}$ \\
\hline & Osterode am Harz, Deutschland \\
\hline \multirow[t]{2}{*}{ Mikroskop } & Diavert; Serien Nr.: 043641 \\
\hline & Leica Service Benzheim, Deutschland \\
\hline Kontrast-Fluoreszenz & Axiovert S100 TV \\
\hline \multirow[t]{2}{*}{ Mikroskop } & Carl Zeiss AG \\
\hline & Oberkochen, Deutschland \\
\hline \multirow[t]{2}{*}{ Computer } & Optiplex 780, DELL GmbH \\
\hline & Frankfurt am Main, Deutschland \\
\hline \multirow[t]{2}{*}{ Software: Cell D 5.1} & Olympus Europe \\
\hline & Hamburg, Deutschland \\
\hline \multirow[t]{3}{*}{$\mathrm{CO}_{2}$-Inkubator } & Modell-Nr.: MCO-19AICUV-PE \\
\hline & Panasonic Healthcare Co., Ltd. \\
\hline & Tokyo, Japan \\
\hline \multirow[t]{2}{*}{ Wasserbad } & Schütt Labortechnik \\
\hline & Göttingen, Deutschland \\
\hline \multirow[t]{3}{*}{ Vortexer } & Typ VF2 \\
\hline & Janke\&Kunkel IKA Labortechnik \\
\hline & Staufen Deutschland \\
\hline \multirow{3}{*}{$\begin{array}{l}\text { Elektrische Pipettierhilfe: } \\
\text { Pipetus }{ }^{\circ}\end{array}$} & Hirschmann Laborgeräte GmbH \& Co. \\
\hline & $\mathrm{KG}$ \\
\hline & Eberstadt, Deutschland \\
\hline \multirow[t]{2}{*}{ Neubauer Zählkammer } & Tiefe $0,100 \mathrm{~mm} ; 0,0025 \mathrm{~mm}^{2}$ \\
\hline & $0,0625 \mathrm{~mm}^{2}$ \\
\hline \multirow[t]{3}{*}{ Durchflusszytometer } & FACS Calibur $^{\mathrm{TM}}$ \\
\hline & Becton Dickinson \\
\hline & New Jersey, USA \\
\hline \multirow[t]{2}{*}{ Software: BD Cell Quest ${ }^{\mathrm{TM}}$} & Becton Dickinson \\
\hline & New Jersey, USA \\
\hline \multirow[t]{2}{*}{ iCYS Laserscanning Zytometer } & Compucyte / Beckman Coulter \\
\hline & Indianapolis, USA \\
\hline
\end{tabular}




\begin{tabular}{|l|l|}
\hline Name & Bezeichnung/Hersteller \\
\hline Software: iCYS 3.4.12.92 & Compucyte / Beckman Coulter \\
& Indianapolis, USA \\
\hline MTS Oberarm & Medisana AG \\
Blutdruckmessgerät & Neuss, Deutschland \\
\hline Blutdruckmonitor & Modell 90207 \\
& Spacelabs Medical Healthcare \\
& Snoqualmie, USA \\
\hline Ultraschall-Doppler & Acuson S2000 ${ }^{\mathrm{TM}}$ Ultrasound System \\
& Modell Nr.: 10041461 \\
& Siemens Medical Solutions USA \\
& Malvern, USA \\
\hline
\end{tabular}

\section{2 $\quad$ Formale Kriterien}

\subsubsection{Studiendesign}

Es handelte sich um eine monozentrische, prospektive, klinisch-experimentelle Beobachtungsstudie mit nicht-randomisiertem Design. Die Studie wurde von den Kliniken für Nephrologie und Rheumatologie sowie Kardiologie und Pneumologie durchgeführt. Die gemeinschaftlich und getrennt erhobenen Endpunkte sind unter 2.2.5 aufgelistet sowie im Detail unter 6.0 beschrieben.

Die kardiologischen Endpunkte werden in der Dissertationsarbeit von Paul SchulzeBrock dargestellt.

\subsubsection{Ethik}

Die Durchführung der Studie wurde von der örtlichen Ethik-Kommission der Universitätsmedizin Göttingen anerkannt (Ethikvotumnummer: 14/1/13). Alle Patienten erklärten nach Aufklärung schriftlich ihr Einverständnis zur Teilnahme an der Studie. 


\subsubsection{Patienten}

Die Patienten wurden über ihren ambulanten oder stationären Kontakt mit den Abteilungen Nephrologie/Rheumatologie bzw. Kardiologie/Pneumonologie in die Studie eingeschlossen. Nach den erläuterten gültigen Kriterien bestand eine therapierefraktäre arterielle Hypertonie mit nicht leitliniengerechter Blutdruckeinstellung. Die Indikation zur renalen Denervation wurde durch die behandelnden Ärzte gestellt. 


\subsubsection{Ein- und Ausschlusskriterien der Studie}

Folgende Kriterien mussten zum Einschluss in die Studie gegeben sein:

- Therapierefraktäre arterielle Hypertonie bestätigt

- Indikation zur renalen Denervation besteht

- Alter über 18 Jahre

- Einwilligungsfähigkeit gegeben

- Einverständniserklärung vorliegend

Folgende Kriterien widersprachen einer Aufnahme in die Studie:

- Ablehnung der Studienteilnahme

- Volljährigkeit noch nicht erreicht

- Schwangerschaft, Stillzeit, Kinderwunsch

- Unbehandelte sekundäre Hypertonie

- Umstände, die die Durchführung oder Interpretation der Messgrößen stören, wie z.B. Gehbehinderung, Querschnittslähmung, stark einschränkende Atemwegserkrankung, stark schwankende Blutdruckwerte usw.

- Gleichzeitige Teilnahme an einer anderen klinischen Prüfung innerhalb von vier Wochen bzw. vier Halbwertszeiten eines zu untersuchenden Medikamentes (außer Teilnahme am deutschlandweiten GREAT (German Renal Denervation Register) Register

- Suchtkranke

- Begleiterkrankungen, die eine Nachverfolgung über einen Zeitraum von mehr als drei Jahren nicht erwarten lassen 


\subsubsection{Studienverlauf und Studienendpunkte}

Der Studienverlauf sah die folgende Vorgehensweise vor:

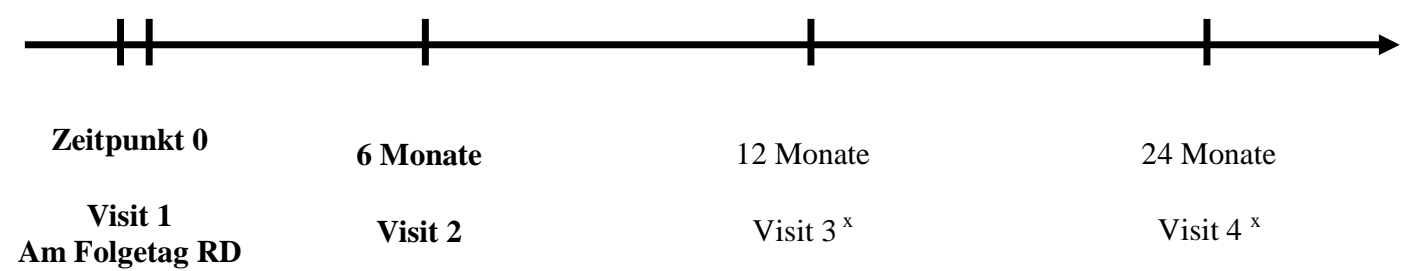

Tabelle 1: Studienverlauf und erhobene Studienparameter

\begin{tabular}{|l|l|l|l|l|}
\hline Renale Denervation & Vor & Nach & Nach & Nach \\
\hline Visite & 1 & 2 & $3^{\mathrm{X}}$ & $4^{\mathrm{X}}$ \\
\hline Monat & bis -1 & $6 \pm 1$ & $12 \pm 2$ & $24 \pm 2$ \\
\hline Aufklärung & $\mathrm{X}$ & & & \\
\hline Einwilligung & $\mathrm{X}$ & & & \\
\hline $\begin{array}{l}\text { Einschluss-/Ausschluss- } \\
\text { Kriterien }\end{array}$ & $\mathrm{X}$ & & & \\
\hline & & & & \\
\hline $\begin{array}{l}\text { Demographie/ } \\
\text { Eigenanamnese }\end{array}$ & $\mathrm{X}$ & & & \\
\hline Zwischenanamnese & & $\mathrm{X}$ & $\mathrm{X}$ & $\mathrm{X}$ \\
\hline Vitalzeichen & $\mathrm{X}$ & $\mathrm{X}$ & $\mathrm{X}$ & $\mathrm{X}$ \\
\hline $\begin{array}{l}\text { Komplette körperliche } \\
\text { Untersuchung }\end{array}$ & $\mathrm{X}$ & & $\mathrm{X}$ & $\mathrm{X}$ \\
\hline $\begin{array}{l}\text { Kurze körperliche } \\
\text { Untersuchung }\end{array}$ & & $\mathrm{X}$ & & \\
\hline Größe/Gewicht & $\mathrm{X}$ & $\mathrm{X}$ & $\mathrm{X}$ & $\mathrm{X}$ \\
\hline Vor-/Begleitmedikation & $\mathrm{X}$ & $\mathrm{X}$ & $\mathrm{X}$ & $\mathrm{X}$ \\
\hline
\end{tabular}




\begin{tabular}{|c|c|c|c|c|}
\hline Renale Denervation & Vor & Nach & Nach & Nach \\
\hline Labor $^{1}$ & $\mathrm{X}$ & $\mathrm{X}$ & $\mathrm{X}$ & $\mathrm{X}$ \\
\hline Schwangerschaftstest ${ }^{2}$ & $\mathrm{X}$ & & & \\
\hline Biomarker $^{3}$ & $X$ & $X$ & & \\
\hline $\begin{array}{l}\text { Endotheliale Progenitor } \\
\text { Zellen (EPCs) }\end{array}$ & $X$ & $X$ & & \\
\hline EKG und LZ-EKG ${ }^{\mathrm{y}}$ & $\mathrm{X}$ & $\mathrm{X}$ & $X$ & $\mathrm{X}$ \\
\hline LZ-RR & $\mathrm{X}$ & $X$ & $\mathrm{X}$ & $\mathrm{X}$ \\
\hline Echokardiographie ${ }^{\mathrm{y}}$ & $\mathrm{X}$ & $X$ & $\mathrm{X}$ & $\mathrm{X}$ \\
\hline Nierenarteriendoppler & $\mathrm{X}$ & $X$ & & \\
\hline 6-Minuten-Gehtest ${ }^{\mathrm{y}}$ & $\mathrm{X}$ & $X$ & $\mathrm{X}$ & $\mathrm{X}$ \\
\hline $\begin{array}{l}\text { Schlafapnoe-Screening } \\
\text { (ambulant) }\end{array}$ & $\mathrm{X}$ & $X^{5}$ & $X^{5}$ & $X^{5}$ \\
\hline $\begin{array}{l}\text { Lebensqualität, Angst } \\
\text { (Fragebögen) }\end{array}$ & $X$ & $X$ & $\mathrm{X}$ & $\mathrm{X}$ \\
\hline
\end{tabular}

${ }^{1}$ Routine: kleines Blutbild, Quick, pTT, GOT, GPT, AP, $\gamma$-GT, CRP, Na, K, Calcium gesamt, $\mathrm{CK}$, eGFR, Kreatinin (nephrologisch erhobene Parameter)

Urinanalytik: Protein ges., Albumin, IgG, $\alpha-1-$ Mikroglobulin, Kreatinin, Natrium (nephrologisch erhobene Parameter)

${ }^{2}$ bei Frauen im gebärfähigen Alter

${ }^{3}$ BNP, ANP, Plasmareninaktivität, Aldosteron, Serum für Adipokine, TNF- $\alpha$, IL-6 (kardiologisch erhobene Parameter)

4 PBMCs, EPC-Proliferation und Quantifizierung (nephrolog. erhobene Parameter)

5 wird nur durchführt, falls initial pathologisch

${ }^{x}$ Visit 3 und Visit 4 sind nicht mehr Teil dieser Arbeit

${ }^{\mathrm{y}}$ im Rahmen des kardiologischen Studienteils erhobene Untersuchungen 


\subsubsection{Renale Denervation}

Die renale Denervation erfolgte mit Hilfe des vom Hersteller Medtronic bereitgestellten „Symplicity ${ }^{\mathrm{TM}}$ renal denervation system“. Dieses besteht aus einem steuerbaren Ablationsskatheter sowie einem Generator, der die Abgabe von Radiofrequenz-Energie über die Katheterspitze automatisch kontrolliert und regelt. Über die Arteria femoralis wurde der Katheter in die Nierengefäße eingebracht. Dort konnten unter Sicht in der Durchleuchtung mit Kontrastmittel fünf bis sieben Ablationspunkte in beiden Nierenarterien spiralförmig gesetzt werden. Über Elektroden in der Spitze des Katheters wurde Radiofrequenz-Energie appliziert, welche zu einer fokalen Erwärmung von 45 bis maximal $70{ }^{\circ} \mathrm{C}$ führte mit dem Ziel in der Adventitia gelegene sympathische Nervenfasern zu veröden. Durch den hohen intraluminalen Blutfluss wurde das Gefäß gleichzeitig gekühlt. Der Eingriff dauerte etwa 40 bis 60 Minuten. Eine adäquate Schmerzmedikation mit einem Opioid wurde für die Prozedur verabreicht. Die Punktionsstelle wurde anschließend mit einem Druckverband für mindestens sechs Stunden versorgt.

\subsection{Klinische Methoden}

\subsubsection{Eigenanamnese}

Bei jeder Vorstellung der Patienten erfolgte ein ausführliches Anamnesegespräch, in dem mögliche Symptome und Zeichen der Hypertonie erfragt wurden. Kardiovaskuläre Risikofaktoren, bisherige bzw. im Studienverlauf durchgeführte kardiovaskuläre Interventionen, kardiale Diagnosen sowie insbesondere vaskuläre und zerebrovaskuläre Nebendiagnosen, aber auch Befunde wie die chronisch obstruktive Lungenerkrankung (COPD), Depression oder Malignome wurden erfasst. Der Genussmittelkonsum von Nikotin und Alkohol wurde erfragt. 


\subsubsection{Körperliche Untersuchung}

Die Patienten wurden hinsichtlich folgender klinischer Parameter untersucht: Körpergröße und Gewicht sowie Umfang der Taille und Hüfte wurden gemessen. Blutdruck und Herzfrequenz wurden nach 10-minütiger Ruhe im Sitzen dreimalig mit einem automatischem Blutdruckmessgerät des Herstellers Medisana gemessen und daraus der Mittelwert errechnet. Eine Auskultation der Lunge sowie eine Inspektion auf periphere Ödeme wurden durchgeführt.

\subsubsection{Technische Untersuchungen}

\subsubsection{Langzeit-Blutdruckmessung}

Bei allen Patienten wurde vor der renalen Denervation eine Langzeit-Blutdruckmessung über 24 Stunden erhoben. Diese sah automatisierte Messungen wie folgt vor: in der Zeit von 6-22 Uhr alle 15 Minuten, von 22-24 Uhr alle 20 Minuten sowie von 0-6 Uhr alle 30 Minuten. Kam es zu Fehlmessungen, wurde die Messung nach zwei Minuten wiederholt. Die Armmanschettengröße wurde entsprechend des Oberarmumfanges der Patienten ausgewählt. Erfolgte die Langzeitblutdruckmessung über die nephrologische Ambulanz der Universitätsmedizin Göttingen, wurde der ambulante Blutdruckmonitor (Modell 90207) von Spacelabs Medical Healthcare verwendet, in der Kombination mit der entsprechenden Software, dem Berichtmanagementsystem für ambulante Blutdruckmonitore. Zur Kontrolluntersuchung nach sechs Monaten nach erfolgter renaler Denervation, brachte die Mehrheit der Patienten eine hausärztlich durchgeführte Langzeitblutdruckaufzeichnung mit. War dies nicht der Fall, erhielten die Patienten erneut einen Blutdruckmonitor der hauseigenen Ambulanz über 24 Stunden mit nach Hause.

\subsubsection{Nierenarteriendopplersonographie}

Zum Ausschluss einer Nierenarterienstenose oder anatomischen Besonderheiten, welche eine Kontraindikation für eine renale Denervation ergeben hätten, erhielten alle Patienten vor Einschluss in die Studie eine beidseitige dopplersonographische 
Untersuchung der Nierenarterien. Diese wurde mit dem Gerät Acuson S2000 ${ }^{\mathrm{TM}}$ der Firma Siemens Medical Solutions USA durchgeführt.

\subsubsection{Laborparameter}

Den Patienten wurden etwa $60 \mathrm{ml}$ Blut abgenommen, sowie eine Urinprobe von etwa 50-100 ml. Die Analytik der oben aufgeführten Parameter fand in zertifizierten UMGLaboren sowie im nephrologischen Speziallabor statt. Eine Teilmenge der Proben wurde für weitere Messungen asserviert. Etwa $6 \mathrm{ml}$ Serum wurden in 12 E-cups à $500 \mu \mathrm{l}$ bei $-20{ }^{\circ} \mathrm{C}$ eingefroren, und etwa $50 \mathrm{ml}$ Urin wurden nach Zentrifugation bei $-80{ }^{\circ} \mathrm{C}$ konserviert.

\subsection{Berechnete glomeruläre Filtrationsrate - Estimated Glomerular} Filtration Rate (eGFR)

Die Stadieneinteilung der Niereninsuffizienz erfolgt meist auf Grundlage der eGFR. Es handelt sich dabei um einen Wert, der aus einfach zu erhebenden Größen errechnet wird und eine Einschätzung der Funktionsfähigkeit der Nieren erlaubt. Die Berechnung der eGFR im Rahmen dieser Studie erfolgte auf der Grundlage der MDRD-Formel (Modification of Diet in Renal Disease). Diese erlaubt bei moderaten bis schweren Funktionseinschränkungen eine relativ genaue Bestimmung der glomerulären Filtrationsrate, standardisiert auf eine Körperoberfläche von 1,73 $\mathrm{m}^{2}$.

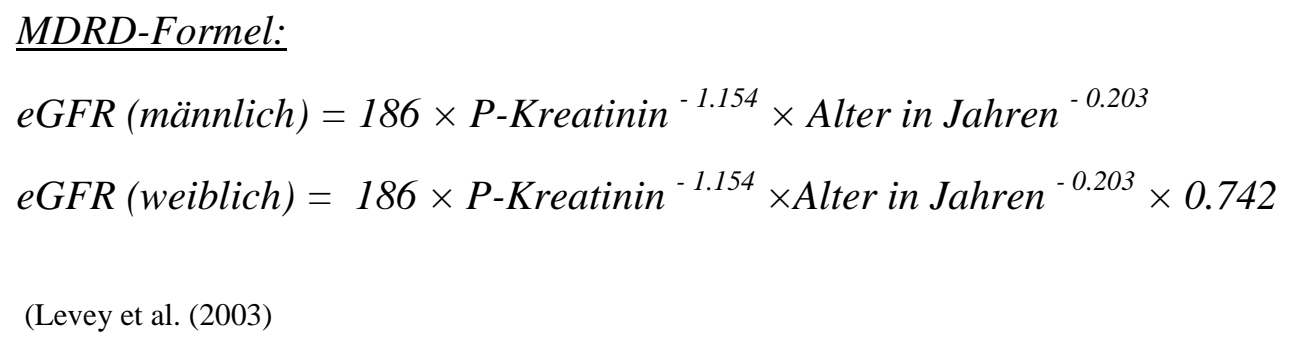

\subsection{Protein im Urin}

Bei allen Patienten wurde der Urin laborchemisch auf das Vorliegen einer Proteinurie untersucht. Dabei wurde die Menge des Gesamtproteins im Spontanurin bestimmt sowie die Anteile an Albumin, Immunglobulin $G$ und alpha-1-Mikroglobulin. Um die 
Spezifität der Messung zu erhöhen, wurde zudem der Protein-Kreatinin-Quotient sowie der Albumin-Kreatinin-Quotient errechnet. Es lässt sich hierdurch, durch Ausschaltung von Verdünnungseffekten, eine hohe Korrelation zu der quantitativen Bestimmung von Protein bzw. Albumin aus dem 24h-Sammelurin erreichen.

\subsection{Laborchemische Beurteilung der Nierenfunktion}

Zur weiteren laborchemischen Beurteilung der Nierenfunktion erfolgte die Bestimmung von Kreatinin und Cystatin C aus dem Serum. Im Urin wurden die Konzentrationen von Natrium und Kreatinin bestimmt, und die fraktionierte Natriumexkretion berechnet.

Formel zur Berechnug der fraktionierten Natriumexkretion (FE) [\%]:

$F E($ Natrium $)=\frac{\operatorname{Natrium~}(\text { Urin }) \frac{m m o l}{l} \times \operatorname{Kreatinin}(\text { Serum }) \frac{m g}{d l}}{\operatorname{Natrium~}(\text { Serum }) \frac{m m o l}{l} \times \operatorname{Kreatinin}(\text { Urin }) \frac{m g}{d l}} \times 100$

(Kawasaki et al. (1993)

\subsection{Aldosteron-Renin-Quotient}

Zum Screening der Patienten auf das Vorliegen eines primärem Hyperaldosteronismus und somit sekundärer Hypertonie, wurde der Aldosteron-Renin-Quotient mit etablierten Standardmethoden im zertifizierten nephrologischen Routinelabor der Universitätsmedizin Göttingen ermittelt.

\subsection{Experimentelle Methoden}

\subsubsection{Isolation von PBMCs (Peripheral Blood Mononuclear Cells)}

Zur Isolation der mononukleären Zellen des Blutes (PBMC) wurden etwa $10 \mathrm{ml}$ Blut aus einer peripheren Vene verwendet. Die PBMCs wurden mithilfe von Leukosep ( entsprechend ihrem Dichtegradienten durch Zentrifugation separiert. Durch 
Zentrifugation wurde das Biocoll-Separationsmedium unterhalb von der porösen Polyethylen-Trennmembran gebracht. Anschließend erfolgte die Zugabe des in Lithium-Heparinat gelösten Vollblutes auf die Membran sowie die Zentrifugation ohne Abbremsung. Es entstand eine Schichtung aus Plasma, der Zellfraktion aus PBMC und Lymphozyten und dem Separationsmedium. Unterhalb der Trennscheibe sammelte sich das Pellet aus Erythrozyten und Granulozyten. Die Schicht aus zu gewinnenden PBMCs und Leukozyten konnte nun abpipettiert werden. Es folgte ein zweimaliger Waschgang mit phosphatgepufferter Salzlösung (PBS). Zur Quantifizierung der kernhaltigen Zellen wurden diese mit Hilfe einer Neubauer-Zählkammer ausgezählt.

\subsubsection{Durchflusszytometrie}

2.4.2.1 Durchflusszytometrische Quantifizierung endothelialer Progenitorzellen (EPCs)

Die Durchflusszytometrie dient der Quantifizierung und Analyse von Zellpopulationen. Mit Hilfe der FACS-Analyse (Fluorescence Activated Cell Sorting) lassen sich fluoreszenzfarbstoff-markierte Antikörper gegen spezifische Oberflächenantigene detektieren und entsprechend charakterisierte Zellen zählen. Das Prinzip beruht darauf, dass die markierten Zellen einzeln einen fokussierten Laserstrahl passieren und das dabei erzeugte Streu- und Fluoreszenszlicht separat detektiert wird. Das Streulicht wird unterschieden in das Vorwärtsstreulicht $(\mathrm{FSC}=$ Forward Scatter), welches entsteht durch die Beugung des Lichts im flachen Winkel und Rückschlüsse auf das Volumen der Zelle schließen lässt, sowie in das Seitwärtsstreulicht (SSC = Sidewards Scatter), welches durch die Brechung des Lichts im rechten Winkel entsteht und von der Granularität, Größe und Struktur des Zellkerns sowie der Menge der Vesikel in der Zelle bestimmt wird. So lassen sich die nativen Zellen des Blutes bereits charakteristisch auftrennen. 


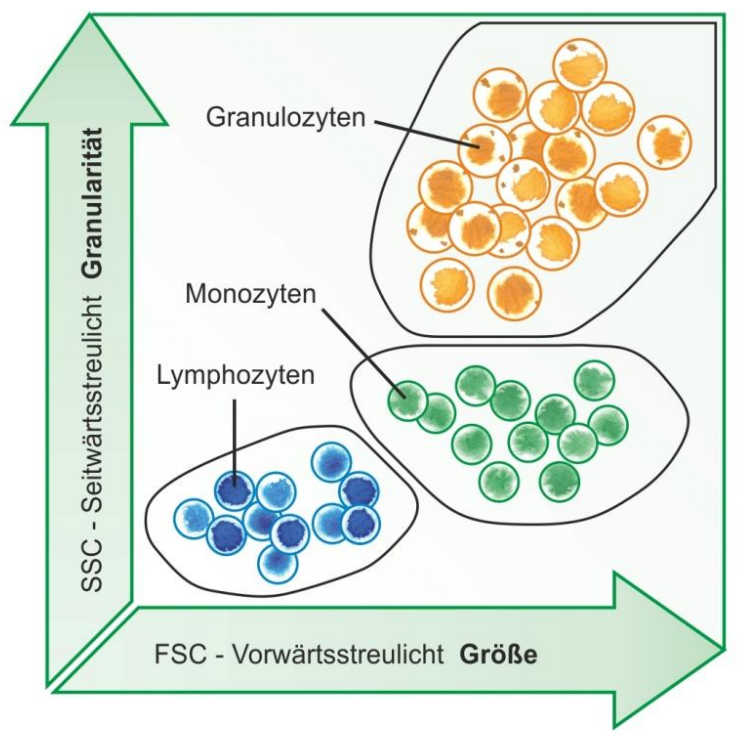

Abbildung 2: Charakteristische Auftrennung ungefärbter Zellen in der Durchflusszytometrie. Veränderungen der Lichtstreuung führen im Dot Plot zu einer Sortierung anhand der Merkmale Größe und Granularität.

CJohannes Erzberger (2017); Abbildung modifiziert nach: http://www.antikoerperonline.de/resources/17/1247/durchflusszytometrie-facs-messprinzip-aufbau/ (07.01.2017)

Werden die Zellen zusätzlich mit fluoreszenzmarkierten Antikörpern markiert, lassen sie sich anhand ihrer Oberflächenmarker näher charakterisieren. Mithilfe verschiedenfarbiger Laser und Filter werden die Fluoreszenzen angeregt und die emittierten Signale detektiert.

(Vgl. http://www.antikoerper-online.de/resources/17/1247/Durchflusszytometrie+FACS +Messprinzip++Aufbau/ (05.02.2017))

Zur Identifizierung der EPCs wurde als standardisierte Methode die Kombination des Oberflächenmarkers CD133 und Flk-1, auch vascular endothelial growth factor receptor 2 - VEGFR2 bzw. kinase insert domain receptor KDR verwendet (Lenk et al. 2011). CD133 gilt als Marker unreifer Progenitorzellen, Flk-1 als Marker endothelialer Zellen (Urbich und Dimmeler 2004). Ein weiteres Oberfächenantigen hämatopoetischer Stammzellen ist die Rezeptor-Tyrosinkinase c-Kit, auch bezeichnet als CD117. Nahezu alle Zellen, die Flk-1 exprimieren, zeigen eine Coexpression des c-Kit-Antigens, sodass über die Kombination von CD133 mit beiden Oberflächenmarker ein sinnvoller Vergleichswert gewonnen werden konnte (Hibbert et al. 2011). 
Tabelle 2: Oberflächenmarker endothelialer Progenitorzellen und deren Chrakteristika in der Durchflusszytometrie

\begin{tabular}{|c|c|c|c|}
\hline $\begin{array}{l}\text { Oberflächen } \\
\text { marker }\end{array}$ & & $\begin{array}{l}\text { Fluoreszenz- } \\
\text { Emissions-Farbe }\end{array}$ & $\begin{array}{l}\text { Max. } \\
\text { Emissions- } \\
\text { Wellenlänge } \\
{[\mathrm{nm}]}\end{array}$ \\
\hline CD133 + & $\begin{array}{l}\text { Marker } \\
\text { hämatopoetischer } \\
\text { Stammzellen }\end{array}$ & $\begin{array}{l}\text { Sekundär PE } \\
\text { gekoppelt: gelb }\end{array}$ & 578 \\
\hline Flk-1+ & $\begin{array}{l}\text { Marker endothelialer } \\
\text { Zellen }\end{array}$ & FITC: grün & 520 \\
\hline $\begin{array}{l}\text { CD133 Flk-1 } \\
++\end{array}$ & $\begin{array}{l}\text { Doppelt positive } \\
\text { Zellen zur } \\
\text { Charakterisierung } \\
\text { EPCs }\end{array}$ & & \\
\hline c-Kit + & $\begin{array}{l}\text { Marker } \\
\text { hämatopoetischer } \\
\text { Stammzellen }\end{array}$ & $\begin{array}{l}\text { AlexaFluor® 488: } \\
\text { grün }\end{array}$ & 519 \\
\hline $\begin{array}{l}\text { CD133 c-Kit } \\
++\end{array}$ & $\begin{array}{l}\text { Doppelt positive } \\
\text { Zellen zur } \\
\text { Charakterisierung } \\
\text { EPCs }\end{array}$ & & \\
\hline
\end{tabular}

\subsubsection{Antikörperfärbungen}

Zur Vorbereitung von fünf FACS-Messungen wurden 7,5 Millionen Zellen (1,5 Millionen Zellen pro Messung) gewonnen, wie unter 2.4.1. beschrieben. Nach Zentrifugation der in PBS gelösten Zellen wurden zum Pellet $500 \mu 11 \%$ ige PBS-BSA (BSA: Bovines Serumalbumin) Lösung zugegeben. Je $100 \mu 1$ wurden in die fünf FACSRöhrchen verteilt. Je $1 \mu$ l Blocking Peptid (FcR Blocking Reagent (human), MACS Miltenyi Biotec, Auburn, USA) wurde hinzugefügt, und für 10 min bei $4{ }^{\circ} \mathrm{C}$ inkubiert. Es folgte ein Waschgang mit je $2 \mathrm{ml}$ PBS-BSA Lösung, die Zentrifugation über 5 min sowie die Entfernung des Überstandes durch Dekantieren. Im nächsten Schritt erfolgte die Zugabe der Primärantikörper zu den entstandenen Pellets: $100 \mu 1$ Rabbit anti CD133 (CD133 antibody, EMELCA Bioscience; Breda, Niederlande) in der Verdünnung 1:100 wurde in zwei Röhrchen gegeben, einmal kombiniert mit $3 \mu$ mouse anti human Flk-1 (RD Systems, Minneapolis, USA), sowie einmal mit $2 \mu 1$ mouse anti c-Kit (Cell 
Signaling Technologies, Danvers, USA). Diese wurden anschließend für 30 min bei $4{ }^{\circ} \mathrm{C}$ inkubiert. Nach einem erneuten Waschvorgang mit $2 \mathrm{ml}$ PBS-BSA sowie Zentrifugation und Entfernen des Überstandes wurde je $1 \mu \mathrm{l}$ des sekundären PEAntikörpers für CD133 (Goat Anti-Rabbit IgG, Dianova/Jackson Immuno Research, West Grove, USA) in beide Röhrchen mit CD133 markierten Zellen gegeben, sowie in ein weiteres Röhrchen zu einer der Kontrolle dienenden, ungefärbten Zelllösung. In ein Röhrchen unbehandelter Zellen wurde $1 \mu 1$ der Isotypkontrolle (IgG1-FITC / IgG2a-PE, Immunotech SAS Beckman Coulter, Marseille, France) zugegeben. Ein Röhrchen blieb nativ. Es folgte die erneute Inkubation für $10 \mathrm{~min}$ bei $4{ }^{\circ} \mathrm{C}$. Anschließend wurden alle Lösungen mit $2 \mathrm{ml}$ PBS-BSA gewaschen und zentrifugiert. Der Überstand wurde abgenommen und $450 \mu 1$ PBS zugeben.

\subsubsection{FACS-Analyse}

Die FACS-Analyse erfolgte mithilfe des Gerätes FACS Calibur ${ }^{\mathrm{TM}}$ der Firma Becton Dickinson. Mit der Datenerfassungs- und Analysesoftware BD Cell Quest wurden im Dot Plot (Punktwolkendarstellung) die Signale des Forward Scatters (FSC) auf der x-Achse, und die des Sideward Scatters (SSC) auf der y-Achse aufgetragen, sodass die übliche Zellverteilung nach Lymphozyten, Monozyten und Granulozyten entstand. Die Population der Monozyten konnte nun mithilfe eines Gates markiert werden, und die darin enthaltenen Zellen auf ihre Fluoreszenzsignale untersucht werden. Durch Selektion eines Gates können neue Dot-Plot-Darstellungen generiert werden, wodurch es möglich ist verschiedene Merkmale miteinander zu verknüpfen. Um unspezifische Bindungen zu eruieren, wurden Dot Plots der Isotypkontrolle, sowie des sekundären PE-Antikörpers erstellt. In einem Dot Plot erfolgte die Darstellung von CD133 und Flk-1 (VEGFR2/KDR) positiven, sowie doppelt positiven Zellen. Diese Merkmale wurden zur Charakterisierung EPCs herangezogen. Um unspezifische Bindungen nicht mitzuzählen, wurde die Anzahl der vorher ermittelten Adhäsionen des sekundären PEAntikörpers von der Anzahl der doppelt positiven Zellen subtrahiert. Ein vergleichender Wert wurde in einem weiteren Dot Plot gewonnen, in dem CD133- und c-Kit (CD117)doppelt positive Zellen abgebildet wurden (Vgl. Weigand 2013). 


\subsubsection{Zellkultur von Colony Forming Units (CFU) endothelialer Progenitorzellen (EPCs)}

Die Isolation der PBMCs erfolgte wie oben beschrieben unter Punkt 2.2.1.3 Die Blutproben wurden am Tag der Abnahme verarbeitet.

Um die Proliferationsfähigkeit der EPCs zu bestimmen, wurde eine von STEMCELL Technologies standardisierte Methode einer Zellkultur über fünf Tage mit dem EndoCult Kit aus Zellnährlösungen angewandt, die es erlaubt, die von EPCs gebildeten Colony Forming Units (CFUs) zu quantifizieren.

Fünf Millionen Zellen pro Well wurden in Stammzellnährmedium resuspendiert. Um die Kontamination mit reifen Endothelzellen $\mathrm{zu}$ minimieren, wurden die Zellen zunächst auf einer mit humanem Fibronektin beschichteten 6-Well-Platte aufgebracht, und 48 Stunden inkubiert, bei $37{ }^{\circ} \mathrm{C}$ in $5 \% \mathrm{CO}_{2}$ und über $95 \%$ iger Luftfeuchtigkeit. Anschließend wurden nicht adhärente Zellen wieder aufgenommen, auf einer mit Fibronektin beschichteten 24-Well-Platte aufgebracht und erneut bei gleichen Bedingungen für weitere 72 Stunden inkubiert. Nach Ende der Kultur wurde das Medium entfernt, die Wells mit PBS gewaschen, und die CFUs unter dem Lichtmikroskop ausgezählt. Ab einer Gruppierung von drei lanzettförmigen EPCs um einen Kern aus runden Zellen wurde diese als Kolonie gezählt. Im Anschluss erfolgte die Fixierung mit 2 \%igem Formaldehyd.

\subsubsection{Immunfluoreszenzmikroskopische Analyse}

\subsubsection{Laserscanning-Zytometrie (iCYS)}

Die eNOS-Expression der EPCs wurde mithilfe der Laserscanning-Zytometrie detektiert, welche es ermöglicht, mikroskopische Bildgebung mit den statistischen Möglichkeiten eines Durchflusszytometers zu kombinieren. Es wurde das iCYS Laserscanning Zytometer der Firma Compucyte (USA) mit der entsprechenden Software iCYS 3.4.12.92 genutzt. Zur Anregung der fluoreszenzmarkierten Antikörper werden ein blauer Argon-Laser der Wellenlänge 488 nm, ein roter Helium-Neon-Laser der Wellenlänge $633 \mathrm{~nm}$ sowie ein violetter Diodenlaser der Wellenlänge $405 \mathrm{~nm}$ verwendet. Die Probe wird mit der beweglichen Trägerplatte durch die Anregungslaser 
geführt. Mithilfe eines dichromatischen Spiegels wird das Anregungs- und Emissionslicht voneinander getrennt. Das durch die angeregten Fluorochrome der Antikörper entstehende Emissionslicht wird mit einer Linse fokussiert, während das Anregungslicht mithilfe des dichromatischen Spiegels reflektiert wird. Das Emissionslicht wird auf Filterwürfel gelenkt, welche aus einem dichroischen Spiegel zur Trennung der verschiedenen Wellenlängen und einem Bandpass-Filter bestehen. Die Fluoreszenzsignale werden auf einen Photomultiplier (PMT) gespiegelt, wo sie separat detektiert werden und ein digitales Signal generiert wird. Somit können verschiedene Spektralbereiche simultan gemessen und verrechnet werden. Dies ermöglichte die Kontrolle der Zellen auf die Expression von eNOS, sowie gleichzeitig auf das Vorhandensein eines Zellkerns.

(Vgl.: http://www.bostonind.com/laboratory/microscopes-and-imaging/confocalmicroscopes/compucyte-icys-laser-scanning-cytometer-with-olympus-ix 71-microscope (26.01.2017); Hoffschulte 2009) 


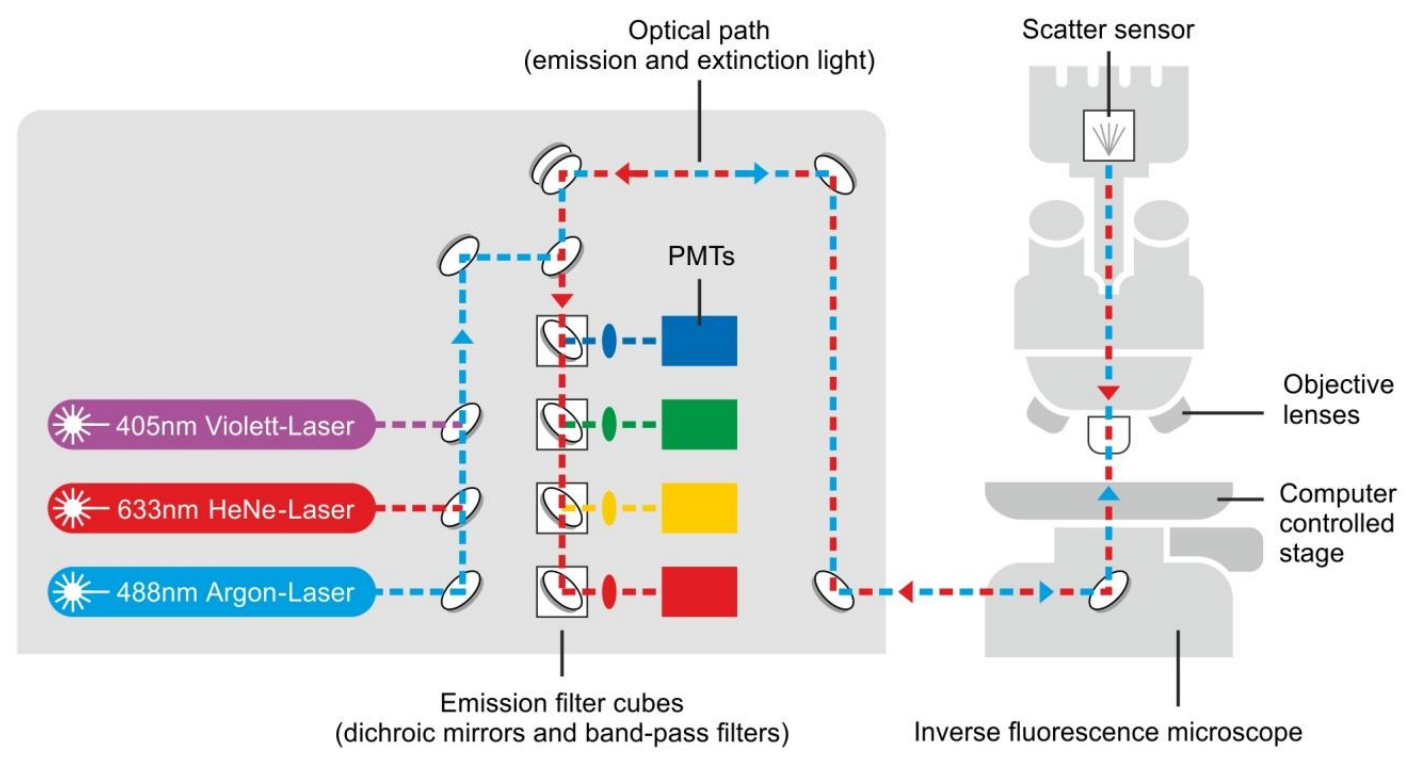

Abbildung 3: Modell eines iCYS Laserscanning-Zytometers

(C) Johannes Erzberger (2017);

Abbildung modifiziert nach: https://www.researchgate.net/figure/Figure-2-Block-diagramof-a-Laser-Scanning-Cytometer_240630243_fig2 (07.01.2017), mit Darstellung eines Blockdiagrams der Firma CompuCyte Corporation, Cambridge, MA

\subsubsection{Immunologische Identifizierung}

Die 24-Well Platten mit den fixierten EPC-CFUs (siehe Punkt 2.3.2.2.) wurden mithilfe von Antikörpern immunologisch auf die Expression von eNOS untersucht. Zur Vorbereitung wurden die Wells mit PBS gespült, welches anschließend entfernt wurde. Es erfolgte die Permeabilisierung der Zellmembranen mit Triton-X-100 0,1\% in PBS, mit welchem die Wells für 10 min bedeckt und inkubiert wurden. Es folgte ein Waschgang mit 1 \%igem PBS-BSA, welches ebenfalls $10 \mathrm{~min}$ inkubierte und anschließend abgesaugt wurde. Im nächsten Schritt wurden die Wells bedeckt mit $300 \mu \mathrm{l}$ der Anti-eNOS Antikörperlösung (BD Bioscience, San Diego, USA) in der Verdünnung mit PBS 1:100, und für 24 Stunden bei $4{ }^{\circ} \mathrm{C}$ inkubiert. Die Lösung wurde entfernt, die Wells mit PBS gewaschen, und $300 \mu$ des sekundären Antikörpers Northern Light Anti-Mouse IgG-NL637 (R\&D Systems, Minneapolis, USA) in der Verdünnung mit PBS 1:500 in die Wells gegeben. Es folgte eine Inkubation über eine Stunde bei Raumtemperatur unter Lichtschutz. Anschließend wurde die Lösung abgesaugt, ein Waschgang mit PBS durchgeführt und die Zellkernfärbung mit DAPI 
(4',6-Diamidin-2-phenylindol) vorgenommen. $300 \mu 1$ DAPI (Konzentration $5 \mathrm{mg} / \mathrm{ml}$ ) in Verdünnung mit Aqua 1:1000 wurde in die Wells gegeben und für 10 min inkubiert. Nach Entfernen dieser Lösung wurden die Wells erneut mit PBS gewaschen und bedeckt. Anschließend erfolgte die Messung mit dem iCYS-Laserscanning-Zytometer.

\subsubsection{Software-Analyse}

Die verwendeten Antikörper wiesen die folgenden Merkmale auf

Tabelle 3: Oberflächenmarker endothelialer Progenitorzellen und deren Charakteristika in der Laserscanning-Zytometrie

\begin{tabular}{|l|l|l|l|}
\hline $\begin{array}{l}\text { Oberflächen } \\
\text { marker }\end{array}$ & $\begin{array}{l}\text { Fluoreszenz- } \\
\text { Emissions-Farbe }\end{array}$ & $\begin{array}{l}\text { Max. } \\
\text { Emissions- } \\
\text { Wellenlänge } \\
\text { [nm] }\end{array}$ \\
\hline $\begin{array}{l}\text { Anti eNOS } \\
+\end{array}$ & $\begin{array}{l}\text { Marker der } \\
\text { endothelialen } \\
\text { Sekundärer } \\
\text { Antikörper: } \\
\text { Northern Light } \\
\text { Anti-Mouse }\end{array}$ & $\begin{array}{l}\text { Stickstoffmonoxid- } \\
\text { Synthase }\end{array}$ & NL637: rot \\
\hline $\begin{array}{l}\text { DAPI } \\
\text { (4',6- }\end{array}$ & Marker von & blau & \\
$\begin{array}{l}\text { Diamidin-2- } \\
\text { phenylindol) }\end{array}$ & DNA/Zellkernen & & 461 \\
\hline
\end{tabular}

Mithilfe der iCYS-Software konnten Dot-Plots generiert werden. Auf der x-Achse wurden die blauen Signale der DAPI-Kernfärbung aufgetragen, auf der y-Achse die des roten sekundären Antikörpers gegen eNOS. Im rechten oberen Quadranten fanden sich die Zellen, welche für beide Signale positiv waren. Das System speicherte alle festgelegten Einstellungen für sämtliche durchgeführten Messungen. 


\section{5 $\quad$ Statistische Auswertung}

\subsubsection{Statistische Analysen}

Alle erhobenen Daten waren im Verlauf der Studie in Tabellen des Progamms Microsoft Exel 2007 gesammelt worden. Ebenso erfolgte hier die Berechnung der Differenzen der Werte von Visit I und Visit II. Die weiteren statistischen Analysen der gewonnen Größen erfolgten mithilfe der Datenanalyse-Software STATISTICA 12.7 des Unternehmens StatSoft ${ }^{\circledR}$. Alle ermittelten Parameter wurden auf ihre Normalverteilung getestet. Lag diese vor, so wurde zum Testen auf einen statistischen Unterschied zwischen den Zeitpunkten vor renaler Denervation sowie sechs Monate danach ein verbundener t-Test mit Bestimmung des Mittelwertes, der Standardabweichung sowie des Signifikanzniveaus $\mathrm{p}$ durchgeführt. Konnte keine Normalverteilung bestätigt werden, wurde der Wilcoxon-Rangsummen-Test angewendet. Das Signifikanzniveau für einen statistischen Unterschied wurde mit $\mathrm{p}=0,05$ definiert.

Aufgrund der geringen Anzahl an in die Studie eingeschlossenen Patienten wurde bezüglich einiger Parameter eine Poweranalyse mit einer festgelegten Teststärke von $80 \%$ durchgeführt, um statistisch eine Aussage zu treffen, mit welcher Anzahl von Werten das Signifikanzniveau erreicht worden wäre. Weiterhin erfolgte eine SpearmanKorrelation, um die Entwicklung des Blutdrucks unter der Berücksichtigung der Reduktion der Antihypertensiva zu betrachten.

\subsubsection{Graphische Darstellung der Ergebnisse}

Die graphische Darstellung der Ergebnisse erfolgte ebenfalls mithilfe der DatenanalyseSoftware STATISTICA 12.7. Es wurden 2D-Whiskers-Box-Plots generiert, sowie ein 2D-Balkenplot. 


\section{Ergebnisse}

\subsection{Auswertung der Patientendaten}

Die demographischen Daten des untersuchten Patientenkollektivs werden in den nachfolgenden Tabellen dargestellt. Weiterhin wird die Medikation zur Senkung des arteriellen Blutdrucks der Patienten beschrieben, und Veränderungen der Therapie nach erfolgter renaler Denervation aufgezeigt.

Tabelle 4: Stichprobengröße und Geschlechterverteilung

\begin{tabular}{|l|rr|}
\hline Stichprobengröße & $\mathbf{1 2}$ \\
\hline Männlich & 5 & $(41,7 \%)$ \\
\hline Weiblich & 7 & $(58,3 \%)$ \\
\hline
\end{tabular}

Tabelle 5: Demographische Daten des untersuchten Patientenkollektivs

\begin{tabular}{|l|l|}
\hline Demographische Daten & $\begin{array}{l}\text { Mittelwert ( } \pm \text { Standardabweichung SA) } \\
\text { oder Absolutwerte (Prozent) }\end{array}$ \\
\hline Alter $[\mathrm{a}]$ & $63,92( \pm 11,21)$ \\
\hline BMI $\left[\mathrm{kg} / \mathrm{m}^{2}\right]$ & $31,09( \pm 4,11)$ \\
\hline Umfang Hüfte $[\mathrm{cm}]$ & $111,92( \pm 13,51)$ \\
\hline Umfang Taille $[\mathrm{cm}]$ & $108,92( \pm 11,07)$ \\
\hline & Anzahl \\
\hline Raucher & $1(8,3 \%)$ \\
\hline Diabetes mellitus & $2(16,6 \%)$ \\
\hline Hyperlipidämie & $6(50 \%)$ \\
\hline
\end{tabular}


Tabelle 6: Anzahl und Typ antihypertensiver Medikation vor und sechs Monate nach renaler Denervation

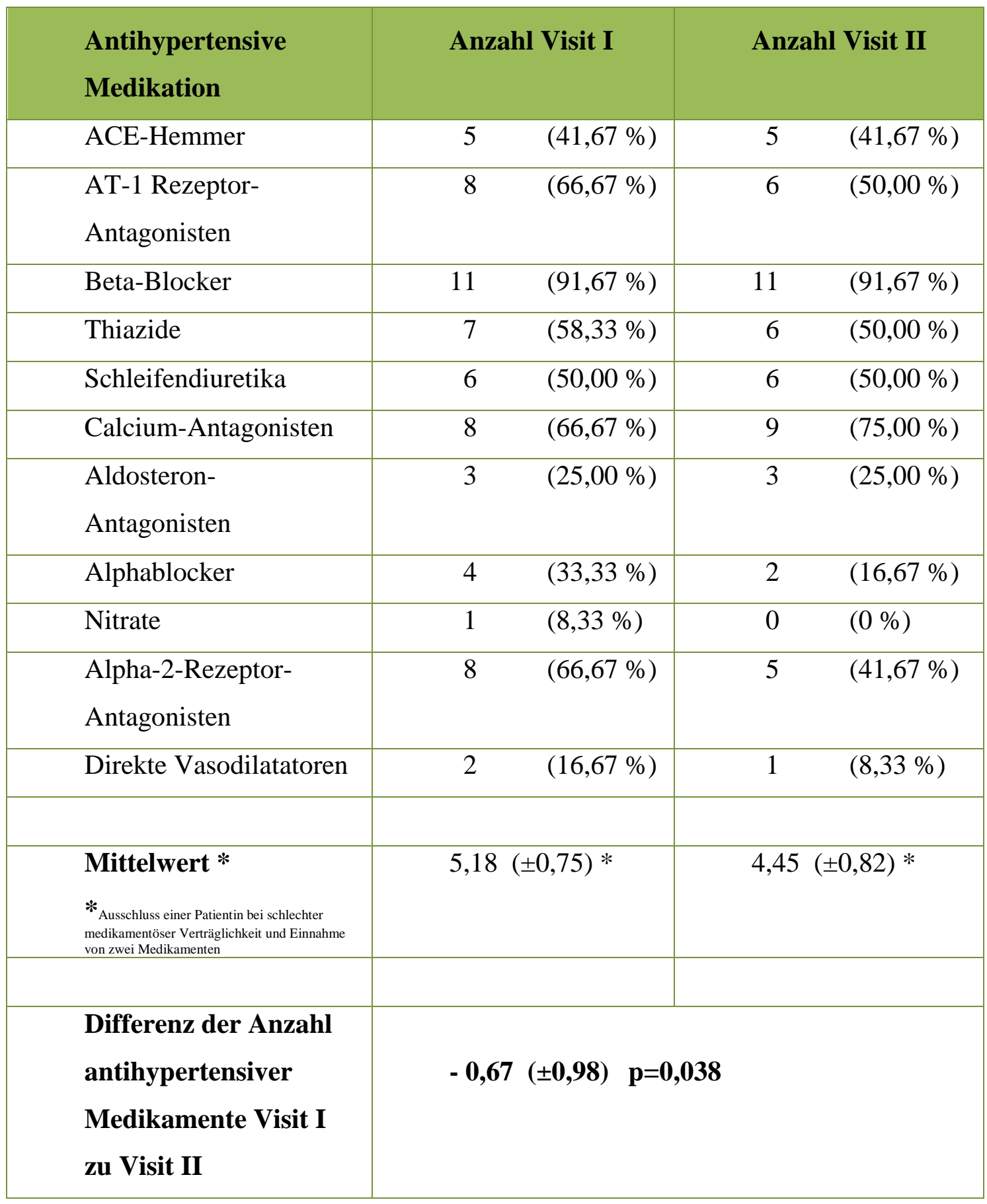




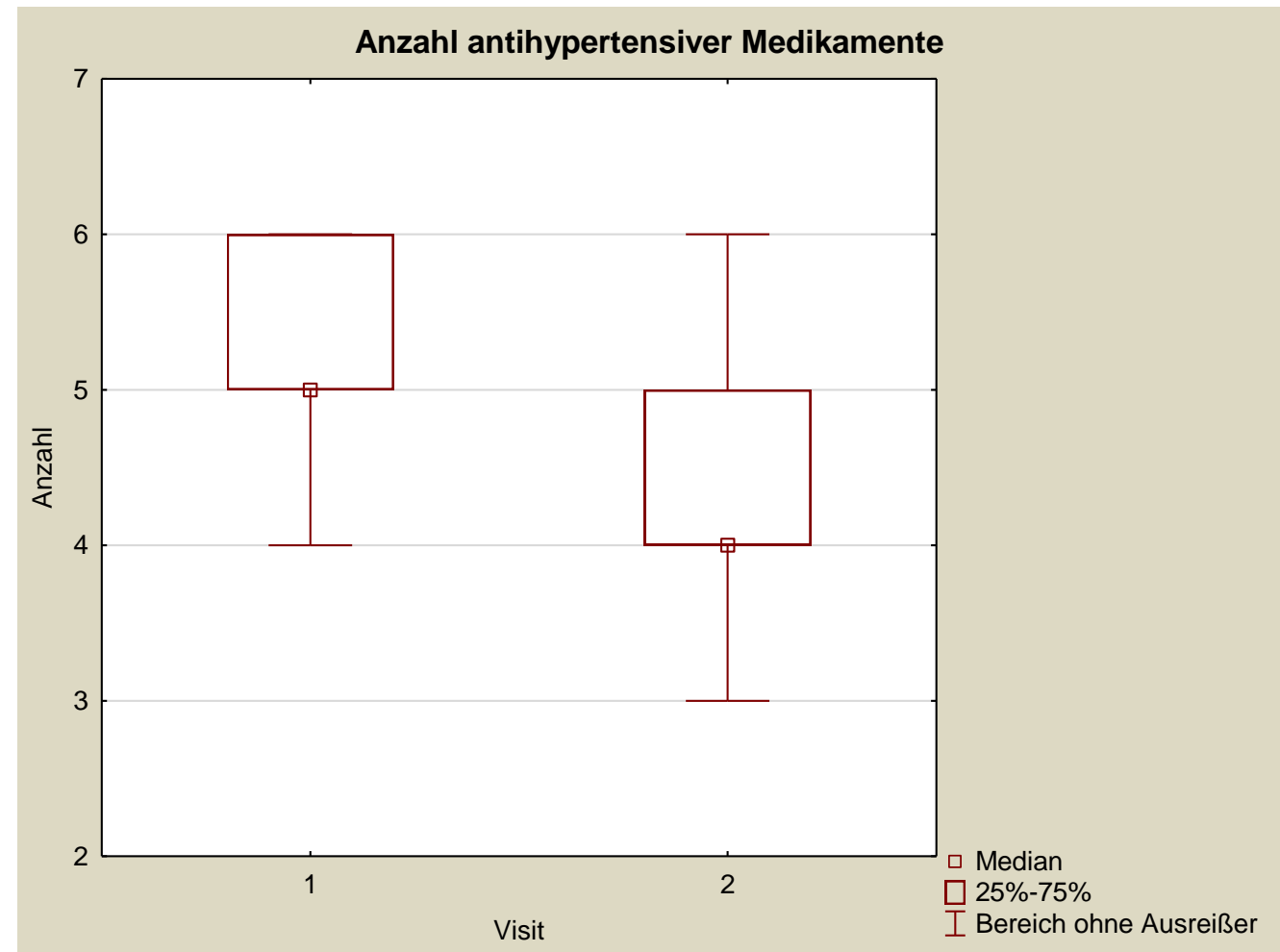

Abbildung 4: Box-Whiskers-Plot der Anzahl antihypertensiver Medikamente vor und sechs Monate nach renaler Denervation

\subsection{Auswertung der Blutdruckmessungen vor und nach renaler Denervation}

\subsubsection{Einzelmessungen}

Die folgende Tabelle gibt die klinisch erhobenen Einzelmessungen des arteriellen Blutdrucks wieder. Es ergibt sich keine Änderung des systolischen und diastolischen Wertes (vgl. Tabelle 7). Da jedoch eine signifikante Reduktion der Anzahl antihypertensiver Medikamente stattgefunden hatte, wurde zusätzlich eine SpearmanRangkorrelation durchgeführt. Hierbei ergab sich im Bereich der systolischen Blutdruckwerte ein Korrelationskoeffizient $\mathrm{R}=-0,48 \quad(\mathrm{p}=0,11)$ und somit keine signifikante Korrelation. Bei der Betrachtung des diastolischen Blutdrucks hingegen, ergab sich zwischen der Reduktion der antihypertensiven Medikation und der Steigerung des diastolischen Blutdrucks eine signifikante gegensinnige Korrelation mit Spearman $R=-0,62(p=0,03)$. 
Tabelle 7: Mittelwerte des arteriellen Blutdrucks in der klinischen Einzelmessung vor und sechs Monate nach renaler Denervation

\begin{tabular}{|c|c|c|}
\hline $\begin{array}{l}\text { Arterieller Blutdruck } \\
(\mathrm{RR}) \\
{[\mathrm{mmHg}]}\end{array}$ & $\begin{array}{l}\text { Visit I } \\
\text { Mittelwert }( \pm \text { SA })\end{array}$ & $\begin{array}{l}\text { Visit II } \\
\text { Mittelwert ( } \pm \text { SA) }\end{array}$ \\
\hline RR systolisch & $148,08 \quad( \pm 27,67)$ & $146,25 \quad( \pm 16,87)$ \\
\hline RR diastolisch & $85,75 \quad( \pm 15,69)$ & $87,75 \quad( \pm 13,40)$ \\
\hline $\begin{array}{l}\text { Entwicklung Visit I zu } \\
\text { Visit II }\end{array}$ & \multicolumn{2}{|c|}{$\begin{array}{l}\text { RR systolisch: }-1,83( \pm 19,07) p=0,75 \\
\text { RR diastolisch: } 2,00( \pm 8,15) \quad p=0,41\end{array}$} \\
\hline
\end{tabular}

\subsubsection{4-Stunden-Blutdruckmessung}

Zusätzlich wurde stets eine ambulante Aufzeichnung des Blutdrucks über 24 Stunden durchgeführt und ausgewertet. Es zeigte sich kein signifikanter Unterschied bei den Messungen sechs Monate nach renaler Denervation. So war bei den über 24 Stunden gemittelten systolischen Werten eine tendenzielle Erhöhung um 8,58 $( \pm 14,74) \mathrm{mmHg}$ zu beobachten sowie um $1,58( \pm 7,56) \mathrm{mmHg}$ bei den diastolischen Werten bei jeweils fehlender Signifikanz. In der weiteren Aufschlüsselung der Aufzeichnungen zeigte sich der mittlere arterielle Druck (MAD) über 24 Stunden um 7,0 $( \pm 11,52) \mathrm{mmHg}$ tendenziell erhöht $(\mathrm{p}=0,06)$. Während des Tages zeigte sich eine signifikante Differenz des MAD von 7,33 $( \pm 10,59) \mathrm{mmHg}$ mit $\mathrm{p}=0,04$, in den Stunden der Nacht betrug die Differenz des MAD $3,93( \pm 14,46) \mathrm{mmHg} \quad(\mathrm{p}=0,37)$ ohne Erreichen eines Signifikanzniveaus. Die gemittelten Werte des systolischen arteriellen Blutdrucks während des Tages ergaben eine nicht-signifikante Tendenz zur Erhöhung um $9,58( \pm 15,61) \mathrm{mmHg}(\mathrm{p}=0,06)$, während der Nacht um 6,92 $( \pm 21,06) \mathrm{mmHg}(\mathrm{p}=0,28)$ zum Zeitpunkt der Visit II. Die diastolischen Werte waren am Tag sowie in der Nacht unverändert (Tabelle 8). Die maximalen gemessenen systolischen Blutdruckwerte lagen sechs Monate nach renaler Denervation im Mittel 12,67 $( \pm 26,06) \mathrm{mmHg}$ höher. Maximale diastolische Werte waren ebenfalls um $12,58( \pm 13,02) \mathrm{mmHg}$ gesteigert zu verzeichnen mit $p=0,007$. Der minimal erhobene systolische Blutdruck war um $9,75( \pm 11,03) \mathrm{mmHg}(\mathrm{p}=0,01)$ erhöht. Wenn nicht gesondert erwähnt, lagen die ermittelten Differenzen über dem Signifikanzniveau von 0,05. 
Tabelle 8: Auswertung der Langzeitblutdruckaufzeichungen über 24 Stunden vor und sechs Monate nach renaler Denervation

\begin{tabular}{|c|c|c|}
\hline $\begin{array}{l}\text { Arterieller Blutdruck } \\
(\mathrm{RR}) \\
{[\mathrm{mmHg}]}\end{array}$ & $\begin{array}{l}\text { Visit I } \\
\text { Mittelwert }( \pm \text { SA })\end{array}$ & $\begin{array}{l}\text { Visit II } \\
\text { Mittelwert }( \pm \text { SA })\end{array}$ \\
\hline 24-h RR systolisch & $131,17 \quad( \pm 17,62)$ & $139,75 \quad( \pm 18,20)$ \\
\hline 24-h RR diastolisch & $75,50 \quad( \pm 12,25)$ & $77,08 \quad( \pm 12,32)$ \\
\hline $\begin{array}{l}\text { Entwicklung Visit I zu } \\
\text { Visit II }\end{array}$ & \multicolumn{2}{|c|}{$\begin{array}{l}\text { RR systolisch: } 8,58 \quad( \pm 14,74) p=0,07 \\
\text { RR diastolisch: } 1,58 \quad( \pm 7,56) p=0,48\end{array}$} \\
\hline $\begin{array}{l}\text { Mittlerer arterieller } \\
\text { Druck (MAD) über 24-h }\end{array}$ & $92,67 \quad( \pm 11,43)$ & $99,67 \quad( \pm 14,61)$ \\
\hline MAD Tag & $94,33 \quad( \pm 11,99)$ & $101,67 \quad( \pm 14,75)$ \\
\hline MAD Nacht & $88,92 \quad( \pm 12,75)$ & $92,83 \quad( \pm 11,63)$ \\
\hline $\begin{array}{l}\text { Entwicklung Visit I zu } \\
\text { Visit II }\end{array}$ & \multicolumn{2}{|c|}{$\begin{array}{l}\text { MAD 24-h: } 7,00( \pm 11,52) \\
\text { MAD Tag: 7,33 }( \pm 10,59) \\
\text { MAD Nacht: } 3,92( \pm 14,46)\end{array}$} \\
\hline Tag RR systolisch & $132,17 \quad( \pm 17,75)$ & $141,75 \quad( \pm 20,68)$ \\
\hline Tag RR diastolisch & $77,33 \quad( \pm 13,52)$ & $78,92 \quad( \pm 13,61)$ \\
\hline Nacht RR sytolisch & $128,42 \quad( \pm 20,91)$ & $135,33 \quad( \pm 18,00)$ \\
\hline Nacht RR diastolisch & $71,17 \quad( \pm 12,13)$ & $70,92 \quad( \pm 11,92)$ \\
\hline $\begin{array}{l}\text { Entwicklung Visit I zu } \\
\text { Visit II }\end{array}$ & $\begin{array}{l}\text { Tag RR syst.: 9,58 } \\
\text { Tag RR diast.: 1,5 } \\
\text { Nacht RR syst: 6,9 } \\
\text { Nacht RR diast: - }\end{array}$ & $\begin{array}{l}p=0,06 \\
p=0,56 \\
p=0,28 \\
p=0,93\end{array}$ \\
\hline
\end{tabular}




\begin{tabular}{|c|c|c|}
\hline $\begin{array}{l}\text { Arterieller Blutdruck } \\
\text { (RR) } \\
{[\mathrm{mmHg}]}\end{array}$ & $\begin{array}{l}\text { Visit I } \\
\text { Mittelwert }( \pm \text { SA })\end{array}$ & $\begin{array}{l}\text { Visit II } \\
\text { Mittelwert }( \pm \text { SA })\end{array}$ \\
\hline Max. RR systolisch & $168,17 \quad( \pm 19,06)$ & $180,83 \quad( \pm 22,47)$ \\
\hline Max. RR diastolisch & $97,50 \quad( \pm 12,02)$ & $110,08 \quad( \pm 18,33)$ \\
\hline Min. RR sytolisch & $95,75 \quad( \pm 21,29)$ & $105,50 \quad( \pm 19,71)$ \\
\hline Min. RR diastolisch & $50,00 \quad( \pm 13,02)$ & $52,58 \quad( \pm 13,37)$ \\
\hline $\begin{array}{l}\text { Entwicklung Visit I zu } \\
\text { Visit II }\end{array}$ & \multicolumn{2}{|c|}{$\begin{array}{ll}\text { Max. RR syst.: } 12,67( \pm 26,06) & p=0,12 \\
\text { Max. RR diast.: } 12,58( \pm 13,02) & p=0,007\end{array}$} \\
\hline
\end{tabular}

\subsection{Auswertung von Laborparametern vor und nach renaler Denervation}

\subsubsection{Beurteilung der Nierenfunktion}

Die Nierenfunktion wurde mittels laborchemischer Parameter jeweils vor und nach renaler Denervation beurteilt. Hierbei ergab sich eine Tendenz zur Verbesserung der Nierenfunktion. Die berechnete glomeruläre Filtrationsrate lag bei Studienbeginn im Mittel bei $86,46( \pm 25,40) \mathrm{ml} / \mathrm{min}$, und zeigte sechs Monate nach renaler Denervation eine Tendenz zur Steigerung auf 91,61 $( \pm 30,62) \mathrm{ml} / \mathrm{min}$, ohne Erreichen einer statistischen Signifikanz. Dies entspricht einer mittleren Differenz von $5,15( \pm 14,84) \mathrm{ml} / \mathrm{min}$. Auf der Grundlage dieser Daten wäre zum Erreichen eines Signifikanzniveaus der Einschluss von 68 Patienten erforderlich gewesen (Berechnung mittels Powerananalyse/Statistica12.7 bei einer Teststärke von $80 \%$ ). 


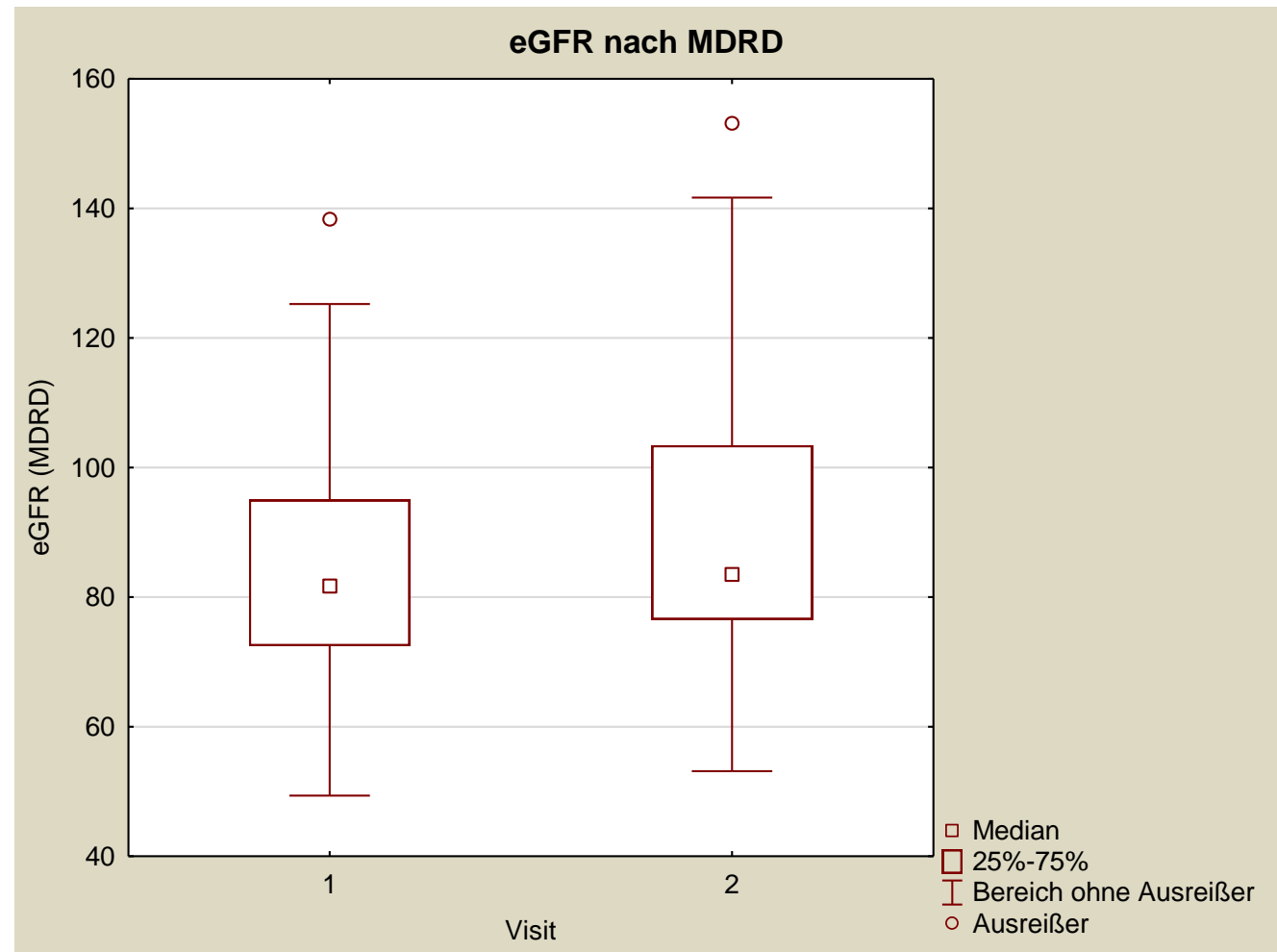

Abbildung 5: Box-Whiskers-Plot der Veränderung der berechneten glomerulären Filtrationsrate vor und sechs Monate nach renaler Denervation

Bei der Bestimmung des Kreatinins und des Cystatin C ergaben sich keine signifikanten Änderungen vor und sechs Monate nach renaler Denervation. Es gingen bei der Berechnung der Differenz des Cystatin $\mathrm{C}$ jedoch nur neun Patienten ein, da bei drei Patienten kein Vergleichswert vorlag.

Tabelle 9: Laborchemische Beurteilung der Nierenfunktion vor und sechs Monate nach renaler Denervation

\begin{tabular}{|l|c|c|}
\hline & \multicolumn{1}{|l|}{$\begin{array}{l}\text { Visit I } \\
\text { Mittelwert }( \pm \text { SA })\end{array}$} & $\begin{array}{l}\text { Visit II } \\
\text { Mittelwert }( \pm \text { SA })\end{array}$ \\
\hline $\begin{array}{l}\text { Berechnete glomeruläre } \\
\text { Filtrationsrate (eGFR) } \\
{[\mathrm{ml} / \mathrm{min}]}\end{array}$ & $86,46 \quad( \pm 25,40)$ & $91,61 \quad( \pm 30,62)$ \\
\hline Kreatinin $[\mathrm{mg} / \mathrm{dl}]$ & $0,89( \pm 0,26)$ & $0,86 \quad( \pm 0,27)$ \\
\hline Cystatin C $[\mathrm{mg} / \mathrm{l}]$ & $1,11 \quad( \pm 0,18)$ & $1,12 \quad( \pm 0,32)$ \\
\hline
\end{tabular}


Tabelle 10 (Fortsetzung): Laborchemische Beurteilung der Nierenfunktion vor und sechs Monate nach renaler Denervation

\begin{tabular}{|l|ll|}
\hline Entwicklung Visit I zu & eGFR: $5,15( \pm 14,84)$ & p=0,25 \\
Visit II & Kreatinin: $-\mathbf{0 , 0 3}( \pm 0,14)$ & $p=0,52$ \\
& Cystatin C: $0,01( \pm 0,22)$ & $p=0,94$ \\
\hline
\end{tabular}

\subsubsection{Laborchemische Marker einer Proteinurie}

Eine laborchemische Analyse des Urins wurde bei allen Patienten vor und nach renaler Denervation durchgeführt. Die Gesamtmenge des Proteins im Urin zeigte sich unverändert, die Differenz betrug nach sechs Monaten 0,23 $( \pm 133,21) \mathrm{mg} / \mathrm{l}$. Die Bestimmung des Albumins ergab einen nicht signifikanten Trend zu einer Reduktion um $-8,30( \pm 71,28) \mathrm{mg} / \mathrm{l}$ nach sechs Monaten. Das Alpha-1-Mikroglobulin zeigte einen ebenfalls nicht signifikanten Trend zu einem leichten Anstieg um 1,99 $( \pm 16,98) \mathrm{mg} / \mathrm{l}$. Immunglobulin $\mathrm{G}$ wurde bei der Erstuntersuchung bei zwei Patienten detektiert und lag gemittelt bei 20,05 $( \pm 12,65) \mathrm{mg} / \mathrm{l}$. Nach sechs Monaten war Immunglobulin $\mathrm{G}$ bei vier Patienten nachweisbar mit Werten von $12,85( \pm 7,41) \mathrm{mg} / \mathrm{l}$.

Bei der Auswertung des Kreatinins im Urin ergab sich keine Änderung. Die Berechnung des Protein-Kreatinin-Quotienten blieb nahezu unverändert mit einer Differenz von $0,08( \pm 0,24) \mathrm{mg} / \mathrm{mg}$ Kreatinin. Ähnlich war bei der Berechnung des Albumin-Kreatinin-Quotienten kein Unterschied zu ermitteln.

Die fraktionierte Natrium-Exkretion erreichte sechs Monate nach renaler Denervation keine signifikante Änderung $(-0,17( \pm 1,07) \%)$.

Das Signifikanzniveau wurde bei keiner der Auswertungen erreicht.

Tabelle 11: Laborchemische Beurteilung einer Proteinurie vor und sechs Monate nach renaler Denervation

\begin{tabular}{|c|c|c|}
\hline & $\begin{array}{l}\text { Visit I } \\
\text { Mittelwert }( \pm \text { SA })\end{array}$ & $\begin{array}{l}\text { Visit II } \\
\text { Mittelwert }( \pm \text { SA) }\end{array}$ \\
\hline Protein gesamt [mg/l] & $133,88 \quad( \pm 190,50)$ & $134,10 \quad( \pm 111,97)$ \\
\hline Albumin $[\mathrm{mg} / \mathrm{l}]$ & $50,08 \quad( \pm 132,94)^{a}$ & $41,78( \pm 72,01)^{a}$ \\
\hline
\end{tabular}




\begin{tabular}{|c|c|c|}
\hline & $\begin{array}{l}\text { Visit I } \\
\text { Mittelwert }( \pm \text { SA) }\end{array}$ & $\begin{array}{l}\text { Visit II } \\
\text { Mittelwert }( \pm \text { SA })\end{array}$ \\
\hline $\begin{array}{l}\text { Alpha-1- Mikroglobulin } \\
\text { [mg/l] }\end{array}$ & $6,16( \pm 7,57)^{b}$ & $8,15( \pm 13,93)^{b}$ \\
\hline $\begin{array}{l}\text { Immunglobulin } \mathrm{G}(\mathrm{Ig} \mathrm{G}) \\
{[\mathrm{mg} / \mathrm{l}]}\end{array}$ & $\underset{\substack{+{ }_{n=2}}}{20,05}( \pm 12,65)^{+}$ & $\begin{array}{c}12,85 \\
{ }_{n=4}\end{array}$ \\
\hline $\begin{array}{l}\text { Entwicklung Visit I zu } \\
\text { Visit II }\end{array}$ & \multicolumn{2}{|c|}{$\begin{array}{lr}\text { Protein gesamt: } 0,23( \pm 133,21) & p=0,10 \\
\text { Albumin: }-8,30( \pm 71,28) & p=0,59 * \\
\text { Alpha-1- Mikroglobulin: } 1,99( \pm 16,98) & p=0,87 * \\
\text { Ig G: } 1,03( \pm 8,52) & p=0,18 *\end{array}$} \\
\hline $\begin{array}{l}\text { Kreatinin im Urin } \\
{[\mathrm{mg} / \mathrm{dl}]}\end{array}$ & $80,99 \quad( \pm 61,95)$ & $79,35 \quad( \pm 56,82)$ \\
\hline $\begin{array}{l}\text { Protein-Kreatinin- } \\
\text { Quotient [mg/mg } \\
\text { Kreatinin] }\end{array}$ & $0,17 \quad( \pm 0,16)$ & $0,24 \quad( \pm 0,30)$ \\
\hline $\begin{array}{l}\text { Albumin-Kreatinin- } \\
\text { Quotient } \\
\text { [mg/mg Kreatinin] }\end{array}$ & $0,05 \quad( \pm 0,10)$ & $0,09 \quad( \pm 0,18)$ \\
\hline $\begin{array}{l}\text { Entwicklung Visit I zu } \\
\text { Visit II }\end{array}$ & $\begin{array}{l}\text { Kreatinin im Urin } \\
\text { Prot.-Krea.-Quoti } \\
\text { Albumin-Krea.-Q }\end{array}$ & $\begin{array}{ll}( \pm 78,82) & p=0,53 * \\
8( \pm 0,24) & p=0,75 * \\
: 0,05( \pm 0,11) & p=0,35 *\end{array}$ \\
\hline $\begin{array}{l}\text { Fraktionierte Natrium- } \\
\text { Exkretion [\%] }\end{array}$ & $1,07 \quad( \pm 0,76)$ & $0,90 \quad( \pm 0,65)$ \\
\hline $\begin{array}{l}\text { Entwicklung Visit I zu } \\
\text { Visit II }\end{array}$ & Frakt. Na.-Exkre & $17( \pm 1,07) \quad p=0,64 *$ \\
\hline
\end{tabular}

* Berechnung mittels Wilcoxon-Rangsummentest

${ }^{a}$ Aufgrund der Sensitivität des Tests konnte Albumin erst ab einer Konzentration von 5 mg/l detektiert werden; Werte $<5 \mathrm{mg} / \mathrm{l}$ gingen in die Berechnung mit $5 \mathrm{mg} / \mathrm{l}$ ein

${ }^{\mathrm{b}}$ Aufgrund der Sensitivität des Tests konnte Alpha-1-Mikroglobulin erst ab einer Konzentration von $2 \mathrm{mg} / \mathrm{l}$ detektiert werden; Werte $<2 \mathrm{mg} / \mathrm{l}$ gingen in die Berechnung mit $2 \mathrm{mg} / \mathrm{l}$ ein 


\subsection{Auswertung der Quantifizierung endothelialer Progenitorzellen mittels Durchflusszytometrie (FACS-Analyse)}

Mithilfe der Durchflusszytometrie erfolgte die Bestimmung der Oberflächenmarker endothelialer Progenitorzellen. Sechs Monate nach renaler Denervation zeigte sich ein Trend für eine Zunahme CD133/Flk-1-doppelt positiver Zellen um 0,68 $( \pm 1,28) \%$, ohne Erreichen einer statistischen Signifikanz $(\mathrm{p}=0,25)$.

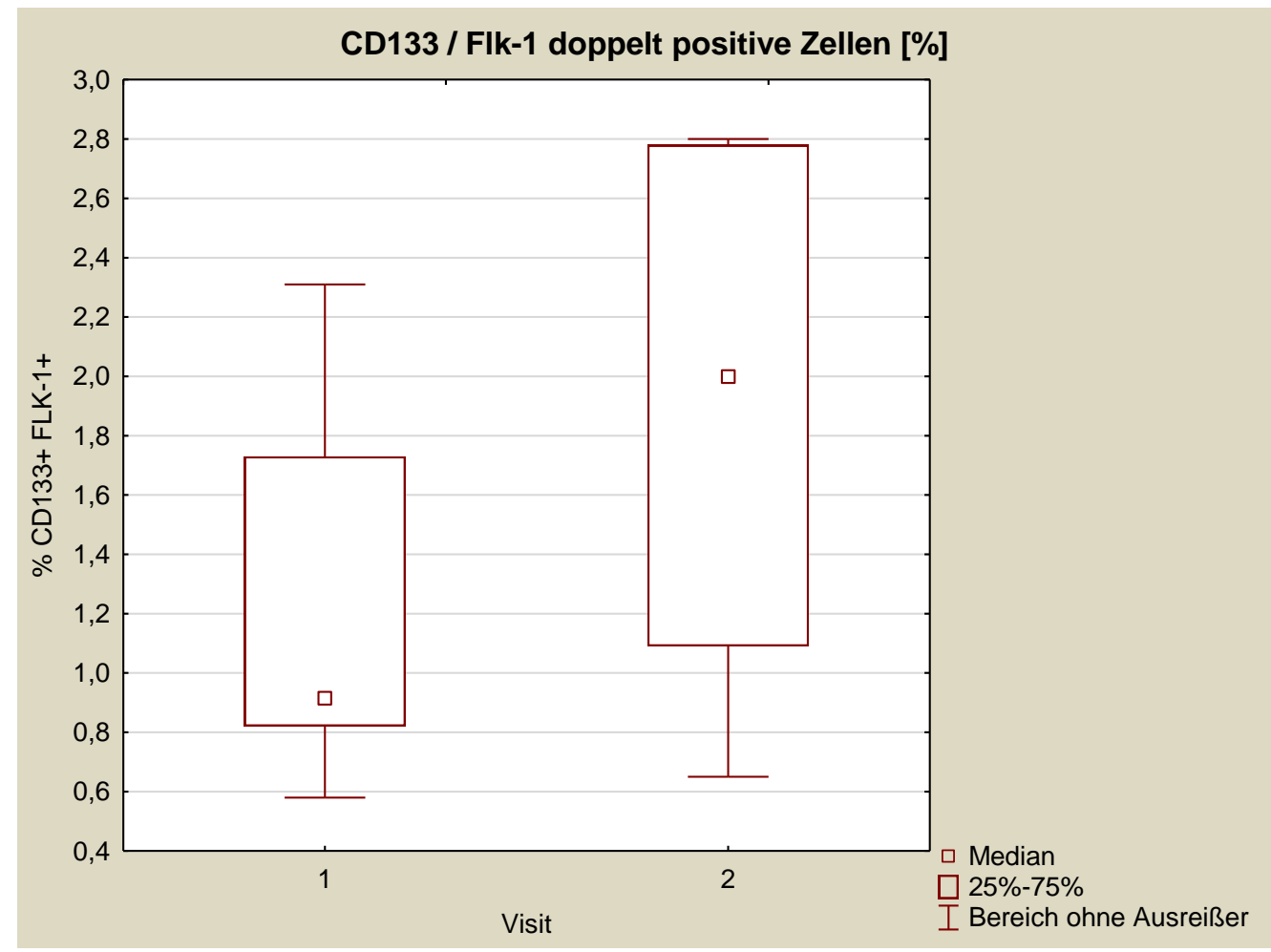

Abbildung 6: Box-Whiskers-Plot der Quantität endothelialer Progenitorzellen (CD133/Flk-1 doppelt positiv) vor und sechs Monate nach renaler Denervation

Sechs Monate nach renaler Denervation zeigte sich ein nicht-signifikanter Trend für eine Zunahme der CD133/cKit-doppelt positiven Zellen um 0,9 $( \pm 1,29) \%$ (bezogen auf die Gesamtzahl der mononukleären Zellen) $(\mathrm{p}=0,07)$. 


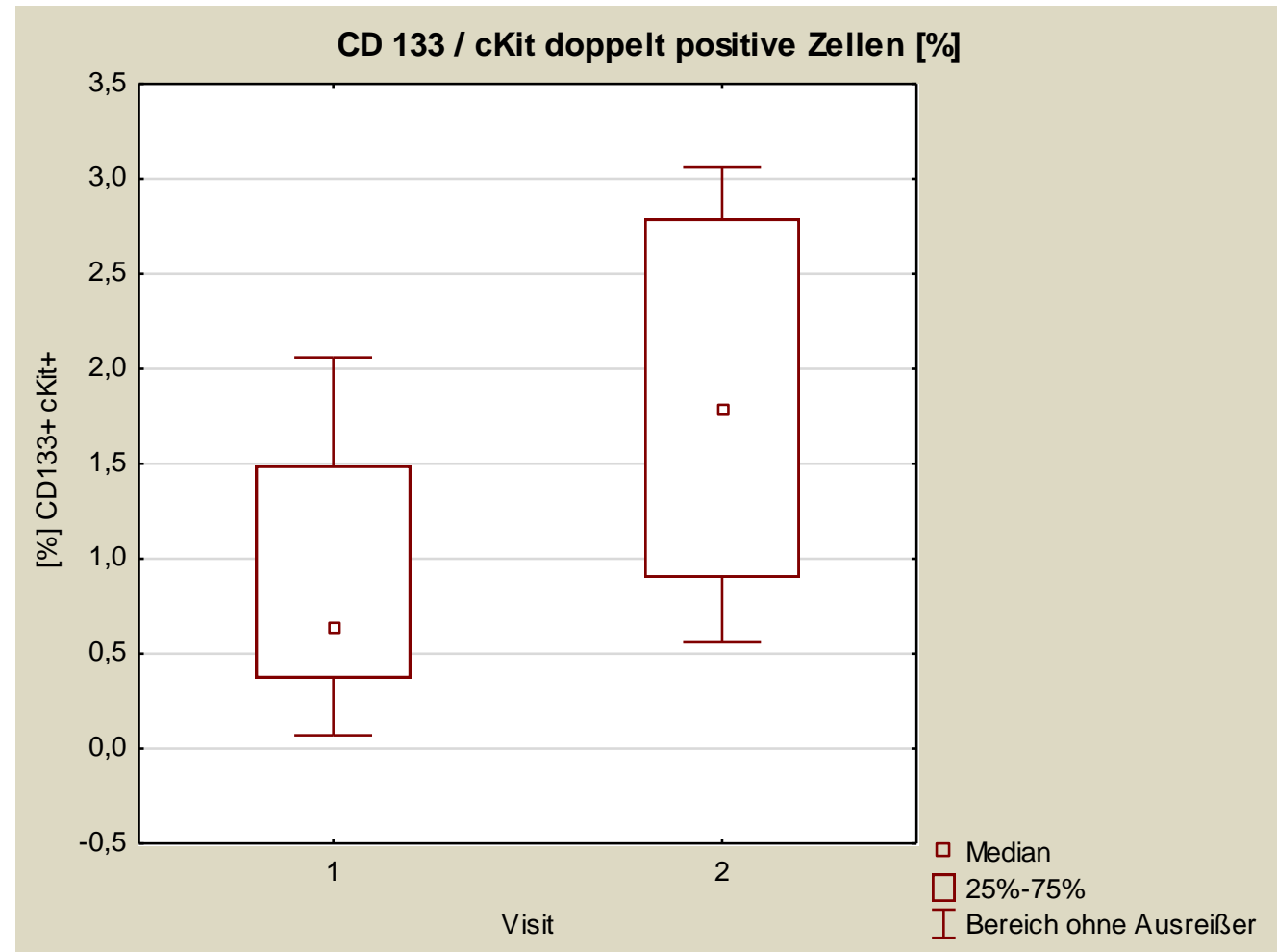

Abbildung 7: Box-Whiskers-Plot der Quantität endothelialer Progenitorzellen (CD133/cKit doppelt positiv) vor und sechs Monate nach renaler Denervation

Die Ergebnisse zeigen einen Trend für eine Zunahme endothelialer Progenitorzellen nach renaler Denervation, ohne dass eine statistische Signifikanz erreicht werden konnte. Die FACS-Analytik konnte aufgrund der Koloniezahlen nur bei sechs von zwölf Patienten durchgeführt werden. Bei dieser geringen Patientenzahl konnte das Signifikanzniveau nicht erreicht werden. Unter Berücksichtigung der vorliegenden Daten ergibt die Berechnung mittels Poweranalyse auf der Basis einer Teststärke von $80 \%$, dass zum Erreichen einer statistischen Signifikanz n=30 bei CD133/Flk-1-doppelt positiven Zellen sowie $n=19$ bei CD133/cKit-doppelt positiven Zellen nötig gewesen wären. 
Tabelle 12: Auswertung der Quantität der in der Durchflusszytometrie detektierten endothelialen Progenitorzellen

\begin{tabular}{|c|c|c|}
\hline & $\begin{array}{l}\text { Visit I } \\
\text { Mittelwert }( \pm \text { SA })\end{array}$ & $\begin{array}{l}\text { Visit II } \\
\text { Mittelwert }( \pm \text { SA })\end{array}$ \\
\hline $\begin{array}{l}\text { CD133/Flk-1-positive } \\
\text { Zellen } \\
{[\%]}\end{array}$ & $1,21 \quad( \pm 0,67)$ & $1,79 \quad( \pm 0,94)$ \\
\hline $\begin{array}{l}\text { CD133/cKit-positive } \\
\text { Zellen } \\
{[\%]}\end{array}$ & $0,79 \quad( \pm 0,70)$ & $1,68 \quad( \pm 0,90)$ \\
\hline $\begin{array}{l}\text { Entwicklung Visit I zu } \\
\text { Visit II }\end{array}$ & $\begin{array}{l}\text { CD133/Flk-1-pos } \\
0,68( \pm 1,28) \\
\text { CD133/cKit-posi } \\
0,90( \pm 1,29)\end{array}$ & $\begin{array}{l}\text { Zellen [\%]: } \\
\text { p=0,25 } \\
\text { Zellen [\%]: } \\
\text { p=0,07 }\end{array}$ \\
\hline
\end{tabular}

3.5 Auswertung der Proliferationsfähigkeit endothelialer Progenitorzellen (EPCs) über Quantifizierung von Colony Forming Units (CFUs) in Zellkultur

Die Proliferationsfähigkeit der endothelialen Progenitorzellen wurde in Zellkultur über die Quantifizierung von Zellkolonien (colony forming units) bestimmt. 


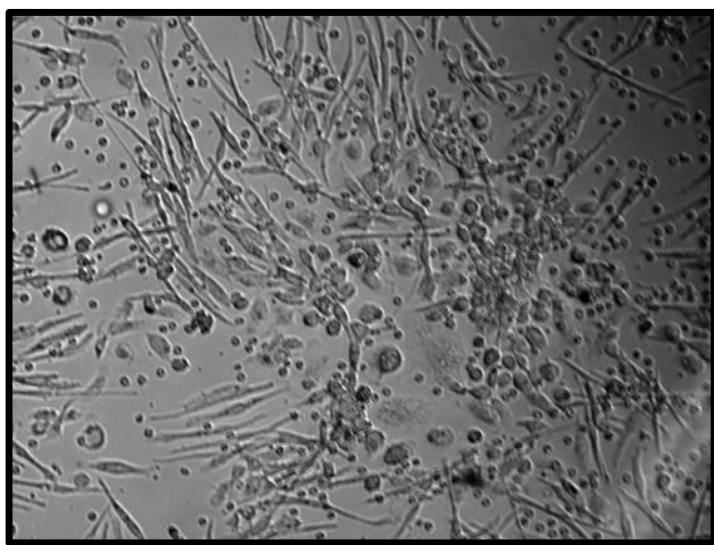

Abbildung 8: Zellkolonien EPCs (lanzettförmige Zellen)

Pat. 004 Visit II (08.04.2014)

Vergrößerung 20x; Belichtungszeit $2000 \mathrm{~ms}$ Eigenes Bild

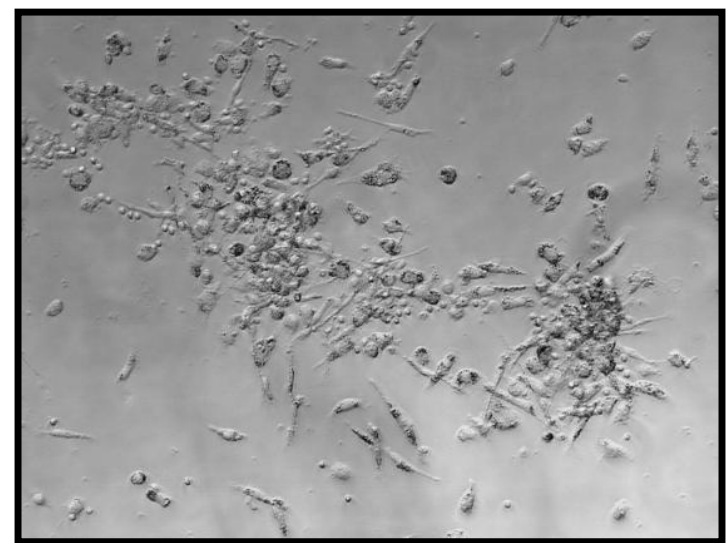

Abbildung 9: Zellkolonien EPCs (lanzettförmige Zellen)

Pat. 005 Visit II (30.07.2014)

Vergrößerung 20x; Belichtungszeit 2,87 ms Eigenes Bild

Es erfolgte die Zuordung zu den Gruppen eins bis fünf entsprechend der Anzahl der Kolonien (siehe Grafik). Fünf Patienten $(41,67 \%)$ wurden bei Visit II, sechs Monate nach erfolgter renaler Denervation, einer höheren Gruppe zugeordnet, entsprechend einer Zunahme der Ausbildung von Kolonien endothelialer Progenitorzellen. Bei drei Patienten $(25,00 \%)$ ergab sich keine Veränderung der Zuordnung der Gruppe. Vier $(33,33 \%)$ Patienten wurden bei Visit II einer niedrigeren Guppe zugeordnet. 


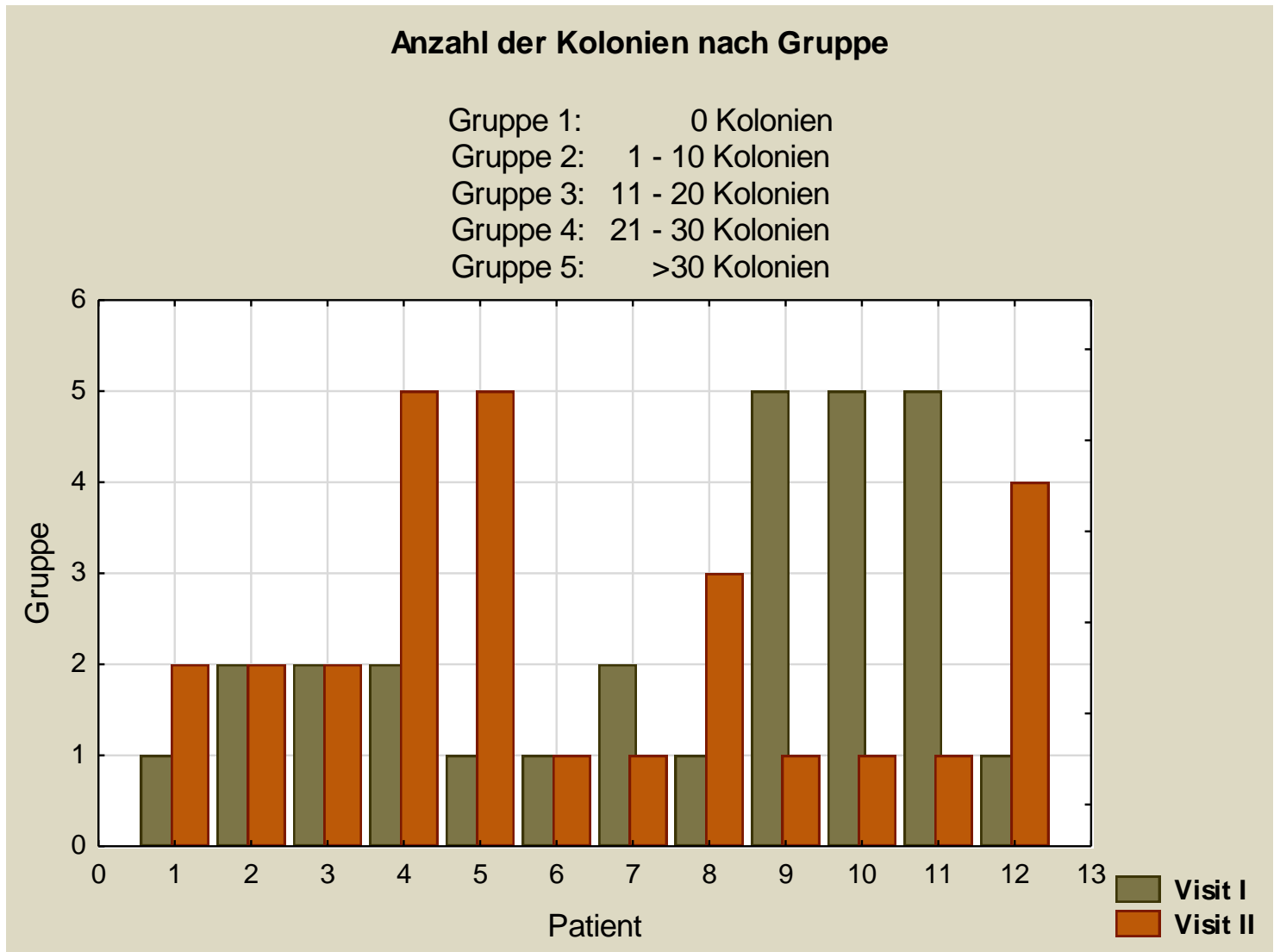

Abbildung 10: Balkendiagramm nach Gruppen entsprechend der Anzahl von Kolonien EPCs in der Zellkultur vor (Visit I) und sechs Monate nach renaler Denervation (Visit II)

\subsection{Auswertung der mittels Laserscanning-Zytometrie (iCys) bestimmten eNOS-Expression endothelialer Progenitorzellen (EPCs)}

Die Bestimmung der Expression der endothelialen Stickstoffmonoxid-Synthase (eNOS) erfolgte mittels Laserscanning-Zytometrie. Hierbei ergaben sich keine Änderungen des Anteils an eNOS exprimierenden Zellen von den gesamt detektierten kernhaltigen Zellen (vgl. Tabelle 12). Die weitere Analytik des Aktivitätsmarkers eNOS konnte aufgrund der Kolonienzahlen nur bei sechs von zwölf Patienten durchgeführt werden. Das Ergebnis ist nicht signifikant. 
Tabelle 13: Auswertung der Expression der endothelialen Stickstoffmonoxid-Synthase endothelialer Progenitorzellen vor und sechs Monate nach renaler Denervation

\begin{tabular}{|c|c|c|}
\hline & $\begin{array}{l}\text { Visit I } \\
\text { Mittelwert ( } \pm \text { SA) }\end{array}$ & $\begin{array}{l}\text { Visit II } \\
\text { Mittelwert ( } \pm \text { SA) }\end{array}$ \\
\hline $\begin{array}{l}\text { eNOS-positive Zellen } \\
{[\%]}\end{array}$ & $36,08 \quad( \pm 37,97)$ & $31,08 \quad( \pm 32,50)$ \\
\hline $\begin{array}{l}\text { Entwicklung Visit I zu } \\
\text { Visit II }\end{array}$ & \multicolumn{2}{|c|}{ eNOS-positive Zellen [\%]: } \\
\hline
\end{tabular}




\section{Diskussion}

\subsection{Renale Denervation nach der SYMPLICITY HTN-3-Studie}

\subsubsection{Wissenschaftliche Diskussionen und Betrachtungen}

Die Publikation der Studie SYMPLICITY HTN-3 im Frühjahr 2014 (Bhatt et al. 2014), in der die primären Effektivitätsendpunkte, die Senkung des systolischen Blutdrucks in der klinischen Einzelmessung sowie der ambulanten 24-h-Blutdruckmessung sechs Monate nach renaler Denervation nicht erreicht worden waren, führte $\mathrm{zu}$ intensiven wissenschaftlichen Diskussionen. Die Ergebnisse der SYMPLICITY HTN-3-Studie standen einer Vielzahl vorangegangener Studien gegenüber, welche eine deutliche und langanhaltende Senkung des arteriellen Blutdrucks dokumentiert hatten. Hierzu zählen unter anderem die SYMPLICITY HTN-1 (Krum et al. 2009) und SYMPLICITY HTN-2 (Simplicity HTN-2 Investigators et al. 2010) Studien. Da die hier präsentierte Studie vor dem Hintergrund des aktuellen wissenschaftlichen Konsens entworfen wurde, sind die SYMPLICITY HTN-Studien als bisher größte und repräsentativste Studien von wichtiger Bedeutung. Zum Zeitpunkt der Initiierung der hier präsentierten Studie im April 2013 galt die Effektivität der renalen Denervation bezüglich der Blutdrucksenkung als überwiegend anerkannt, sodass der Schwerpunkt unserer Studiengruppe auf der Untersuchung weiterer organoprotektiver Effekte im Zusammenhang mit der Durchführung der Intervention gelegt wurde. Das Verfehlen der primären Effektivitätsendpunkte der SYMPLICITY HTN-3-Studie sowie die nachfolgende wissenschaftliche und öffentliche Diskussion der renalen Denervation hatte auch für den Verlauf der hier beschriebenen Studie eine entscheidende Bedeutung, insbesondere bezüglich der weiteren Rekrutierung von Patienten. Es soll im folgenden daher zunächst ein Überblick über die SYMPLICITY HTN-Studien, weitere Studienhintergründe sowie aktuelle wissenschaftliche Betrachtungen, Kritikpunkte und Diskussionen gegeben werden.

\subsubsection{1 Überblick über die SYMPLICITY HTN-Studien}

Die folgende Tabelle stellt einen Überblick über die SYMPLICITY HTN-Studien dar, welche als größte Studien zur renalen Denervation eine zentrale Stellung in der 
Forschung einnehmen. Alle Studien wurden von Medtronic mitfinanziert, dem Unternehmen welches weltweit das Kathersystem, „Symplicity ${ }^{\mathrm{TM}}$ RDN System“, zur renalen Denervation vertreibt.

Tabelle 14: Überblick über die SYMPLICITY HTN-Studien

\begin{tabular}{|c|c|c|c|}
\hline & $\begin{array}{l}\text { SYMPLICITY } \\
\text { HTN-1 (2009) }\end{array}$ & $\begin{array}{l}\text { SYMPLICITY } \\
\text { HTN-2 (2010) }\end{array}$ & $\begin{array}{l}\text { SYMPLICITY HTN-3 } \\
\text { (2014) }\end{array}$ \\
\hline $\mathbf{n}$ & 45 & $\begin{array}{l}106 \\
\text { Renale Denervation: } \\
\mathrm{n}=52 \\
\text { Kontrollgruppe ohne } \\
\text { Intervention: } \mathrm{n}=54\end{array}$ & $\begin{array}{l}535 \\
\text { Renale Denervation: } n=364 \\
\text { Nierenarteriographie: } \\
n=171\end{array}$ \\
\hline $\begin{array}{l}\text { Studien- } \\
\text { design }\end{array}$ & $\begin{array}{l}\text { Prospektiv } \\
\text { Offen }\end{array}$ & $\begin{array}{l}\text { Prospektiv } \\
\text { Offen } \\
\text { Randomisiert }\end{array}$ & $\begin{array}{l}\text { Prospektiv } \\
\text { Einseitig verblindet } \\
\text { Randomisiert } \\
\text { Placebokontrolliert }\end{array}$ \\
\hline $\begin{array}{l}\text { Primäre } \\
\text { End- } \\
\text { punkte }\end{array}$ & $\begin{array}{l}\text { Veränderung } \\
\text { des Blutdrucks } \\
\text { in der } \\
\text { klinischen } \\
\text { Einzelmessung } \\
\text { Sicherheit der } \\
\text { Intervention }\end{array}$ & $\begin{array}{l}\text { Veränderung des } \\
\text { Blutdrucks in der } \\
\text { klinischen } \\
\text { Einzelmessung } \\
\text { Sicherheit der } \\
\text { Intervention }\end{array}$ & $\begin{array}{l}\text { Veränderung des } \\
\text { Blutdrucks in der } \\
\text { klinischen Einzelmessung } \\
\text { und } \\
\text { ambulanten 24-h- } \\
\text { Langzeitmessung } \\
\text { Sicherheit der Intervention }\end{array}$ \\
\hline
\end{tabular}




\begin{tabular}{|c|c|c|c|}
\hline & $\begin{array}{l}\text { SYMPLICITY } \\
\text { HTN-1 (2009) }\end{array}$ & $\begin{array}{l}\text { SYMPLICITY } \\
\text { HTN-2 (2010) }\end{array}$ & SYMPLICITY HTN-3 (2014) \\
\hline $\begin{array}{l}\text { Ergeb- } \\
\text { nisse } \\
\text { nach } \\
\text { sechs } \\
\text { Mona- } \\
\text { ten: }\end{array}$ & $\begin{array}{l}\underline{\text { Reduktion des }} \\
\text { Blutdrucks: } \\
\text { Einzelmessung: } \\
\frac{N a c h ~ R D:}{22( \pm 10)} \\
\text { mmHg } \\
\text { systolisch; } \\
-11( \pm 5) \text { mmHg } \\
\text { diastolisch } \\
\text { Signifikant } \\
\text { (p<0,001) } \\
\text { Primärer } \\
\text { Sicherheitsend- } \\
\text { punkt erreicht }\end{array}$ & $\begin{array}{l}\underline{\text { Reduktion des }} \\
\text { Blutdrucks: } \\
\text { Einzelmessung: } \\
\frac{\text { Nach RD: }}{\text {-32 }( \pm 23) \mathrm{mmHg}} \\
\text { systolisch; } \\
-12( \pm 11) \mathrm{mmHg} \\
\text { diastolisch } \\
\text { Kontrollgruppe: } \\
-1 \text { ( } \pm 21) \mathrm{mmHg} \\
\text { systolisch; } \\
-0 \text { ( } \pm 10) \mathrm{mmHg} \\
\text { diastolisch } \\
\text { Differenz } \\
\mathbf{- 3 3 / 1 1 ~ m m H g ;} \\
\text { Signifikant } \\
\text { (p<0,0001) } \\
\text { Primärer } \\
\text { Sicherheitsend- } \\
\text { punkt erreicht }\end{array}$ & $\begin{array}{l}\text { Reduktion des Blutdrucks: } \\
\text { Einzelmessung: } \\
\text { Nach RD: } \\
-14,13 \text { ( } \pm 23,93) \text { mmHg } \\
\text { systolisch; } \\
-6,6 \text { ( } \pm 11,9) \text { mmHg diastolisch } \\
\text { Nach Nierenarteriographie: } \\
-11,74 \text { ( } \pm 25,95) \text { mmHg } \\
\text { systolisch; } \\
-4,6 \text { ( } \pm 13,6) \text { mmHg diastolisch } \\
\text { Differenz }-2,39 \text { mmHg } \\
\text { systolisch; } \\
\text { Nicht signifikant (p=0,26) } \\
\text { Primärer Sicherheitsendpunkt } \\
\text { erreicht } \\
\text { 24-h-Messung: } \\
\text { Nach RD: } \\
-6,75 \text { ( } \pm 15,11) \text { mmHg systolisch; } \\
-4,1 \text { ( } \pm 9,2) \text { mmHg diastolisch } \\
\text { Nach Nierenarteriographie: } \\
-4,79 \text { ( } \pm 17,25) \text { mmHg systolisch; } \\
-3,1 \text { ( } \pm 10,1) \text { mmHg diastolisch } \\
\text { Differenz -1,96 mmHg } \\
\text { systolisch; nicht signifikant } \\
\text { (p) }\end{array}$ \\
\hline
\end{tabular}




\subsubsection{Weiterer Studienhintergrund zur renalen Denervation}

Eine Vielzahl kleinerer Studien erbrachte ebenfalls vielversprechende Ergebnisse. So zeigte beispielsweise die Arbeitsgruppe um Ott et al. eine Senkung des Blutdrucks um $-13 / 7 \mathrm{mmHg}(\mathrm{p}<0,001)$ in der Einzelmessung, sowie um $-14 / 7 \mathrm{mmHg}(\mathrm{p}<0,001)$ in der Langzeitblutdruckmessung über $24 \mathrm{~h}$. In $51 \%$ der 54 eingeschlossenen Patienten konnte eine Reduktion des arteriellen Blutdrucks auf Werte kleiner 140/90 mmHg erzielt werden (Ott et al. 2013). Weiterhin konnte in Follow-up-Studien eine Reduktion der Blutdruckwerte um im Mittel $-28 / 10 \mathrm{mmHg}(\mathrm{p}<0,001)$ nach 12 Monaten (Esler et al. 2012) und -32/14 mmHg (systolischer Wert $\mathrm{p}<0,0001$, diastolischer Wert $\mathrm{p}<0,002$ ) nach 24 Monaten verzeichnet werden (Investigators 2011). Im Jahr 2013 publizierte ein internationales Expertenkomitee in Zusammenschau bisheriger Studienergebnisse eine Stellungnahme, in der die renale Denervation, angewandt an Patienten mit therapieresistenter Hypertonie, in der Nachverfolgung über drei Jahre ein Sicherheitsprofil aufweist, welches zum Grad und der Verlässlichkeit einer Senkung des Blutdrucks als akzeptabel eingestuft wird. Weiterhin wird erläutert, dass möglicherweise ein Effekt über die Kontrolle des arteriellen Blutdrucks hinaus besteht (Schlaich et al. 2013).

In Europa und anderen Ländern wurde die renale Denervation aufgrund der vielversprechenden Datenlage an spezialisierten Zentren, so auch an der Universitätsmedizin Göttingen, zu einem von gesetzlichen Krankenkassen übernommenen Routineeingriff. In den USA hingegen war eine Zulassung durch die FDA (Food and Drug Administration) ohne vorherige Durchführung einer Shamkontrollierten, doppel-blinden randomisierten Studie nicht möglich, sodass die Durchführung einer renalen Denervation wissenschaftlichen Studien vorbehalten blieb. Aus diesem Grund wurde die SYMPLICITY HTN-3-Studie initiiert, welche erstmalig ein doppeltverblindetes Konzept anwandte und mithilfe einer Kontrollgruppe die Intervention auf einen möglichen Placeboeffekt untersuchte. Da weiterhin eine große Anzahl von Patienten $(n=535)$ eingeschlossen wurde, erfüllte die Studie hohe wissenschaftliche Ansprüche. Das Verfehlen der primären Effektivitätsendpunkte dieser Studie erregte entsprechend großes wissenschaftliches Interesse und Kontroversen über die Einordnung der Ergebnisse sowie den zukünftigen Umgang mit der Therapieoption einer renalen Denervation. 


\subsubsection{Kritik am Design früherer Studien}

Die Autoren der SYMPLICITY HTN-3-Studie selbst beschreiben Erklärungsmodelle, wie es zu den bisherigen Publikationen entgegenstehenden Ergebnissen gekommen sein mag. Zum einen wurde in früheren Studien meist die Blutdruckentwicklung im Vergleich zu den Werten bei Studieneinschluss dokumentiert, ohne eine Kontrollgruppe zu bilden und auszuwerten. Hierbei mag das Phänomen der Regression zur Mitte einen fälschlicherweise zu hoch eingeschätzen Therapieeffekt begünstigt haben. Ebensowenig konnte der Hawthorne-Effekt ausgeschlossen werden, sodass möglicherweise bereits die Studienteilnahme $\mathrm{zu}$ einer verbesserten Compliance der Patienten bezüglich antihypertensiver Therapien führte. Ein weiterer entscheidender Punkt, welcher im Studiendesign ohne Verblindung und Kontrollgruppe nicht zu eruieren war, besteht in der Wirkung eines Placeboeffektes. Dieser wird zudem insbesondere durch die Invasivität der Intervention begünstigt. Somit besteht eine hohe Wahrscheinlichkeit, dass die Placebowirkung fälschlicherweise dem Therapieerfolg zugeschrieben wurde (Bhatt et al. 2014). Bereits vor Publikation der SYMPLICITY HTN-3-Studie wurde entsprechende Kritik am Design der Vorläuferstudien vorgebracht. Diese bezog sich vornehmlich auf das nicht verblindete Vorgehen sowie die alleinige Erhebung klinischer Einzelmessungen des arteriellen Blutdrucks. Untersucher-, Erwartungs- und Auswertungs-Bias sind demnach mögliche Faktoren, welche die Ergebnisse beeinflusst haben könnten. Auch in der SYMPLICITY HTN-2-Studie konnten die oben genannten Kritikpunkte nicht ausgeschlossen werden, da kein standardisiertes antihypertensives Therapiekonzept angewandt wurde, die Compliance bezüglich der medikamentösen Therapie nicht überprüft wurde und keine verblindeten Messungen erhoben wurden. Zudem wussten Patienten der Kontrollgruppe, dass ihnen die Behandlung der renalen Denervation nur dann zuteil werden würde, wenn ihre Blutdruckwerte weiterhin hoch blieben, weshalb diese Patienten möglicherweise eine verminderte Compliance bezüglich ihrer Medikation und Lebensstilveränderungen aufwiesen. Während in der Gruppe nach erfolgter renaler Denervation ein gegenteiliger Effekt denkbar ist, wobei durch hohe Erwartungen an die neue und vielversprechende Intervention sowie durch den Hawthorne-Effekt eine verbesserte Compliance zur verzeichneten Reduktion des arteriellen Blutdrucks beitrugen (Azizi et al. 2012). Kritiker der renalen Denervation sahen sich nach der Publikation der SYMPLICITY HTN-3-Studie darin bestätigt, dass der echte therapeutische Effekt der renalen Denervation aufgrund all dieser Faktoren 
und Mängel im Studiendesign deutlich überschätzt worden war (Fadl Elmula et al. 2015). Dies scheint sich auch in der Differenz der erzielten Blutdrucksenkung im Vergleich der klinischen Einzelmessung mit der ambulanten 24-h-Messung wiederzuspiegeln. Die ambulante 24-h-Langzeitmessung des Blutdrucks reduziert die Untersucher-Bias, Messfehler, den Weißkitteleffekt, und weißt eine höhere Reproduzierbarkeit auf (Fadl Elmula et al. 2015). Eine später durchgeführte Metaanalyse, welche Blutdruckwerte von Patienten nach renaler Denervation aus zehn europäischen Zentren auswertete, beschrieb eine deutlich stärker ausgeprägte Senkung des arteriellen Blutdrucks in der klinischen Einzelmessung $(-17,6 / 7,1 \mathrm{mmHg} ; \mathrm{p} \leq 0,03)$ im Vergleich zur 24-h-Langzeitmessung $(-5,9 / 3,5 \mathrm{mmHg} ; \mathrm{p} \leq 0,03)$. Weiterhin wurde eine deutliche interindividuelle Varianz des Ansprechens auf die Intervention beschrieben, und zum Teil auch eine Steigerung des Blutdrucks verzeichnet (Persu et al. 2014).

\subsubsection{Kritik an der SYMPLICITY HTN-3-Studie}

Die Publikation der SYMPLICITY HTN-3-Studie eröffnete viele wissenschaftliche Diskussions- und Ansatzpunkte, welche eine Verstärkung von Dringlichkeit und Interesse erfuhren. Eine Entwicklung, welche zweifelsohne im Interesse von Patienten ist.

Obwohl das Studiendesign der SYMPLICITY HTN-3-Studie im Vergleich mit vorangegangenen Studien die bisher höchsten wissenschaftlichen Kriterien erfüllt, ergeben sich in spezifischen Analysen auch hier Kritikpunkte, welche in der Beurteilung der Ergebnisse zu berücksichtigen sind.

4.1.1.4.1 Konsistenz im medikamentösen Therapieregime, Monitoring und Besonderheiten von Subgruppen

Änderungen der pharmakologischen antihypertensiven Therapie der in die Studie eingeschlossenen Patienten waren laut dem Studienprotokoll in zwei Wochen vor dem endgültigem Studieneinschluss und Randomisierung nicht erlaubt. Patienten wurden angewiesen ein Tagebuch über Blutdruckwerte und Medikamenteneinnahme zu führen. Da jedoch aus vielen Studien bekannt ist, dass der maximale therapeutische Effekt vieler Antihypertensiva erst nach acht Wochen erreicht wird, nachdem Änderungen der 
Dosierung vorgenommen oder neue Medikamente kombiniert wurden, ist es möglich, dass viele Patienten bei Studieneinschluss noch keine adäquate Stabilisierung ihres Therapieregimes erfahren hatten. Diese Hypothese wird insbesondere auch durch die deutliche Reduktion der Blutdruckwerte in der scheinbehandelten Kontrollgruppe bestärkt (Lüscher und Mahfoud 2014). Weiterhin wurden bei $39 \%$ der Patienten im Zeitraum zwischen Studieneinschluss und Erhebung der primären Endpunkte nach sechs Monaten Änderungen der Dosierung oder Medikamentenklasse vorgenommen (Kandzari et al. 2015). Ein objektives Messverfahren zur Ermittlung der Compliance bezüglich der pharmakologischen Therapie, z. B. über Bestimmung der Urinmetabolite, war im Studiendesign nicht vorgesehen. Es fanden jedoch acht Arzt-Patienten-Kontakte im Verlauf der Studie statt, sodass möglicherweise auch hier der Hawthorne-Effekt zum Tragen kam, und die Compliance der Patienten bezüglich der Medikamenteneinnahme hierdurch verstärkt wurde (Lobo et al. 2015).

Subgruppenanalysen ergaben außerdem eine Besonderheit in der Medikation mit direkten Vasodilatatoren. Diese erwiesen sich als negativer prädiktiver Faktor in Bezug auf eine Senkung des arteriellen Blutdrucks nach sechs Monaten (Kandzari et al. 2015). 26,2 \% der in die Studie eingeschlossenen Patienten waren Afroamerikaner, und es zeigte sich, dass diese präferenziell mit direkten Vasodilatatoren therapiert wurden. In der Kontrollgruppe erhielten $56 \%$ der Afroamerikaner, und 40,5\% der weißen Amerikaner Vasodilatatoren, während in der renal denervierten Gruppe 46,7\% der Afroamerikaner und 33,7\% der weißen Amerikaner Vasodilatatoren einnahmen. Genauere Analysen hierzu ergaben, dass in der Kontrollgruppe Afroamerikaner unter Medikation mit direkten Vasodilatatoren eine deutlich größere Reduktion des arteriellen Blutdrucks erfuhren $(-21,9 \pm 29,1 \mathrm{mmHg})$ als Afroamerikaner ohne Vasodilatatoren oder weiße Amerikaner, unabhängig davon, ob sie Vasodilatatoren einnahmen oder nicht. In der Gruppe renal denervierter Patienten ergab sich bei weißen Amerikanern ohne Therapie mit Vasodilatatoren eine signifikant größere Senkung des Blutdrucks in der klinischen Einzelmessung nach renaler Denervation $(-17,6 \mathrm{mmHg})$ im Vergleich zur Kontrollgruppe $(-10,4 \mathrm{mmHg} ; \mathrm{p}=0,03)$. In der 24-h-Langzeitmessung ergab sich ein gleichsinniger Trend, erreichte jedoch keine Signifikanz (Kandzari et al. 2015). Schlussfolgernd aus ebensolchen Analysen muss im Design nachfolgender Studien die Möglichkeit unterschiedlichen therapeutischen Ansprechens auf pharmakologische 
Therapien und die renale Denervation entsprechend der Zugehörigkeit verschiedener Ethnien berücksichtigt werden.

Weitere statistische Post-hoc-Analysen ergaben eine Medikation mit Aldosteronantagonisten als positivem prädiktivem Faktor zur Reduktion des Blutdrucks nach sechs Monaten, sowohl in der klinischen Einzelmessung, als auch in der ambulanten 24-h-Aufzeichnung (Kandzari et al. 2015).

\subsection{Durchführung der renalen Denervation}

Ein weiterer Kritikpunkt an der SYMPLICITY HTN-3-Studie betrifft die Ausführung der renalen Denervation. Bemerkenswert hierbei ist, dass die in die Studie eingeschlossenen 535 Patienten an 88 Zentren rekrutiert worden waren. Die insgesamt 364 renalen Denervationen wurden von 111 Interventionalisten durchgeführt. Von diesen führten $34 \%$ nicht mehr als eine Intervention durch, und lediglich 26 Interventionalisten kam die Ausführung von mehr als fünf renalen Denervationen zu (Lobo et al. 2015). Da in den USA die renale Denervation noch nicht als Routineeingriff etabliert war, ist anzunehmen, dass ohne vorherige Erfahrungen die Lernkurve der ausführenden Interventionalisten einen Einfluss auf die erzielten Ergebnisse hatte. Dies ist insbesondere von Bedeutung, da bisher kein Test zur Verfügung steht, welcher den Nachweis adäquaten Kontakts zur Arterienwand sowie eine effektive Zerstörung renaler Nerven erlaubt (Lüscher und Mahfoud 2014).

In statistischen Post-hoc-Kohortenanalysen der SYMPLICITY HTN-3-Studie zeigte sich zudem, dass das Setzen von Ablationspunkten in allen vier Quadranten beider Nierenarterien mit einer größeren Reduktion des systolischen Blutdrucks in Verbindung steht, sowohl in der der klinischen Messung $(-24,3 \mathrm{mmHg})$ als auch in der ambulanten Messung (-10,3 mmHg). Jedoch wurde eine solche Durchführung nur bei 19 von 364 renal denervierten Patienten protokolliert. Weiterhin zeigte sich, dass auch die Anzahl der Ablationpunkte mit dem Ausmaß der Senkung des Blutdrucks korreliert. In 40 Patienten mit mehr als 13 Ablationsversuchen zeigte sich eine Reduktion des systolischen Blutdrucks in der ambulanten Messung um -10,3 mmHg. Dies entspricht der im „Global Symplicity Registry“ verzeichneten Effektivität, bei entsprechender Anzahl von Ablationspunkten. Durchschnittlich wurden während der SYMPLICITY 
HTN-3-Studie jedoch nur 11,2 $\pm 2,8$ Ablationsversuche unternommen, und 9,2 $\pm 2,0$ Ablationspunkte protokolliert (Lobo et al. 2015).

\subsubsection{Auswirkungen der Publikation der SYMPLICITY HTN-3-Studie auf die vorliegende Studie}

Die hier präsentierte Studie wurde im April 2013 initiiert und von der örtlichen Ethikkommission anerkannt. Bis zur Publikation der SYMPLICITY HTN-3-Studie im Frühjahr 2014 waren acht Patienten bereits in die Studie eingeschlossen worden. Da diese wie bereits beschrieben, $\mathrm{zu}$ großen wissenschaftlichen und auch öffentlichen Diskussionen führte, galt es selbstverständlich auch für unsere Studiengruppe den für Patienten bestmöglichen Umgang mit den Studienergebnissen zu eruieren. In einer Stellungnahme der Deutschen Gesellschaft für Kardiologie-Herz- und Kreislaufforschung e.V. zur SYMPLICITY HTN-3-Studie empfahl diese, die Durchführung der renalen Denervation auf ausgewiesene Zentren zu beschränken, sowie möglichst den Einschluss der Patienten in ein Register oder Studien anzustreben (Böhm 2014). Da diese Empfehlungen der im Rahmen der an der Universitätsmedizin Göttingen durchgeführten Studie entsprachen, die primären Sicherheitsendpunkte der SYMPLICITY HTN-3-Studie eindeutig erreicht worden waren, vorangegangene Studien hoher wissenschaftlicher Qualität für das Verfahren der renalen Denervation sprachen und eine standardisierte sorgfältige klinische Untersuchung der Patienten auf deren Eignung zur renalen Denervation im Studiendesign verankert war, wurde die Studie fortgeführt. Alle im Folgenden eingeschlossenen Patienten wurden jedoch sorgfältig über das Verfahren sowie die Ergebnisse der SYMPLICITY HTN-3-Studie aufgeklärt. Da bis zum Erzielen weiterer differenzierter wissenschaftlicher Erkenntnisse bezüglich der Effektivität der renalen Denervation jedoch eine gewisse Zurückhaltung in der Anwendung des Verfahrens sowohl von den Patienten als auch von den behandelnden Ärzten angezeigt war, konnten nur deutlich weniger Patienten in die Studie eingeschlossen werden als ursprünglich angestrebt. Schwierigkeiten ergaben sich weiterhin dadurch, dass die Finanzierung der Prozedur durch die Kostenträger durch die Ergebnisse der SYMPLICITY HTN-3-Studie beeinflusst wurde. Die fehlende Kostenübernahme schränkte die Rekrutierung zusätzlich ein. Die endgültige Zahl der Studienteilnehmer belief sich schließlich auf zwölf Patienten, im Vergleich zu der ursprünglich kalkulierten Anzahl von 30 Patienten. Hierdurch resultierte eine geringe 
Power der statistischen Analysen, so dass die im Vorfeld definierten Endpunkte zum Erfassen potentieller organoprotektiver Effekte verfehlt wurden. Dennoch ergaben sich aus der Verknüpfung der experimentellen Fragestellung mit der klinischen Studie einige interessante Entwicklungen, insbesondere bezüglich der Anzahl endothelialer Progenitorzellen (EPCs) sowie der Nierenfunktion, die Grundlage für weitere wissenschaftliche Arbeiten darstellen könnte. Von besonderem Interesse für die Evaluation von potentiell vasoprotektiven Effekten durch die renale Denervation ist dabei die Analyse von endothelialen Progenitorzellen. Bei Bestimmung der Oberflächenmarker CD133/Flk-1 ergab sich eine tendenzielle Zunahme der Anzahl EPCs um $0,68( \pm 1,28) \%$ mit $\mathrm{p}=0,25$ nach sechs Monaten. Um hier das Signifikanzniveau zu erreichen, wäre, laut Berechnung mittels einer Poweranalyse, die Auswertung von Daten von 30 Patienten nötig gewesen. Die Kreuzkontrolle mit Bestimmung der Oberflächenmarkerkombination CD133/cKit ergab eine tendenzielle Steigerung der Zahl EPCs um 0,90 $( \pm 1,29) \%$ mit $\mathrm{p}=0,07$. Auf der Basis einer Power Analyse mit einem Signifikanzniveau von 0,05 und einer statischen Power von $80 \%$ wäre das Signifikanzniveau bei Einschluss von 19 Patienten erreicht worden. Auch bei der Entwicklung der eGFR ließ sich eine tendenzielle Steigerung um $5,15( \pm 14,84) \mathrm{ml} / \mathrm{min}$ dokumentieren $(\mathrm{p}=0,25)$. Zum Erreichen einer statischen Signifikanz hätte auf dem Boden dieser Daten bei einem Signifikanzniveau von 0,05 sowie einer statischen Power von $80 \%$ ein Kollektiv von 68 Patienten rekrutiert werden müssen. Trotz fehlendem Effektivitätsnachweis der renalen Denervation auf die untersuchten Variablen bei sehr kleiner Fallzahl, liefert die vorliegende Studie innovative Ansatzpunkte, um reno- und vaskuloprotektiver Effekte der renalen Denervation zu untersuchen.

\subsection{Interpretation und Einordnung der Ergebnisse}

\subsubsection{Entwicklung des arteriellen Blutdrucks}

Die Entwicklung des arteriellen Blutdrucks muss in Zusammenschau mit der Einnahme antihypertensiver Medikamente betrachtet werden. Hier ist auffällig, dass bei $50 \%$ der Patienten eine Reduktion der Anzahl der Medikamente nach renaler Denervation erfolgt war. Dies war ausdrücklich nicht die Intention der Studie beziehungsweise der 
Intervention, jedoch war bei klinischer Notwendigkeit eine Anpassung der Medikation zulässig. Der Mittelwert der Anzahl antihypertensiver Medikamente betrug bei Studienbeginn 5,18 $( \pm 0,75)$, und lag sechs Monate nach renaler Denervation bei 4,45 $( \pm 0,82)$. Die Differenz von $-0,67( \pm 0,98)$ erreichte mit $p=0,038$ statistische Signifikanz. Möglicherweise wurde hierdurch einem potentiellen Effekt der renalen Denervation entgegengewirkt, so dass tendenziell angestiegene Blutdruckwerte sechs Monate nach renaler Denervation dokumentiert wurden. Hier ergab sich statistisch eine signifikante gegensinnige Spearman-Korrelation zwischen dem Anstieg des diastolischen Blutdrucks und der Reduktion der Antihypertensiva $(R=-0,62 ; p=0,03)$. Dies vermag die Hypothese einer Beeinflussung der Studienergebnisse durch verfrühte Umstellung der blutdrucksenkenden Medikation zu stützen. Ebenso war in der ambulanten 24-hLangzeitblutdruckmessung keine Änderung der systolischen und diastolischen Blutdruckwerte festgestellt worden. Auffällig jedoch ist die ausgebliebene Absenkung des arteriellen Blutdrucks in jedem Fall dahingehend, dass offensichtlich abgesehen von der Effektivität des Verfahrens an sich, auch Effekte wie der Placebo- und Hawthorneeffekt nicht in ebensolchem Maße zum Tragen kamen wie in anderen Studien beschrieben. Dies ist gegebenenfalls tatsächlich als Hinweis einer Verschleierung der blutdrucksenkenden Effekte durch eine $\mathrm{zu}$ frühe Reduktion antihypertensiver Medikamente zu werten. Alle Patienten waren zwar darüber aufgeklärt worden, dass Veränderungen der Medikation nicht Ziel der Intervention seien, jedoch besteht bei vielen Patienten ein dringlicher Wunsch, weniger Medikamente einzunehmen. Zudem ist es möglich, dass bei häuslichen Selbstmessungen der Patienten fälschlicherweise niedrigere Werte dokumentiert wurden, sodass sich betreuende Hausärzte veranlasst sahen eine Reduktion der Antihypertensiva durchzuführen. Eine Rücksprache mit unserer Studienambulanz erfolgte hierbei nicht. Um den Grad der Adhärenz bei den Patieneten abzuschätzen, sollten Adhärenzmessungen bei der Durchführung von Folgestudien implementiert werden.

\subsubsection{Renoprotektive Effekte}

Die Nieren sind ein im besonderem Maße an der sympathischen Überaktivität sowohl beteiligtes wie auch betroffenes Organ. Da die arterielle Hypertonie mit einer erhöhten Natriumretention einhergeht, kommt es zur Überaktivität des efferenten sympathischen 
Nervensystems (Kopp 2015). Zusätzlich führt eine Schädigung der Nieren, wie sie bei Hypertonikern häufig vorliegt, zu einer Umkehr der inhibitorischen renorenalen Reflexe zu exzitatorischen Signalen. Hieraus resultiert eine weitere Verstärkung der sympathischen Überaktivität und eine zusätzlich vermehrte Natriumretention und Steigerung des arteriellen Blutdrucks (Kopp 2015). Da eine renale Denervation an dem sympathischen Nervengeflecht um die Nierenarterien interveniert und somit den Versuch repräsentiert, den sich entwickelnden Circulos vitiosus zu durchbrechen, liegt es nahe, dass rückwirkend eine Verbesserung im Natrium- und Wasserhaushalt, hierdurch eine verbesserte Regulation des Blutdrucks und somit auch ein Fortschreiten einer Nephrosklerose vermindert werden kann bzw. es sogar zu einer Verbesserung der Nierenfunktion kommen könnte. Mit der vorliegenden Studie wurden klinische, laborchemische und experimentelle Parameter eruiert, welche zur Überprüfung einer solchen Hypothese dienlich sein sollen. Das Fortschreiten der histologisch erkennbaren Nephrosklerose resultiert in einer Reduktion der berechneten glomerulären Filtrationsrate (eGFR). Da in der prospektiv klinischen Studie die histologische Untersuchung aus ethischen Gründen nicht möglich war, wurde zur Beurteilung der Nierenfunktion, wie im klinischen Alltag üblich, die eGFR herangezogen. Sechs Monate nach renaler Denervation war ein tendenzieller, jedoch nicht signifikanter Anstieg zu verzeichnen gewesen. Weiterhin erfolgte, wie ebenfalls klinisch üblich, die Bestimmung des Kreatinins. Auch hier wurde eine leichte, jedoch in dieser Studie ebenfalls nicht signifikante Reduktion ermittelt. Als zusätzlicher Kontrollparameter wurde außerdem das sensitivere und von anderen Faktoren wie Muskelmasse oder Ernährung unabhängigere und möglicherweise für ältere Patienten besser geeignete Cystatin C bestimmt (Fan et al. 2015). Der Referenzbereich wird vom Zentrallabor der Universitätsmedizin mit $0,4-0,99 \mathrm{mg} / \mathrm{l}$ angegeben (http://www.clinchem.med.unigoettingen.de/media/projekt/Hinweisheft__ 20151015.pdf. (02.03.2017)). Bei Studieneinschluss lag der mittlere Wert des Cystatin C mit 1,11 $( \pm 0,18) \mathrm{mg} / \mathrm{l}$ somit über diesem Referenzbereich. Sechs Monate nach renaler Denervation war dieser um $0,01( \pm 0,22) \mathrm{mg} / \mathrm{l}$ angestiegen auf $1,12( \pm 0,32) \mathrm{mg} / \mathrm{l}(\mathrm{p}=0,94)$. Da jedoch nur bei neun Patienten ein Vergleichswert vorlag und die Differenz sehr klein ist, lässt sich aus diesem Ergebnis kein Rückschluss auf eine mögliche Veränderung ziehen. Generell bleibt zu diskutieren, ob die erzielten Ergebnisse durch die fehlende postinterventionelle Absenkung des Blutdrucks beeinflusst sind und hierdurch andernfalls womöglich deutlichere positive Effekte abgeschwächt wurden. Andererseits ist aufgrund der 
trotzdem verzeichneten tendenziellen Veränderungen die Hypothese zu prüfen, ob eine Verbesserung der Nierenfunktion nach renaler Denervation unabhängig von der erzielten Reduktion des arteriellen Blutdrucks eintritt. Um eine wissenschaftliche Evidenz zu erlangen, ist eine größere Anzahl an Studienteilnehmern sowie eine längere Nachverfolgung unabdingbar. Jedoch beobachtete die Arbeitsgruppe um Kiuchi et al. über 24 Monate nach erfolgter renaler Denervation bei insgesamt 30 Patienten einen signifikanten Abfall des Serumkreatinins im Vergleich zum Ausgangswert sowie gleichsinnig einen signifikanten Anstieg der eGFR. Diese stieg von initial $61,9( \pm 23,9) \mathrm{ml} / \mathrm{min}$ auf 88,0 $( \pm 39,8) \mathrm{ml} / \mathrm{min}$ nach 24 Monaten $(\mathrm{p}<0,0001)$, was eine Verbesserung um $42 \%$ bedeutet. In dieser Studie war es ebenfalls zu einer signifikanten Senkung des Blutdrucks sowohl in der Einzelmessung als auch in der 24-hAufzeichnung gekommen (Kiuchi et al. 2016). Eine weitere Studie mit 27 Patienten beschreibt eine Umkehr der generellen Entwicklung der eGFR. Vor renaler Denervation war es zu einer jährlichen Verschlechterung um durchschnittlich $-4,8( \pm 3,8) \mathrm{ml} / \mathrm{min}$ gekommen, während 12 Monate nach der Intervention eine Verbesserung um 1,5 $( \pm 10) \mathrm{ml} / \mathrm{min}$ verzeichnet wurde $(\mathrm{p}=0,009) \quad($ Ott et al. 2015). Des Weiteren schließen Hering et al. aus ihren Beobachtungen von 46 Patienten über 24 Monate, dass die renale Denervation das Fortschreiten einer Verschlechterung der Nierenfunktion verlangsamt, unabhängig von der Blutdrucksenkung (Hering et al. 2016). Entsprechend der statistischen Poweranalyse wäre in der hier beschriebenen Studie zum Erreichen des Signifikanzniveaus der Veränderung der eGFR ein Kollektiv von 68 Patienten nötig gewesen, also eine etwas größere Anzahl als in den beschriebenen Studien. Dies mag auf die geringe statistische Aussagekraft der limitierten Daten zurückzuführen sein bzw. darauf, dass der Nachverfolgungszeitraum kürzer angesetzt war oder möglicherweise tatsächlich geringere Veränderungen auftraten.

Unverzichtbar bei der Beurteilung eines glomerulären oder tubulären Schadens ist außerdem die Differenzierung einer Proteinurie. Die Gesamtmenge der detektierten Proteine im Urin war sechs Monate nach renaler Denervation unverändert. Auffällig in der Betrachtung der Verläufe einzelner Patienten ist hierbei jedoch, dass Patienten mit hohen Werten einer Proteinurie im Studienverlauf häufig eine Verbesserung der Proteinurie erfuhren. Hieraus lässt sich vermuten, dass die Durchführung einer renalen Denervation keinen negativen Effekt auf den Verlauf einer Proteinurie hat. Zur abschließenden Beurteilung wäre eine deutlich größere Fallzahl notwendig. Bei 
Betrachtung der Studie von Wallbach et al., welche Patienten nach Erhalt eines weiteren sympathikoinhibitorischen Verfahrens, der Barorezeptoren-Stimulationstherapie untersuchte, ließ sich eine signifikante Senkung der Proteinurie beobachten (Wallbach et al. 2014), so dass auch ein möglicher therapeutischer Effekt im Rahmen der renalen Denervation diskutiert werden könnte.

Das Hauptmarkerprotein einer glomerulären Schädigung des Nierenparenchyms, das Albumin, lag bei Studienbeginn im Mittel bei 50,08 $( \pm 132,94) \mathrm{mg} / \mathrm{l}$. Sechs Monate nach renaler Denervation lag dieser Wert bei $41,78( \pm 72,01) \mathrm{mg} / \mathrm{l}(\mathrm{p}=0,59)$. Bei fehlender Signifikanz lässt sich auch hier keine direkte Schlussfolgerung bezüglich eines therapeutischen Nutzens ziehen. Die erzielte Reduktion der Albuminurie bleibt jedoch ein interessanter Aspekt, der in nachfolgenden Studien weiterer eruiert werden sollte.

Bei der Berechnung der Quotienten Protein zu Kreatinin sowie Albumin zu Kreatinin im Urin ergaben sich keine Veränderungen im Verlauf der Studie. Zu bemerken ist jedoch, dass aktuelle Studien signifikante Verbesserungen des Albumin-KreatininQuotienten nach renaler Denervation verzeichnen konnten. So beschreiben Sousa et al. in einer Studie mit 31 Patienten eine durchschnittliche Verbesserung des AlbuminKreatinin-Quotienten von 25,8 (9,0-574,0) mg/g zu 14,8 (4,5-61,0) mg/g nach zwölf Monaten $(p=0,007)$. Die Veränderungen des Quotienten waren zudem unabhängig davon, ob es sich um sogenannte Responder oder Non-Responder bezüglich einer Verbesserung des Blutdruckniveaus handelte (Sousa et al. 2017). Ähnlich beobachteten Kiuchi et al. bei 30 Patienten über 24 Monate eine Verbesserung von 99,8 (38,0-192,1) mg/g zu 11,0 (4,1-28,1) mg/g, was einer graduellen Reduktion über diesen Zeitraum um $87 \%$ entspricht (Kiuchi et al. 2016). Diese Ergebnisse unterstreichen die Bedeutsamkeit der Ausrichtung weiterer Studien auf die Eruierung organoprotektiver Effekte der renalen Denervation sowie einer langen Nachverfolgungszeit der Patienten.

Ob die fraktionierte Natriumexkretion, welche auf Grundlage der Kawasaki-Formel in unserer Studie ebenfalls berechnet wurde und keine signifikante Änderung zeigte, im Verlauf größerer Studien mit höherer statistischer Power zu einer signifikanten Änderung führt, sollte in weiteren Forschungsanstregungen berücksichtigt werden. 


\subsubsection{Vaskuloprotektive Effekte}

Patienten mit langjähriger arterieller Hypertonie sind insbesondere gefährdet durch die Entwicklung von Endorganschäden welche durch vaskuläre Defekte hervorgerufen werden. Therapieresistente Hypertoniker sind somit einem besonderen Risiko ausgesetzt von einer Vielzahl kardialer, renaler, vaskulärer und zerebrovaskulärer Erkrankungen betroffen zu sein, und somit auch einem höheren Risiko von Morbidität und Mortalität. Aus diesem Grund ist es von speziellem Interesse, ob eine interventionelle Maßnahme wie die renale Denervation, es vermag, positiv auf ebendiese Aspekte einzuwirken. Die Untersuchung endothelialer Progenitorzellen (EPCs) auf deren Quantität, Proliferationsfähigkeit und Funktionalität erlaubt es, Rückschlüsse, auf das kardiovaskuläre Risiko, die Wahrscheinlichkeit des Fortschreitens artherosklerotischer Prozesse, den Gefäßstatus sowie die endogene Fähigkeit zur Reparatur endothelialer Gefäßschäden zu ziehen (Perticone et al. 2001, Schmidt-Lucke 2005, Asahara et al. 1999).

Prinzipiell zeigten Studien, wie die der Arbeitsgruppe um Hill et al., dass eine bestehende arterielle Hypertonie mit einer signifikanten Reduktion der Anzahl an Kolonien EPCs einhergeht ( $\mathrm{p}=0,04)$ (Hill et al. 2003). Ebenso wie die von Vasa et al. publizierte Studie Bluthochdruck als den individuellen Risikofaktor beschreibt, welcher am stärksten die Migrationsfähigkeit von EPCs reduziert (Vasa et al. 2001). Entsprechend ist rückschließend zu erwarten, dass eine Blutdruckabsenkung zu einer Milderung dieser Effekte und somit $\mathrm{zu}$ einer Verbesserung des individuellen kardiovaskulären Risikos führt.

In der FACS-Analyse wurden typische Oberflächenmarker endothelialer Progenitorzellen mittels Antikörperfärbung bestimmt. Über die Kombinationen von CD133 mit sowohl Flk-1 als auch cKit konnte zudem eine doppelte Kontrollmöglichkeit generiert werden, da bekannt ist, dass nahezu alle Zellen, welche Flk-1 exprimieren eine Coexpression von cKit aufweisen (Hibbert et al. 2011). In der Auswertung zeigten sich sechs Monate nach renaler Denervation CD133/Flk-1-positive Zellen und CD133/cKitpositive Zellen ohne signifikante Änderung, jedoch mit einer tendenziellen Zunahme. Der gleichsinnig ermittelte Trend zur Steigerung der Anzahl endothelialer Progenitorzellen vermag jedoch möglicherweise als Hinweis auf einen positiven Einfluss der renalen Denervation interpretiert werden. Dies sollte in Studien eines 
größeren Patientenkollektivs mit längerer Nachverfolgungszeit überprüft werden. Die Proliferationsfähigkeit der EPCs wurde in Zellkultur über die Ausbildung von Zellkolonien (colony forming units - CFUs) ermittelt. Bei 41,67 \% der Patienten konnte sechs Monate nach erfolgter renaler Denervation eine größere Anzahl an Kolonien gezählt werden. $25 \%$ der Patienten zeigten keine deutlichen Veränderungen, und bei 33,33\% der Patienten bildeten sich weniger CFUs. Ob sich ein Trend zur Steigerung der Proliferationsfähigkeit und somit Ausbildung von CFUs bei der Erfassung einer größeren Anzahl von Patienten sowie gegebenenfalls längerer Nachverfolgung verstärken würde, bleibt zu überprüfen.

Die endothelialen Progenitorzellen wurden des Weiteren mittels LaserscanningZytometrie (iCYS) bezüglich ihrer Funktionalität untersucht. Die Expression der endothelialen Stickstoffmonoxid-Synthase (eNOS) auf der Oberfläche der EPCs lässt Rückschlüsse auf deren Beitrag zur Gefäßhomöostase zu. Bereits seit längerem ist bekannt, dass bei Patienten mit essentieller Hypertonie die Freisetzung von Stickstoffmonoxid herabgesetzt ist (Panza et al. 1993). In der präsentierten Studie konnten entsprechende Daten von sechs Patienten gewonnen werden, welche im Mittel zum Zeitpunkt der Visit II eine tendenzielle Verringerung der eNOS-Expression um $-5,0( \pm 48,61) \%$ ergaben $(\mathrm{p}=0,81)$. Zur Verringerung der Fehlerwahrscheinlichkeit bei der Bestimmung von prozentualen Anteilen müsste jedoch die Auswertung eines deutlich größeren Kollektivs erfolgen. Eine valide Aussage bezüglich einer Veränderung lässt sich somit nicht stellen. Zudem bleibt die Frage zu erörtern, ob die nicht erzielte Absenkung des arteriellen Blutdrucks in dieser Studie einen Einfluss auf das Ergebnis gehabt haben könnte, oder ob die renale Denervation unabhängig vom Erfolg der Blutdrucksenkung positive oder negative Auswirkungen hat. Zum jetzigen Zeitpunkt lässt sich dies nicht beantworten, sollte jedoch Bestandteil zukünftiger Forschung sein. Die vorliegende Studie stellt zum jetzigen Zeitpunkt vorrangig heraus, dass das experimentelle Design wichtige weiterführende Erkenntnissen erbringen könnte, welche in weiteren wissenschaftlichen Erhebungen berücksichtigt werden sollten. 


\subsection{Limitationen der Studie}

Die Limitationen der Studie sind hauptsächlich in der geringen Anzahl eingeschlossener Patienten begründet. Eine statistische Signifikanz konnte so in den meisten zu untersuchenden Parametern nicht erzielt werden, sodass die Fragestellungen Teil weiterer wissenschaftlicher Forschung bleiben sollten. Auch eine längere Nachverfolgungszeit sollte angestrebt werden, um langfristige Effekte und möglicherweise deutlichere Entwicklungen über die Zeit $\mathrm{zu}$ erfassen. $\mathrm{Zu}$ beachten ist außerdem, dass in der Konstellation dieser Studie die primäre Intention der renalen Denervation, im Sinne einer Reduktion des arteriellen Blutdrucks, nicht erzielt wurde. Obwohl die Patienten vor Einschluss in die Studie keine kurzfristigen Änderungen des medikamentösen Therapieregimes erfuhren, kam es im Verlauf der Studie zu häufigen hausärztlich durchgeführten Anpassungen der Medikation. Auch eine Überprüfung der Adhäranz der Patienten mittels objektiver Maßnahmen war im Rahmen dieser Studie nicht vorgesehen. Weitere Limitationen ergeben sich durch die fehlende Kontrollgruppe, weshalb ein Hawthorne Effekt, ein Placeboeffekt sowie das Phänomen der Regression zur Mitte nicht ausgeschlossen werden können. Da das Hauptaugenmerk dieser Studie jedoch auf laborchemisch sowie experimentell erhobenen Parametern liegt, ist davon auszugehen, dass die angesprochenen Effekte einen geringeren Einfluss auf die Ergebnisse haben als bei klinisch erhobenen Größen. Durch die Erhebung einer ambulanten Langzeitblutdruckmessung über 24 Stunden, war es zudem möglich die Untersucher-Bias, Messfehler und den Weißkitteleffekt zu minimieren, sowie eine höhere Reproduzierbarkeit zu erzielen.Die Stärke der Studie liegt vordergründig darin, dass weitere Aspekte der renalen Denervation bezüglich des kardio-reno-vaskulären Risikos beleuchtet werden, Möglichkeiten zu dessen Beurteilung aufgezeigt werden, und somit ein zusätzlicher Beitrag in der Diskussion zur Beurteilung der Effektivität der renalen Denervation geleistet wird. 


\section{Zusammenfassung}

Hintergrund: Die Effektivität der renalen Denervation bezüglich der arteriellen Blutdrucksenkung konnte bereits in vorherigen Studien demonstriert werden. Da die Intervention an der sympathischen Überaktivität, einem entscheidenden Punkt der Kreislaufregulation, ansetzt, sind weitere positive kardio-reno-vaskuläre Effekte zu erwarten.

Zielsetzung: Mittels klinischer und experimenteller Methoden sollen Marker renovaskulärer Schädigung bei Patienten mit therapierefraktärer arterieller Hypertonie erfasst werden sowie deren Beeinflussung durch eine renale Denervation untersucht werden.

Material und Methoden: Ein Patientenkollektiv (n=12) mit nachgewiesener therapieresistenter Hypertonie wurde in die Studie nach gründlicher Prüfung der Eignung zur renalen Denervation eingeschlossen. Klinische Untersuchungen und Anamnese dienten der Einschätzung des Allgemeinzustandes der Patienten sowie der Ermittlung des allgemeinen kardiovaskulären Risikos. Zusätzlich wurde der arterielle Blutdruck in klinischen Einzelmessungen sowie in der 24-h-Langzeitmessung ermittelt. Laborchemische Parameter wurden aus Blut- und Urinproben zur Beurteilung der Nierenfunktion sowie einer glomerulären Schrankenstörung jeweils vor und sechs Monate nach renaler Denervation mit standardisierten Methoden erhoben.

Zur Beurteilung des Gefäßstatus sowie des endogenen Regenerationspotentials erfolgte die Untersuchung endothelialer Progenitorzellen (EPCs) auf deren Quantität, Proliferationsfähigkeit sowie Funktionalität.

Ergebnisse: Ein Patientenkollektiv von 12 Patienten mit nachgewiesener therapieresistenter Hypertonie konnte in die vorliegende Studie eingeschlossen werden. In der ambulanten 24-h-Langzeitblutdruckmessung war ein Trend zum Anstieg des systolischen Blutdrucks um 8,58 $( \pm 14,74) \mathrm{mmHg}(\mathrm{p}=0,07)$ sowie des diastolischen Blutdrucks um $1,58( \pm 7,56) \mathrm{mmHg} \quad(\mathrm{p}=0,48)$ verzeichnet worden. Die Anzahl antihypertensiver Medikamente hatte sich sechs Monate nach renaler Denervation im Mittel von 5,18 $( \pm 0,75)$ auf 4,45 $( \pm 0,82)$ reduziert $(\mathrm{p}=0,038)$.

Die Nierenfunktion zeigte einen nicht signifikanten Trend zur Steigerung der eGFR um $5,15( \pm 14,84) \mathrm{ml} / \mathrm{min} \quad(\mathrm{p}=0,25)$. Ebenso wie sich bei der Untersuchung einer 
Albuminurie eine nicht signifikante Tendenz zur Verringerung um $-8,30( \pm 71,28) \mathrm{mg} / \mathrm{l}$ $(\mathrm{p}=0,59)$ zeigte, bei sonst nahezu unveränderter Gesamtmenge des Proteins im Urin.

Sechs Monate nach renaler Denervation konnte eine tendenzielle Zunahme von EPCs verzeichnet werden. Bei CD133/Flk-1-markierten Zellen um 0,68 $( \pm 1,28) \%(p=0,25$; $\mathrm{n}=6)$, bei CD133/cKit-markierten Zellen um $0,9( \pm 1,29) \% \quad(\mathrm{p}=0,07 ; \mathrm{n}=6)$. Die Proliferationsfähigkeit der EPCs zeigte sich unverändert. Die eNOS-Expression als Marker der Funktionalität der EPCs ergab keine Änderung ( $p=0,81 ; n=6)$.

Schlussfolgerung: Aufgrund der limitierten Anzahl an Studienteilnehmern konnten keine signifikanten Ergebnisse erzielt werden. Es ergaben sich jedoch einige Entwicklungen, welche als Ausgangspunkte für weitere wissenschaftliche Forschung dienen können. Zudem werden reno-vaskuläre Aspekte, welche möglichweise in Zusammenhang mit der renalen Denervation stehen, beleuchtet und klinische sowie experimentelle Möglichkeiten zu deren Beurteilung aufgezeigt. Das Studiendesign eignet sich somit gut zur weitergehenden Forschung organoprotektiver Effekte der renalen Denervation. 


\section{Abgrenzung der vorliegenden Dissertation mit Präsentation der nephrologischen Endpunkte von der Dissertation Schulze-Brock mit kardiologischen Endpunkten}

Die Studie erfolgte in Kooperation der Kliniken für Nephrologie und Rheumatologie sowie Kardiologie und Pneumologie. Während die nephrologischen Endpunkte Teil dieser Arbeit sind, werden die kardiologischen Endpunkte in der Dissertationsarbeit von Paul Schulze-Brock dargestellt.

An dieser Stelle sollen gemeinsam und getrennt erhobene Parameter detailliert dargestellt werden.

\subsection{Gemeinsam erhobene Parameter}

Die klinische körperliche Untersuchung und Anamnese der Patienten sowie die Messungen des arteriellen Blutdrucks, sowohl der klinischen Einzelmessung als auch der 24-Stunden-Langzeitmessung, wurden gemeinsam erhoben und ausgewertet. Auch die Standardlaborparameter wie Quick, pTT, kleines Blutbild, GOT, GPT, AP, $\gamma$ GT, CRP, Na, K, Calcium gesamt und Kreatinkinase wurden im Rahmen der allgemeinen Untersuchung bestimmt.

Die sorgfältige Untersuchung der Patienten auf deren Eignung zur renalen Denervation durch Ausschluss einer sekundären Hypertonie, unter anderem durch Bestimmung des Renin-Aldosteron-Quotienten, Schlafapnoe-Screening sowie Doppler-Untersuchung der Nierenarterien, fand ebenfalls in Kooperation beider Kliniken statt.

\subsection{Nephrologische Parameter}

Spezielle nephrologische Parameter beinhalten die Einschätzung der Nierenfunktion mittels eGFR, Kreatinin, Cystatin C sowie die Analytik des Urins auf die Proteine Albumin, Immunglobulin G, alpha-1-Mikroglobulin sowie Natrium und Kreatinin. 
Die experimentellen Methoden zur Beurteilung des reno-vaskulären Risikos und endogenen Regenerationspotenials erfolgten im Rahmen der hier präsentierten Dissertation in der Klinik für Nephrologie und Rheumatologie. Hierzu zählen die Isolation der PBMCs und die Untersuchung zirkulierender endothelialer Progenitorzellen bezüglich Quantität, Proliferationspotential und Funktionalität mittels FACS-Analyse, Zellkultur und Laserscanning-Zytometrie.

\subsection{Kardiologische Parameter}

In die Dissertationsarbeit von Paul Schulze-Brock gingen die kardio-vaskulären Parameter ein, insbesondere die Laborparameter BNP, TNF- $\alpha$, IL-6, Aldosteron, Renin und Leptin. Außerdem erfolgte die Auswertung des 6-Minuten-Gehtests, der echokardiographischen und elektrokardiographischen Untersuchungen sowie der Fragebögen zum subjektiven Gesundheits- und Wohlbefinden der Patienten zum Zeitpunkt der Baseline und im Vergleich zur Kontrollvisite nach $6 \pm 1$ Monaten. 


\section{Literaturverzeichnis}

Aicher A, Heeschen C, Mildner-Rihm C, Urbich C, Ihling C, Technau-Ihling K, Zeiher AM, Dimmeler S (2003): Essential role of endothelial nitric oxide synthase for mobilization of stem and progenitor cells. Nat Med $\underline{9}, 1370-1376$

Alper J, Arnold B, Calhoun D (1999): Contemporary management of refractory hypertension. Curr Hypertens Rep 1 , 402-407

Asahara T, Masuda H, Takahashi T, Kalka C, Pastore C, Silver M, Kearne M, Magner M, Isner JM (1999): Bone Marrow Origin of Endothelial Progenitor Cells Responsible for Postnatal Vasculogenesis in Physiological and Pathological Neovascularization. Circ Res $\underline{85}, 221-228$

Azizi M, Steichen O, Frank M, Bobrie G, Plouin P-F, Sapoval M (2012): Catheterbased Radiofrequency Renal-nerve Ablation in Patients with Resistant Hypertension. Eur J Vasc Endovasc Surg 43, 293-299

Bakris GL, Nadim MK, Haller H, Lovett EG, Schafer JE, Bisognano JD (2012): Baroreflex Activation Therapy provides durable benefit in patients with resistant hypertension: results of long-term follow-up in the Rheos Pivotal Trial. J Am Soc Hypertens $\underline{6}$, 152-158

Bhatt DL, Kandzari DE, O’Neill WW, D'Agostino R, Flack JM, Katzen BT, Leon MB, Liu M, Mauri L, Negoita M, et al. (2014): A controlled trial of renal denervation for resistant hypertension. N Engl J Med $\underline{370}$, 1393-1401

Böhm M. http://dgk.org/pressemitteilungen/2014-jahrestagung/2014-ft-aktuelle$\mathrm{pm} / 2014$-ft-statements/state-tag2/dgk-stellungnahme-zur-symplicity-htn-3studie-zur-blutdrucksenkung-nach-renaler-denervation/; Zugriff am 02.03.2017

Cai H, Harrison DG (2000): Endothelial Dysfunction in Cardiovascular Diseases: The Role of Oxidant Stress. Circ Res $\underline{87}, 840-844$

Chobanian AV, Bakris GL, Black HR, Cushman WC, Green LA, Izzo JL, Jones DW, Materson BJ, Oparil S, Wright JT, Roccella EJ (2003): Seventh Report of the Joint National Committee on Prevention, Detection, Evaluation, and Treatment of High Blood Pressure. Hypertension $\underline{42}$, 1206-1252

Cravedi P, Remuzzi G (2013): Pathophysiology of proteinuria and its value as an outcome measure in chronic kidney disease. Br J Clin Pharmacol $\underline{76}, 516-523$

Cuspidi C, Macca G, Sampieri L, Michev I, Salerno M, Fusi V, Severgnini B, Meani S, Magrini F, Zanchetti A (2001): High prevalence of cardiac and extracardiac target organ damage in refractory hypertension. J Hypertens $\underline{19}$, 2063-2070

De Groot K, Hermann Bahlmann F, Sowa J, Koenig J, Menne J, Haller H, Fliser D (2004): Uremia causes endothelial progenitor cell deficiency. Kidney Int $\underline{66}$, 641-646 
de la Sierra A, Segura J, Banegas JR, Gorostidi M, de la Cruz JJ, Armario P, Oliveras

A, Ruilope LM (2011): Clinical Features of 8295 Patients With Resistant Hypertension Classified on the Basis of Ambulatory Blood Pressure Monitoring. Hypertension 57, 898-902

Esler MD, Krum H, Schlaich M, Schmieder RE, Böhm M, Sobotka PA (2012): Renal Sympathetic Denervation for Treatment of Drug-Resistant HypertensionClinical Perspective. Circulation 126, 2976-2982

Ewen S, Ukena C, Böhm M, Mahfoud F (2013): Percutaneous renal denervation: new treatment option for resistant hypertension and more? Heart 99, 1129-1134

Fadl Elmula FEM, Larstorp AC, Kjeldsen SE, Persu A, Jin Y, Staessen JA (2015): Renal sympathetic denervation after Symplicity HTN-3 and therapeutic drug monitoring in severe hypertension. Front Physiol $\underline{6}$

Fagard RH (2012): Resistant hypertension. Heart 98, 254-261

Fan L, Levey AS, Gudnason V, Eiriksdottir G, Andresdottir MB, Gudmundsdottir H, Indridason OS, Palsson R, Mitchell G, Inker LA (2015): Comparing GFR Estimating Equations Using Cystatin $\mathrm{C}$ and Creatinine in Elderly Individuals. J Am Soc Nephrol 26, 1982-1989

Gao L, Li P, Zhang J, Hagiwara M, Shen B, Bledsoe G, Chang E, Chao L, Chao J (2014): Novel Role of Kallistatin in Vascular Repair by Promoting Mobility, Viability, and Function of Endothelial Progenitor Cells. J Am Heart Assoc $\underline{3}$, e001194

Grassi G (2009): Assessment of Sympathetic Cardiovascular Drive in Human Hypertension Achievements and Perspectives. Hypertension 54, 690-697

Hering D, Marusic P, Duval J, Sata Y, Esler M, Walton A, Schlaich M (2016): OS 1901 Blood Pressure independent Effects of Renal Denervation on the Decline of Kidney Function in Patients with Chronic Kidney Disease. J Hypertens $\underline{34}$

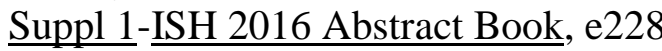

Hibbert B, Ma X, Pourdjabbar A, Simard T, Rayner K, Sun J, Chen Y-X, Filion L, O'Brien ER (2011): Pre-Procedural Atorvastatin Mobilizes Endothelial Progenitor Cells: Clues to the Salutary Effects of Statins on Healing of Stented Human Arteries. PLoS ONE $\underline{6}$

Hill JM, Zalos G, Halcox JPJ, Schenke WH, Waclawiw MA, Quyyumi AA, Finkel T (2003): Circulating Endothelial Progenitor Cells, Vascular Function, and Cardiovascular Risk. N Engl J Med 348, 593-600

Hoffschulte B: Regenerationspotenzial CD133+-hämatopoetischer Progenitorzellen der humanen Nabelschnur beim Nierendefekt im Mausmodell. Medizinische Dissertation Universität Göttingen 2009

Investigators SH-1 (2011): Catheter-Based Renal Sympathetic Denervation for Resistant Hypertension. Hypertension 57, 911-917 
Kandzari DE, Bhatt DL, Brar S, Devireddy CM, Esler M, Fahy M, Flack JM, Katzen BT, Lea J, Lee DP, et al. (2015): Predictors of blood pressure response in the SYMPLICITY HTN-3 trial. Eur Heart J 36, 219-227

Kannel WB, Stampfer MJ, Castelli WP, Verter J (1984): The prognostic significance of proteinuria: The Framingham study. $1984 \underline{108}$, 1347-1352

Kawasaki T, Itoh K, Uezono K, Sasaki H (1993): A simple method for estimating $24 \mathrm{~h}$ urinary sodium and potassium excretion from second morning voiding urine specimen in adults. Clin Exp Pharmacol Physiol 20, 7-14

Kiuchi MG, Graciano ML, Carreira MAM de Q, Kiuchi T, Chen S, Lugon JR (2016): Long-Term Effects of Renal Sympathetic Denervation on Hypertensive Patients With Mild to Moderate Chronic Kidney Disease. J Clin Hypertens $\underline{18}$, 190-196

Klag MJ, Whelton PK, Randall BL, Neaton JD, Brancati FL, Ford CE, Shulman NB, Stamler J (1996): Blood Pressure and End-Stage Renal Disease in Men. N Engl J Med 334, 13-18

Kopp UC: Neural Control of Renal Function. Colloquium Series on Integrated Systems Physiology: from Molecule to Function to Disease; Morgan \& Claypool Life Sciences, San Rafael (CA) 2011

Kopp UC (2015): Role of renal sensory nerves in physiological and pathophysiological conditions. Am J Physiol - Regul Integr Comp Physiol 308, R79-R95

Krum H, Schlaich M, Whitbourn R, Sobotka PA, Sadowski J, Bartus K, Kapelak B, Walton A, Sievert H, Thambar S, et al. (2009): Catheter-based renal sympathetic denervation for resistant hypertension: a multicentre safety and proof-of-principle cohort study. The Lancet $\underline{373}, 1275-1281$

Lemarié CA, Shbat L, Marchesi C, Angulo OJ, Deschênes M-E, Blostein MD, Paradis P, Schiffrin EL (2011): Mthfr deficiency induces endothelial progenitor cell senescence via uncoupling of eNOS and downregulation of SIRT1. Am J Physiol - Heart Circ Physiol 300, H745-H753

Lenk K, Uhlemann M, Schuler G, Adams V (2011): Role of endothelial progenitor cells in the beneficial effects of physical exercise on atherosclerosis and coronary artery disease. J Appl Physiol 111, 321-328

Levey AS, Coresh J, Balk E, Kausz AT, Levin A, Steffes MW, Hogg RJ, Perrone RD, Lau J, Eknoyan G, National Kidney Foundation (2003): National Kidney Foundation Practice Guidelines for Chronic Kidney Disease: Evaluation, Classification, and Stratification. Ann Intern Med 139, 137-147

Liang S, Le W, Liang D, Chen H, Xu F, Chen H, Liu Z, Zeng C (2016): Clinicopathological characteristics and outcomes of patients with biopsy-proven hypertensive nephrosclerosis: a retrospective cohort study. BMC Nephrol $\underline{17}$ 
Llevadot J, Murasawa S, Kureishi Y, Uchida S, Masuda H, Kawamoto A, Walsh K, Isner JM, Asahara T (2001): HMG-CoA reductase inhibitor mobilizes bone marrow-derived endothelial progenitor cells. J Clin Invest 108, 399-405

Lobo MD, de Belder MA, Cleveland T, Collier D, Dasgupta I, Deanfield J, Kapil V, Knight C, Matson M, Moss J, et al. (2015): Joint UK societies' 2014 consensus statement on renal denervation for resistant hypertension. Heart 101, 10-16

Lüscher TF, Mahfoud F (2014): Renal nerve ablation after SYMPLICITY HTN-3: confused at the higher level? Eur Heart J $\underline{35}$, 1706-1711

Mancia G, Fagard R, Narkiewicz K, Redon J, Zanchetti A, Böhm M, Christiaens T, Cifkova R, De Backer G, Dominiczak A, et al. (2013): 2013 ESH/ESC Guidelines for the management of arterial hypertension. The Task Force for the management of arterial hypertension of the European Society of Hypertension (ESH) and of the European Society of Cardiology (ESC). Eur Heart J $\underline{34}$, 2159-2219

Marín R, Gorostidi M, Fernández-Vega F, Álvarez-Navascués R (2005): Systemic and glomerular hypertension and progression of chronic renal disease: The dilemma of nephrosclerosis. Kidney Int $\underline{68}$, S52-S56

Ng FL, Saxena M, Mahfoud F, Pathak A, Lobo MD (2016): Device-based Therapy for Hypertension. Curr Hypertens Rep $\underline{18}$

Ott C, Mahfoud F, Schmid A, Ditting T, Sobotka PA, Veelken R, Spies A, Ukena C, Laufs U, Uder M, et al. (2013): Renal Denervation in Moderate TreatmentResistant Hypertension. J Am Coll Cardiol 62, 1880-1886

Ott C, Mahfoud F, Schmid A, Toennes SW, Ewen S, Ditting T, Veelken R, Ukena C, Uder M, B?hm M, Schmieder RE (2015): Renal denervation preserves renal function in patients with chronic kidney disease and resistant hypertension: $\mathrm{J}$ Hypertens $\underline{33}$, 1261-1266

Page IH, Heuer GJ (1935): A Surgical Treatment of Essential Hypertension. J Clin Invest $\underline{14}, 22-26$

Panza JA, Casino PR, Kilcoyne CM, Quyyumi AA (1993): Role of endotheliumderived nitric oxide in the abnormal endothelium-dependent vascular relaxation of patients with essential hypertension. Circulation $\underline{87}, 1468-1474$

Parati G, Esler M (2012): The human sympathetic nervous system: its relevance in hypertension and heart failure. Eur Heart J $\underline{33}$, 1058-1066

Patschan D, Patschan S, Henze E, Wessels JT, Koziolek M, Müller GA (2009): LDL lipid apheresis rapidly increases peripheral endothelial progenitor cell competence. J Clin Apheresis 24, 180-185

Peng F, Wu D, Ingram AJ, Zhang B, Gao B, Krepinsky JC (2007): RhoA Activation in Mesangial Cells by Mechanical Strain Depends on Caveolae and Caveolin-1 Interaction. J Am Soc Nephrol 18, 189-198 
Persell SD (2011): Prevalence of Resistant Hypertension in the United States, 20032008. Hypertension 57, 1076-1080

Persu A, Jin Y, Azizi M, Baelen M, Völz S, Elvan A, Severino F, Rosa J, Adiyaman A, Fadl Elmula FE, et al. (2014): Blood pressure changes after renal denervation at 10 European expert centers. J Hum Hypertens $\underline{28}$, 150-156

Perticone F, Ceravolo R, Pujia A, Ventura G, Iacopino S, Scozzafava A, Ferraro A, Chello M, Mastroroberto P, Verdecchia P, Schillaci G (2001): Prognostic Significance of Endothelial Dysfunction in Hypertensive Patients. Circulation $\underline{104}, 191-196$

Riser BL, Cortes P, Zhao X, Bernstein J, Dumler F, Narins RG (1992):

Intraglomerular pressure and mesangial stretching stimulate extracellular matrix formation in the rat. J Clin Invest 90, 1932-1943

RKI (2012): Faktenblatt zu GEDA 2012: Ergebnisse der Studie "Gesundheit in Deutschland aktuell 2012". Robert Koch-Institut, Berlin 2012 http://www.rki.de/DE/Content/Gesundheitsmonitoring/Gesundheitsberichtersta ttung/GBEDownloadsF/Geda2012/Bluthochdruck.pdf?_blob=publicationFile Zugriff am 25.03.2015

Ruilope LM (2002): The Kidney as a Sensor of Cardiovascular Risk in Essential Hypertension. J Am Soc Nephrol 13, S165-S168

Ruilope LM, Bakris GL (2011): Renal function and target organ damage in hypertension. Eur Heart J $\underline{32}$, 1599-1604

Schlaich MP, Schmieder RE, Bakris G, Blankestijn PJ, Böhm M, Campese VM, Francis DP, Grassi G, Hering D, Katholi R, et al. (2013): International Expert Consensus Statement: Percutaneous Transluminal Renal Denervation for the Treatment of Resistant Hypertension. J Am Coll Cardiol 62, 2031-2045

Schmidt-Lucke C (2005): Reduced Number of Circulating Endothelial Progenitor Cells Predicts Future Cardiovascular Events: Proof of Concept for the Clinical Importance of Endogenous Vascular Repair. Circulation 111, 2981-2987

Schmieder R, Schrader J, Zidek W, Tebbe U, Bramlage P, Paar W, Böhm M (2006): Subklinische Albuminurie, Mikroalbuminurie und Proteinurie - akzeptierte kardiovaskuläre Risikomarker? DMW - Dtsch Med Wochenschr 131, 26652671

Schmieder RE (2010): End Organ Damage In Hypertension. Dtsch Ärztebl Int 107, 866-873

Shintani S, Murohara T, Ikeda H, Ueno T, Honma T, Katoh A, Sasaki K, Shimada T, Oike Y, Imaizumi T (2001): Mobilization of Endothelial Progenitor Cells in Patients With Acute Myocardial Infarction. Circulation 103, 2776-2779 
Simplicity HTN-2 Investigators, Esler M, Krum H, Sobotka P, Schlaich M, Schmieder $\mathrm{R}$, et al. (2010): Renal sympathetic denervation in patients with treatment resistant hypertension (The Symplicity HTN-2 Trial): a randomised controlled trial. The Lancet $\underline{376}$, 1903-1909

Sousa H, Branco P, de Sousa Almeida M, de Araújo Gonçalves P, Gaspar A, Dores H, Mesquita J, Andrade MJ, Neuparth N, Aleixo A, et al. (2017): Changes in albumin-to-creatinine ratio at 12-month follow-up in patients undergoing renal denervation. Rev Port Cardiol 36, 343-351

Sudano I, Wolfrum M, Noll G, Lüscher TF. http://kardiologiegefaessmedizin.universimed.com/artikel/die-renale-sympathikusdenervationeine-neue-t\%C3\%BCre-zur-heilung-der; Zugriff am 09.01.2017

Sumida K, Hoshino J, Ueno T, Mise K, Hayami N, Suwabe T, Kawada M, Imafuku A, Hiramatsu R, Hasegawa E, et al. (2016): Effect of Proteinuria and Glomerular Filtration Rate on Renal Outcome in Patients with Biopsy-Proven Benign Nephrosclerosis. PLoS ONE $\underline{11,2}$

Taddei S, Virdis A, Ghiadoni L, Magagna A, Salvetti A (1998): Vitamin C Improves Endothelium-Dependent Vasodilation by Restoring Nitric Oxide Activity in Essential Hypertension. Circulation 97, 2222-2229

Takahashi T, Kalka C, Masuda H, Chen D, Silver M, Kearney M, Magner M, Isner JM, Asahara T (1999): Ischemia- and cytokine-induced mobilization of bone marrow-derived endothelial progenitor cells for neovascularization. Nat Med $\underline{5}$, 434-438

Tepper O M, Galiano R D, Capla J M, Kalka C, Gagne P J, Jacobowitz G R, Levine J, Gurtner G C (2002): Human Endothelial Progenitor Cells From Type II Diabetics Exhibit Impaired Proliferation, Adhesion, and Incorporation Into Vascular Structures. Circulation 106, 2781-2786

Tousoulis D, Kampoli A-M, Tentolouris Nikolaos Papageorgiou C, Stefanadis C (2012): The Role of Nitric Oxide on Endothelial Function. Curr Vasc Pharmacol 10, 4-18

Urbich C, Dimmeler S (2004): Endothelial Progenitor Cells: Characterization and Role in Vascular Biology. Circ Res 95, 343-353

Vasa M, Fichtlscherer S, Aicher A, Adler K, Urbich C, Martin H, Zeiher AM, Dimmeler S (2001): Number and Migratory Activity of Circulating Endothelial Progenitor Cells Inversely Correlate With Risk Factors for Coronary Artery Disease. Circ Res $\underline{89}$, e1-e7

Vonend O, Böhm M, Eckert S, Hausberg M, Rittger H, Rump L-C, Schmieder R, Schulte K-L, Schunkert H, Uder M, et al. (2015): Renal denervation in refractory hypertension: Joint Statement of the German Hypertension League DHL eV and the German Societies of Cardiology, Angiology, Nephrology and Radiology. ResearchGate 140, 363 
Wallbach M, Lehnig L-Y, Schroer C, Hasenfuss G, Müller GA, Wachter R, Koziolek MJ (2014): Impact of Baroreflex Activation Therapy on Renal Function - A Pilot Study. Am J Nephrol 40, 371-380

Weigand S: Neue Biomarker zur Überwachung der zellulären Immunität chronischentzündlicher Darmerkrankungen. Medizinische Dissertation Universität Göttingen (2013)

Weitzman D, Chodick G, Shalev V, Grossman C, Grossman E (2014): Prevalence and Factors Associated With Resistant Hypertension in a Large Health Maintenance Organization in Israel. Hypertension $\underline{64}$, 501-507

Werner N, Kosiol S, Schiegl T, Ahlers P, Walenta K, Link A, Böhm M, Nickenig G (2005): Circulating Endothelial Progenitor Cells and Cardiovascular Outcomes. N Engl J Med 353, 999-1007

WHO (2013): A global brief on hypertension. http://www.who.int/cardiovascular_diseases/publications/global_brief_hyperte nsion/en/; Zugriff am 25.03.2015 


\section{Danksagung}

Meinen ganz herzlichen Dank möchte ich Herrn Professor Michael Koziolek aussprechen. Er ermöglichte mir im Rahmen dieser Dissertation die Mitarbeit in einem guten und auf gegenseitige Unterstützung bauenden Team sowie das Erlernen wissenschaftlicher Methoden im Rahmen eines faszinierenden Studiendesigns. Insbesondere danke ich für die über die gesamte Zeit andauernde unermüdliche und konstruktive Unterstützung, welche in besonderem Maße freundlich, wohlwollend und aufbauend war.

Weiterhin danke ich vielmals Herrn Privatdozenten Manuel Wallbach für die hervorragende Betreuung meiner Promotionsarbeit. Stets schätzte ich den unerschöpflichen Zuspruch, den unerschütterlichen Glauben an das Gelingen, die stete Motivation und die positive und unermüdliche Unterstützung. Für diese mir hier geschenkte Erfahrung, welche über den gemeinsam durchgestandenen Rück- und Niederschlägen steht, bin ich äußerst dankbar.

Herrn Dr. Luca-Yves Lehnig möchte ich ebenfalls meinen herzlichen Dank aussprechen für das geduldige Anlernen in den experimentellen Methoden sowie für die hier ebenfalls erfahrene kollegiale Unterstützung und den wertvollen persönlichen Kontakt. 